\title{
DISCRIMINAÇÃO VARIETAL E ESTIMATIVA DE PRODUTIVIDADE AGROINDUSTRIAL DE CANA-DE-AÇÚCAR PELO SENSOR ORBITAL ETM+/LANDSAT 7
}

\section{CAIO FORTES}

\author{
Dissertação apresentada à Escola \\ Superior de Agricultura "Luiz de \\ Queiroz”, Universidade de São Paulo, \\ para obtenção do título de Mestre em \\ Agronomia, Área de Concentração: \\ Solos e Nutrição de Plantas.
}

PIRA C I C A B A

Estado de São Paulo - Brasil

Dezembro - 2003 


\title{
DISCRIMINAÇÃO VARIETAL E ESTIMATIVA DE PRODUTIVIDADE AGROINDUSTRIAL DE CANA-DE-AÇÚCAR PELO SENSOR ORBITAL ETM+/LANDSAT 7
}

\section{CAIO FORTES}

\section{Engenheiro Agrônomo}

Orientador: Prof. Dr. JOSÉ ALEXANDRE MELO DEMATTÊ

\begin{abstract}
Dissertação apresentada à Escola Superior de Agricultura “Luiz de Queiroz”, Universidade de São Paulo, para obtenção do título de Mestre em Agronomia, Área de Concentração: Solos e Nutrição de Plantas.
\end{abstract}

PIRA C I C A B A

Estado de São Paulo - Brasil

Dezembro de 2003 
Dados Internacionais de Catalogação na Publicação (CIP)
DIVISÃO DE BIBLIOTECA E DOCUMENTAÇÃO - ESALQ/USP

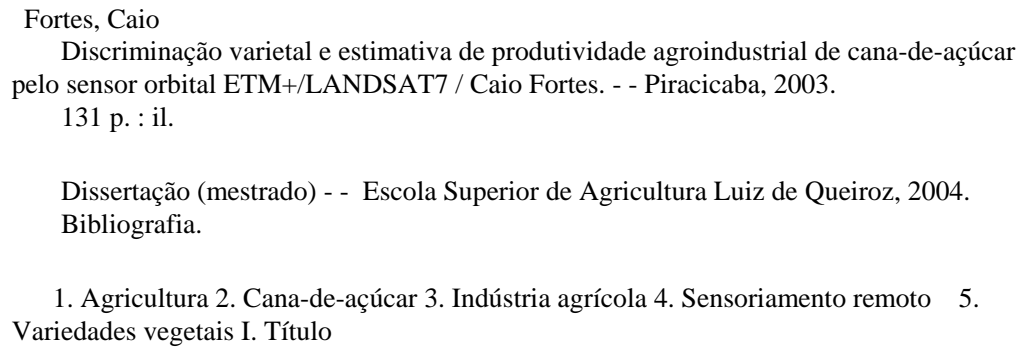

CDD 633.61

\section{"Permitida a cópia total ou parcial deste documento, desde que citada a fonte - O autor"}


Aos meus queridos pais, José Fortes Reina e Clara Maria Raiza Fortes, exemplos de trabalho e honestidade

DEDICO

"Bem aventurado o homem que acha a sabedoria, e o homem que adquire conhecimento" Pv 3:13

Aos meus irmãos José Fernando e Camila Fortes e cunhados Érika e Marcelo 


\section{AGRADECIMENTOS}

À Deus pela oportunidade de viver e a cada dia adquirir mais conhecimento para entender e respeitar suas criações;

Aos meus pais José e Clara, pela minha criação e confiança depositada, pela oportunidade de estudar e pelo apoio e compreensão nas horas mais difíceis;

Ao Prof ${ }^{\circ}$ Dr. José Alexandre M. Demattê pela amizade, orientação e esclarecimentos para composição deste trabalho;

Ao CCA/UFSCar e a ESALQ/USP e seus professores e funcionários pela honra de conviver e me capacitar profissionalmente;

À CAPES e a FAPESP pela bolsa de estudos e auxílio pesquisa concedidos para realização deste curso de mestrado, respectivamente;

Aos engenheiros agrônomos Marcelo C. Alves do CIAGRI/ESALQ e Maximiliano S. Scarpari (PG Fitotecnia) pelo auxílio nas análises estatísticas deste trabalho;

Ao professor Dr. Jurandir Zullo Júnior do CEPAGRI/UNICAMP pelo auxílio na utilização do software de correção atmosférica da imagem utilizada neste trabalho;

À usina Cocal Açúcar e Álcool, especialmente aos engenheiros agrônomos Inês Janegitz Pereira e José Carlos Salata pelos recursos e pelo voto de confiança e Ivaldo dos Santos 
Durães pelos mapas e banco de dados utilizados. Aos demais supervisores, encarregados e funcionários agradeço a amizade e oportunidade de crescimento pessoal e profissional;

Aos engenheiros agrônomos e colegas de profissão Antonio Celso Joaquim, Maurício dos S. Simões, Jorge L. Donzelli, Claudimir P. Penatti, Ivo F. Bellinaso, Hermógenes M. Machado, Maurício Felipe A. Oliveira e todos os outros do Centro de Tecnologia Copersucar pela convivência, pelos conselhos e auxílio na coleta/preparação dos dados;

À meus "irmãos" do laboratório de Sensoriamento Remoto Aplicado ao Estudo de Solos Aline, Marco, Butina, as “simininas” Gláucia, Karina, Lilian, Miriam, Fernanda, Cindy, Camila, Ligia, Maria Luiza e aos colegas, Barizon, Márcio, Michael, Eros, Simão, Marcelo, Laércio, à “Turma da cana” (sabem quem são!) que tornaram este período mais agradável;

Enfim, a todos que de alguma forma contribuíram para a realização deste trabalho. 


\section{SUMÁRIO}

LISTA DE SIGLAS E ABREVIATURAS.......................................................... ix

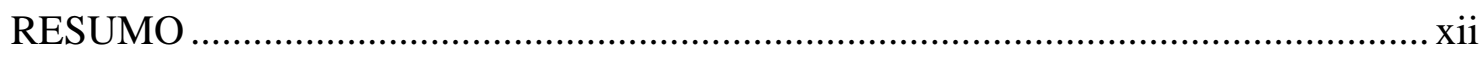

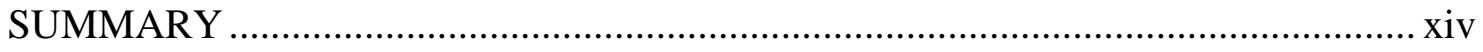

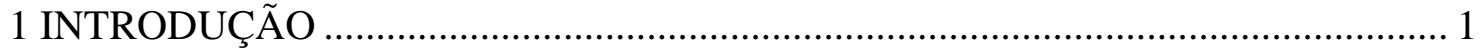

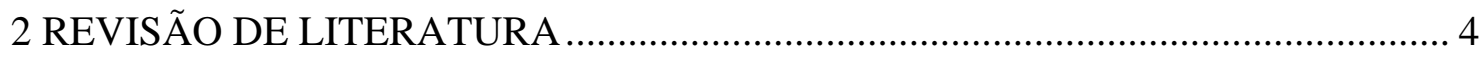

2.1 Cana-de-açúcar........................................................................................................... 4

2.1.1 Características da cultura e importância econômica ................................................... 4

2.1.2 Fisiologia e produção agrícola ............................................................................. 6

2.1.3 Qualidade da matéria-prima ................................................................................... 9

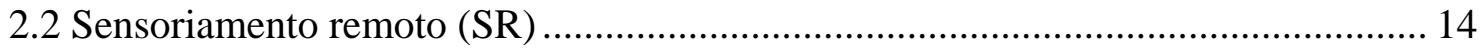

2.2.1 Comportamento espectral de alvos agrícolas ........................................................ 16

2.2.2 Utilização de sensores remotos para avaliação da vegetação ................................. 20

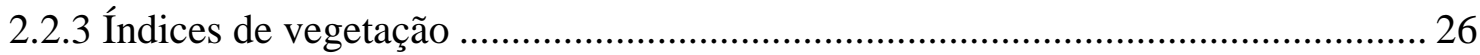

2.3 Utilização de geotecnologias na cultura da cana-de-açúcar........................................ 31

3 INFORMAÇÕES BÁSICAS DO TRABALHO....................................................... 38

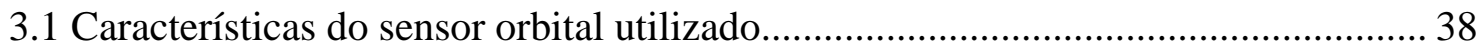

3.2 Variedades de cana-de-açúcar avaliadas .................................................................... 41

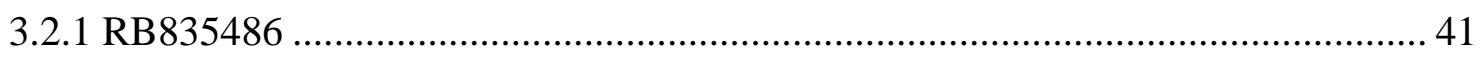

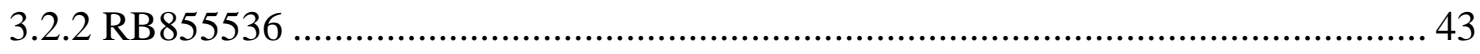

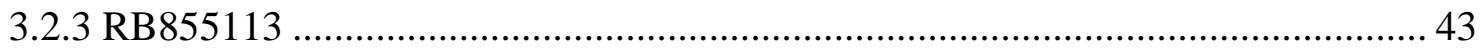

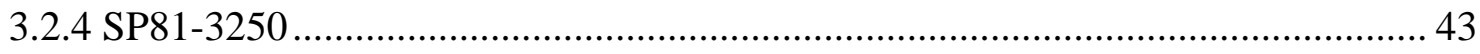

4 DISCRIMINAÇÃO DE VARIEDADES DE CANA-DE-AÇÚCAR POR DADOS ESPECTRAIS ORBITAIS ETM+/LANDSAT 7 ………………………………... 45

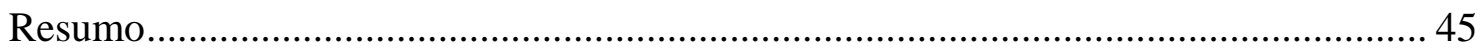




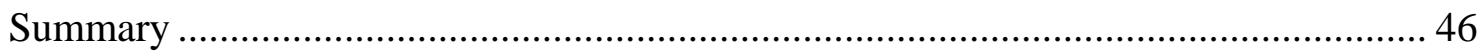

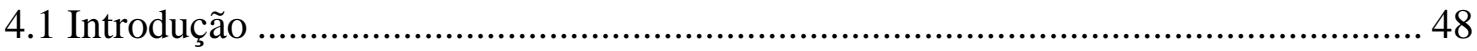

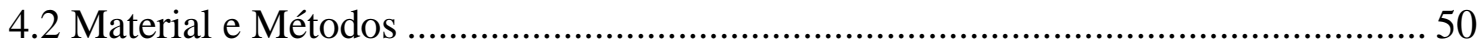

4.2.1 Localização e caracterização da área de estudo ..................................................... 50

4.2.2 Variedades de cana-de-açúcar avaliadas ............................................................. 50

4.2.3 Processamento digital da imagem e obtenção dos índices de vegetação ............... 51

4.2.4 Aquisição de dados espectrais e análise estatística ................................................. 52

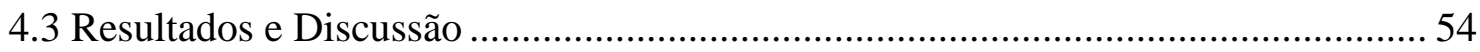

4.3.1 Discriminação espectral das variedades por bandas e índices de vegetação ......... 54

4.3.2 Discriminação espectral das variedades por gráficos de dispersão......................... 59

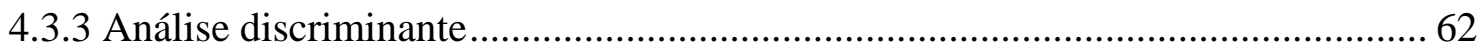

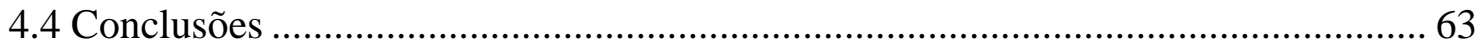

5 ESTIMATIVA DE PRODUTIVIDADE AGROINDUSTRIAL DE CANA-DEAÇÚCAR POR DADOS ESPECTRAIS ORBITAIS ETM+/LANDSAT 7 ............ 75

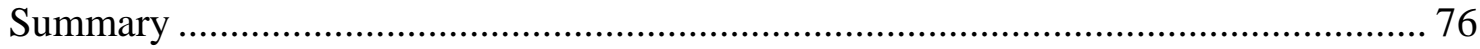

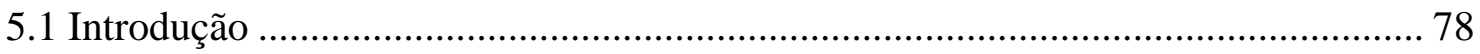

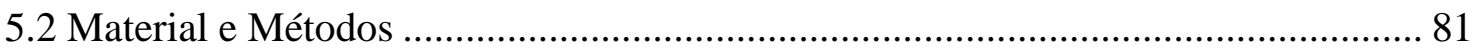

5.2.1 Localização e caracterização da área de estudo ...................................................... 81

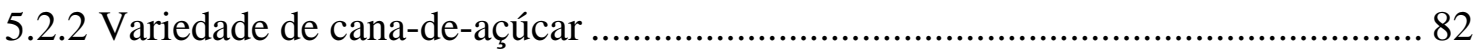

5.2.3 Processamento digital da imagem e obtenção dos índices de vegetação ............... 82

5.2.4 Banco de dados agronômicos.............................................................................. 84

5.2.5 Obtenção das informações espectrais da cana-de-açúcar......................................... 85

5.2.6 Metodologia tradicional para quantificação das características da cultura............ 86

5.2.7 Análise estatística............................................................................................. 87

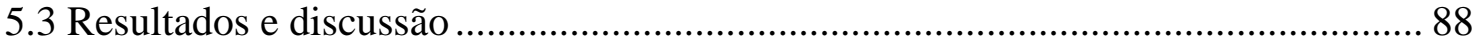

5.3.1 Estimativa de produtividade agroindustrial dos talhões pelo método das médias

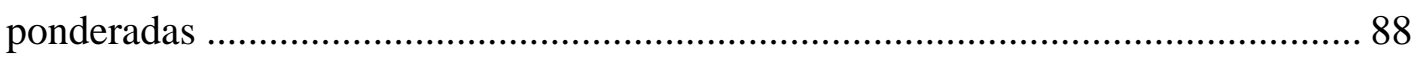

5.3.2 Estimativa de produtividade agroindustrial dos talhões pelo método das médias

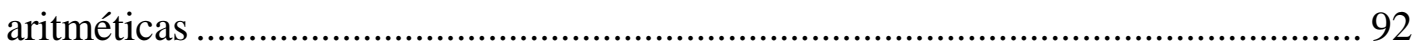


5.3.3 Comparação entre os métodos de coleta de dados espectrais dos talhões ............ 97

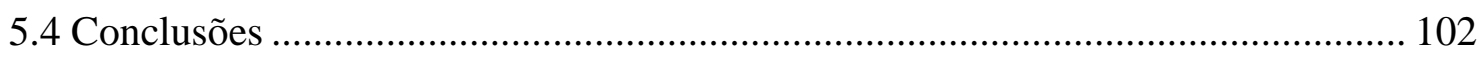

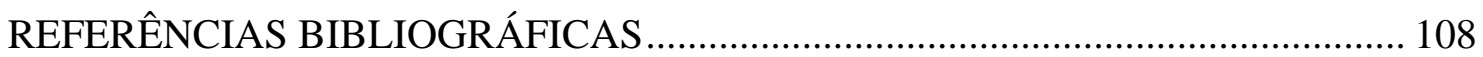

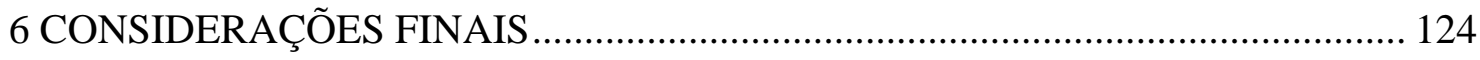

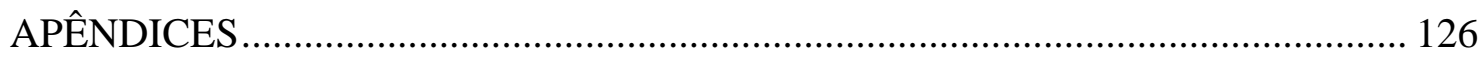




\section{LISTA DE SIGLAS E ABREVIATURAS}

AP: Agricultura de Precisão

AR: Açúcares Redutores

ARVI: Atmospherically Resistant Vegetation Index

ASTER: Advanced Spaceborne Thermal Emission and Reflectance Radiometer

ATR: Açúcar teórico recuperável

AVIRIS: Airborne Visible/Infrared Imaging Radiometer

Brix: sólidos solúveis totais (idem BRX)

CA: Cana-de-ano

CAD: Computer Aided Drawing

CAM: Cana-de-ano e meio

Co: Coimbatore (Variedades da Índia)

CP: Canal Point (Variedades da Flórida/EUA)

DoD: Department of Defense

DSS: Decision Support System

DXF: Drawing Exchange Format

ENVI: Environment for Visualizing Images

EOS: Earth Observing Systems

ETM+: Enhanced Thematic Mapper

FBR: Fibra \% cana

Fe: Ferro

GLAI: Green Leaf Area Index

GPS: Global Positioning System

G: Green (verde) 
HRV: High Resolution Visible

IAC: Instituto Agronômico de Campinas (Variedades IAC)

IAF: Índice de área foliar (idem LAI)

IMP: Impureza \%

INPE: Instituto Nacional de Pesquisas Espaciais

IRS: Indian Remote Sensing

IV's: Índices de Vegetação

K: Potássio

LISS: Linear Imaging Self Scanning

MaxR: Máximo $\mathrm{R}^{2}$ (Procedimento do SAS)

$\mathrm{Mg} / \mathrm{ha:}$ Megagrama por hectare (idem t/ha)

Mn: Manganes

MSS: Multispectral Scanner

N: Nitrogênio

NASA: National Aeronautics and Space Administration

NAVSTAR: Navigation Satellite Time and Ranging

NC: Níveis de Cinza

NDVI: Normalized Difference Vegetation Index

NIR: Near Infrared

NIRS: Near Infrared Reflectance Spectrometry

NOAA: National Oceanics and Atmospheric Administration

P: Fósforo

PCC: Pol \% cana

PCR: Principal Component Regression

PCTS: Pagamento da cana pelo teor de sacarose

PIB: Produto Interno Bruto

PIMS S/C: Pol Information Manager System Client/Server

POL: Pol \% caldo, leitura sacarimétrica, teor de sacarose

PU: Peso do bolo úmido (em gramas)

PUI: Período útil de industrialização 
Q: Queensland (Variedades da Austrália)

R: Red (vermelho)

$\mathrm{R}^{2}$ : Coeficiente de determinação

RB: República do Brasil (Variedades RIDESA)

ROI: Regions of interest (idem regiões de interesse)

RVI: Ratio Vegetation Index

SAS: Statistical Analysis System

SAVI: Soil Adjusted Vegetation Index

SIG: Sistemas de Informação Geográfica (idem GIS e SGI)

SP: São Paulo (Variedades Copersucar)

SPOT: Satellite Pour l'Observation de la Terre

SR: Sensoriamento Remoto

SWIR: Short Wave Infrared Reflectance

TM: Thematic Mapper

TC: Produção total dos talhões (Mg de cana)

TCH: Toneladas de cana por hectare (t/ha)

TSAVI: Transformed SAVI

UMD: Umidade \%

WRS2: World Reference System 2 


\section{DISCRIMINAÇÃO VARIETAL E ESTIMATIVA DE PRODUTIVIDADE AGROINDUSTRIAL DE CANA-DE-AÇÚCAR PELO SENSOR ORBITAL ETM+/LANDSAT 7}

Autor: CAIO FORTES

Orientador: Prof ${ }^{\circ}$ Dr. JOSÉ ALEXANDRE MELO DEMATTÊ

\section{RESUMO}

O desenvolvimento de técnicas de sensoriamento remoto na avaliação da cultura da cana-de-açúcar tem grande importância para o poder público, empresas de melhoramento genético e agricultores, pois proporciona um melhor planejamento de políticas de mercado e otimiza a tomada de decisões. O comportamento espectral de dosséis vegetais reflete características importantes das culturas agrícolas quanto ao seu crescimento, vigor vegetativo e produção de biomassa. O objetivo desta pesquisa é determinar uma metodologia para discriminação de variedades, estimativa da produtividade agrícola da cana-de-açúcar e propriedades industriais importantes como Brix $^{0}$, Pol \% caldo, Pol \% cana, Fibra \%, Umidade \%, Pureza \%, Kg de ATR/Mg cana e Impureza \%, pelo sensor orbital ETM+/LANDSAT 7. Sabe-se que as plantas e culturas de uma forma geral apresentam comportamentos espectrais e interações com a energia eletromagnética em determinadas bandas do espectro eletromagnético devido sua composição/estrutura e também ao efeito dos diversos fatores de produção (solo, clima e variedade). Dessa forma, levanta-se a hipótese de que é possível estabelecer relações entre as características espectrais da cultura de cana-de-açúcar e sua produtividade 
agrícola e industrial. Para tanto, foram escolhidas talhões de cana-de-açúcar localizadas na região de Paraguaçú Paulista, SP. As informações georeferenciadas de cada talhão foram dispostas num ambiente SIG pela montagem de um banco de dados. Foram selecionados talhões de variedades diferentes, porém com mesma data de plantio. Os talhões foram avaliados quanto aos dados espectrais das seis bandas do sensor e seis índices de vegetação, correlacionando-os com as variedades e com as informações das produtividades agroindustriais médias dos talhões. Concluiu-se que é possível caracterizar e estimar atributos da cultura da cana-de-açúcar através de sensor orbital ETM+/LANDSAT 7. O índice médio de acerto foi de 93,55 \% na separação varietal. A observação das curvas espectrais orbitais auxilia na discriminação das variedades e a banda B4 mostrou ser a mais adequada. O gráfico de dispersão entre B4 e o GNDVI auxilia na separação destas variedades. Foram gerados modelos de regressão linear múltipla, visando selecionar variáveis com maior potencial para quantificar os atributos agroindustriais da cultura. Para a estimativa da produtividade agrícola (Mg/ha) obteve-se um coeficiente de determinação $\left(\mathrm{R}^{2}\right)$ de 0,6935 e em média, 0,5807 para as características tecnológicas. Os atributos tecnológicos com melhores resultados na estimativa foram a Pol \% caldo e a Umidade \% com $\mathrm{R}^{2}$ de 0,7416 e 0,6397, respectivamente. O método de coleta das informações espectrais influiu nos resultados e, de maneira geral, o método das médias aritméticas dos pixels foi o mais adequado. A utilização de todas as bandas do sensor ETM+/LANDSAT 7 mostra-se importante na caracterização, discriminação varietal e estimativa de atributos da cultura da cana-deaçúcar. 


\title{
VARIETIES DISCRIMINATION AND SUGARCANE AGROINDUSTRIAL YIELD FORECAST BY THE ORBITAL SENSOR ETM+/LANDSAT 7
}

\author{
Author: CAIO FORTES
}

\author{
Adviser: Prof ${ }^{\circ}$ Dr. JOSÉ ALEXANDRE MELO DEMATTÊ
}

\section{SUMMARY}

The development of remote sensing techniques on the sugarcane crop evaluation has great importance for government agencies, breeding institutions and farmers, because it helps to attempt better planning of market politics and it optimizes the decision support systems. The spectral behavior of vegetation canopies reflects important characteristics of the agricultural crops as its growth, greenness and biomass production. The objective of this research is to develop a methodology for discrimination of sugarcane varieties and to estimate the crop agronomic yield and some important industrial properties like Brix ${ }^{\circ}$, Pol\% juice, Pol\% cane, Fiber \%, Humidity \%, Purity \%, Kg of ATR/Mg of stalks and Impurity \%, by the ETM+/LANDSAT 7 orbital sensor. It is known that plants and crops in general present spectral behaviors and interactions with the electromagnetic energy in certain bands of the electromagnetic spectra due to its composition/structure and also because the effect of the several production factors (soil, climate and variety). It gets up the hypothesis that is possible to establish relationships between the spectral characteristics of the sugarcane crop and its agronomic and industrial productivity. Then, it has been chosen sugarcane fields located in Paraguaçu Paulista County, western of São Paulo state, Brazil. The sugarcane fields 
data were georeferenced and settled into a GIS environment. Fields which possessed different varieties, however with the same planting date were selected. The fields were evaluated about their spectral data of the six sensor bands and six vegetation indexes, correlating with the varieties discrimination and with the fields average agro industrial yield. It has been concluded that is possible to characterize and to foresee attributes of the sugarcane crop through ETM+/LANDSAT 7 orbital sensor. The average accuracy found was $93,55 \%$ in the variety separation. The observation of the orbital spectral plots helps discriminating the sugarcane varieties and B4 appeared to be the most appropriate. The dispersion graphic between B4 and GNDVI also helps in sorting out these varieties. Multiple linear regression models were generated, aiming to select variables with high potential to quantify the crop agro industrial attributes mentioned previously. For the agronomic yield forecast (Mg/ha) it has been obtained 0,6935 of determination coefficient $\left(\mathrm{R}^{2}\right)$ and a averageof 0,5807 for the technological characteristics. The technological attributes with better results in the forecast $\left(\mathrm{R}^{2}\right)$ were Pol \% juice and the humidity \% with 0,7416 and 0,6397 , respectively. The spectral data collection method of the spectral information influences on the results and, in a general way, the arithmetic mean of pixels method was the most appropriate. The application of all of ETM+/LANDSAT 7 was important on the sugarcane varieties characterization, discrimination and in the agro industrial yields forecasts. 


\section{INTRODUÇÃO}

O gerenciamento do setor agrícola em usinas e destilarias tem se tornado cada vez mais sofisticado, requerendo informações mais precisas e com antecedência em relação à época da safra. Essas informações são essenciais para a logística do transporte, processamento e armazenamento da produção, bem como para a tomada de decisões relacionadas à comercialização dos produtos finais (açúcar e álcool) e são fatores importantes para o planejamento estratégico das empresas. A crise energética e a degradação dos recursos naturais também têm chamado a atenção do setor canavieiro, devido ao seu potencial de produção de energia renovável de biomassa e esta ser uma atividade altamente impactante, do ponto de vista ambiental. Outra preocupação das instituições públicas e privadas de melhoramento é a cobrança de royalties sobre a utilização e propagação do material genético por elas desenvolvido. A averiguação da utilização das variedades deve ter abrangência nacional uma vez que estas estão em constante desenvolvimento e lançamento no mercado.

Métodos tradicionais de coleta de informações sobre as variedades e produção agroindustrial do setor sucroalcooleiro, como levantamentos e observações de campo, consomem muito tempo e estão sujeitos a imprecisões que comprometem as estimativas do volume de álcool e açúcar. Este fato influencia diretamente na composição de preços e no fechamento de contratos de fornecimento das empresas ligadas ao setor.

A estimativa de safras agrícolas é uma ferramenta fundamental para o poder público e empresas privadas, pois proporciona um melhor planejamento de políticas de mercado, otimizando a tomada de decisões. Portanto, deve possuir exatidão aceitável e ser obtida em tempo suficiente, ou seja, durante a safra. Entretanto sabe-se que as variedades de cana-de-açúcar têm fisiologia e maturação diferentes, o que influencia na 
produção agroindustrial. Isto nos mostra a importância de primeiro conhecer as variedades e estas diferenças.

No aspecto de avaliação da planta, o sensoriamento remoto proporciona uma visão sinóptica da superfície terrestre, permitindo a análise e o mapeamento da distribuição espacial das áreas plantadas e gera subsídios para o planejamento agrícola. Entetanto, mesmo com os avanços recentes no desenvolvimento de novos sensores, com maiores resoluções espaciais, espectrais e temporais, esta técnica tem sido pouco utilizada no processo de estimativa de produção.

Várias das hoje denominadas geotecnologias, como os sistemas de posicionamento global (GPS - Global Positioning System), sensores remotos terrestres, aéreos e orbitais, programas para armazenamento de dados georreferenciados (SIG Sistemas de Informações Geográficas), sistemas informatizados de medição e coleta de dados além de outros como controles e acionamento automático de máquinas auxiliam no planejamento das operações agrícolas. O uso de tais tecnologias possibilita um melhor gerenciamento do agronegócio, seja pela aplicação localizada de insumos ou pela estimativa de atributos das culturas, com redução no tempo de obtenção dos dados, menores custos de amostragens e menor impacto ambiental.

Por outro lado, sabe-se que diferentes variedades apresentam características espectrais diferentes. O entendimento destas variações deve anteceder a tentativa de estimativa de produção. A detecção da variabilidade de uma mesma espécie de planta (diferenças entre variedades) no caso da cana-de-açúcar, e a própria estimativa de sua produtividade agroindustrial pode auxiliar no avanço da otimização do processo agrícola.

O objetivo geral desta pesquisa foi verificar o potencial do sensor remoto ETM+ do LANDSAT 7 na avaliação de características da cultura de cana-de-açúcar.

Especificamente objetivou-se: 1) Discriminar e avaliar o comportamento espectral de quatro variedades de cana-de-açúcar e; 2) determinar uma metodologia para estimar a produtividade da cana-de-açúcar (Mg/ha) e outras características industriais importantes como Brix ${ }^{\circ}$, Pol \% caldo, Pol \% cana, Fibra \%, Umidade \%, Pureza \% e Kg 
de ATR/Mg cana, através das bandas do sensor orbital ETM+ do LANDSAT 7 e da utilização de índices de vegetação.

As hipóteses para este trabalho foram: 1) Variedades de cana-de-açúcar diferentes proporcionam características distintas nas plantas e, conseqüentemente mudanças nas respostas espectrais dos dosséis, podendo ser discriminadas por dados de sensor orbital e; 2) Sabe-se que as características nutricionais juntamente com a biomassa da planta têm relação com o vigor, que por sua vez se relaciona com produtividade. Espera-se que tais características interfiram nos valores das respostas espectrais das áreas de produção e que isto esteja relacionado com a produção agrícola e qualidade agroindustrial da matéria-prima. 


\section{REVISÃO DE LITERATURA}

\subsection{Cana-de-açúcar}

\subsubsection{Características da cultura e importância econômica}

A cultura da cana-de-açúcar estabeleceu no Brasil ciclos de grande importância econômica e social, pois é fonte de energia renovável e gera divisas para o país. O mercado sucroalcooleiro movimenta cerca de R \$ 12,7 bilhões/ano com faturamentos diretos e indiretos, o que corresponde a 2,3\% do PIB brasileiro (Orplana, 2001).

O Brasil é o maior produtor de cana-de-açúcar do mundo, seguido por Índia e Austrália. Na média, 55\% da cana brasileira vira álcool e 45\%, açúcar. É cultivada no Centro-Sul e no Norte-Nordeste, o que permite dois períodos de safra, de abril a novembro e de setembro a abril (Nunes Junior et al., 1998). O parque sucroalcooleiro nacional é consituído por 307 centrais energéticas, das quais 128 estão em São Paulo, utilizando uma área de 4,5 milhões de hectares de terra (Unica, 2003).

O plantio está distribuído entre variedades nacionais de três instituições de melhoramento (siglas IAC, SP e RB) além de variedades estrangeiras (CP, Q e Co), híbridos do gênero Saccharum, nos quais procura-se obter, além das características agronômicas de produtividade, rusticidade, resistência a pragas e doenças, algumas características industriais como alto teor de sacarose e teor médio de fibra, condições essenciais para uma exploração em bases técnico-econômicas (Nunes Junior et al., 1998; Stupiello, 1987).

A cana-de-açúcar gera açúcar, álcool anidro (aditivo para a gasolina) e álcool hidratado além de outros produtos para os mercados interno e externo, com dinâmica de 
preços e demanda diferentes. Atender a esses mercados sem oscilações significativas requer planejamento e gestão. Durante séculos isso foi feito pelo governo; a partir da década de 90, em processo concluído em 1999, a responsabilidade foi repassada integralmente ao setor privado e hoje prevalece o regime de livre mercado, sem subsídios, e definem-se os preços de açúcar e álcool de acordo com as oscilações de oferta e demanda (Unica, 2003). Os preços da cana são definidos de acordo com a qualidade da matéria-prima e, os preços efetivos são obtidos pelos produtores finais, através da sua participação percentual no preço final dos produtos (Consecana, 1999).

Para fazer esse gerenciamento e dar estabilidade à produção/demanda dos produtos setoriais, a área privada tem buscado criar instrumentos de mercado, como operações futuras, e abrir novos mercados para o açúcar e o álcool, pela quebra das barreiras protecionistas, além de lutar pela transformação do álcool em commodity ambiental, uma vez que cada tonelada de cana tem potencial energético equivalente ao de 1,2 barril de petróleo (Unica, 2003).

A cultura da cana-de-açúcar apresenta nível tecnológico dos mais elevados dentro da agricultura brasileira, lançando mão de técnicas como gerenciamento das áreas produtoras através de bancos de dados, setorização da produção agrícola em talhões e emprego de imagens de satélite no mapeamento de variedades (Joaquim et al., 1994a; Joaquim, 1998; Rocha, 1995).

No Brasil a cana-de-açúcar é uma das maiores culturas de exportação, podendo ser considerada uma cultura de alto custo por área, com aplicações de até $800 \mathrm{~kg} / \mathrm{ha} / \mathrm{ano}$ de fertilizantes além de outros insumos (Corá \& Marques Junior, 2000). Portanto, podese dizer que a cana-de-açúcar é uma candidata potencial para o emprego da Agricultura de Precisão (AP).

Previsões acuradas de safras de cana-de-açúcar são importantes por vários motivos incluindo políticas de preço e marketing para as indústrias, decisões de datas de início e fechamento das safras além de taxas de abastecimento e moagem das unidades industriais (Schmidt et al., 2001). 


\subsubsection{Fisiologia e produção agrícola}

A cana-de-açúcar (Saccharum spp.) é uma gramínea semi-perene e originária provavelmente do sudeste da Ásia. Não é uma cultura exigente em solos, porém, se desenvolve melhor em solos com boa aeração, boa drenagem e com profundidade maior que 1 metro (Copersucar, 1988).

O ciclo evolutivo da cultura pode ser de 12 (cana de ano - CA) e 18 meses (cana de ano e meio - CAM) em cana-planta (Figura 1). Após o primeiro corte o ciclo passa a ser de 12 meses para todas as variedades (Alfonsi et al., 1987). A mesma cana pode ser colhida até cinco ou mais vezes, porém a cada ciclo devem ser feitos investimentos significativos em insumos e tratos culturais para manter a produtividade (Unica, 2003).

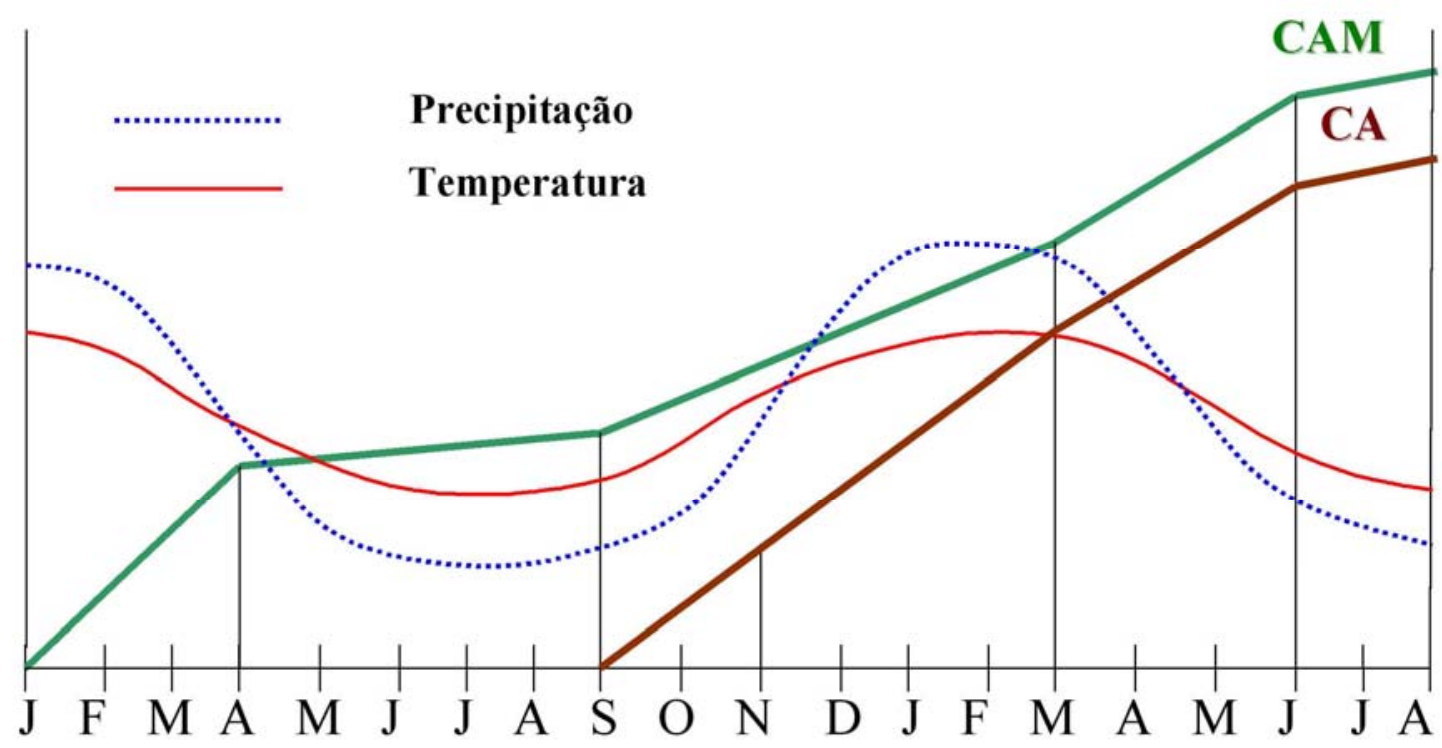

Figura 1 - Ciclos de cana-de-açúcar e variações climáticas da região centro sul do Brasil - CAM: cana de ano e meio, CA: cana de ano. (Adaptado de Casagrande, 1991)

A produção da cana-de-açúcar pode ocorrer numa ampla faixa de latitude, desde $35^{\circ} \mathrm{N}$ a $30^{\circ} \mathrm{S}$ (Magalhães, 1987), sendo cultivada preferencialmente em latitudes entre $15^{\circ} \mathrm{N}$ e $30^{\circ} \mathrm{S}$, correspondente a região intertropical (Lucchesi, 1995). 
Os fatores ambientais que afetam de maneira marcante a produção da cana-deaçúcar são: temperatura, luz (intensidade e qualidade) e a disponibilidade de água e nutrientes (Alfonsi, 1987). Por ser uma gramínea, a cana-de-açúcar desenvolve-se bem em regiões de clima quente, com temperatura oscilando entre $16{ }^{\circ} \mathrm{C}$ e $33{ }^{\circ} \mathrm{C}$ e, temperaturas inferiores a $21^{\circ} \mathrm{C}$, reduzem a taxa de alongamento dos colmos e promovem o acúmulo de sacarose (Magalhães, 1987).

A cana-de-açúcar é uma planta com metabolismo fotossintético C4, que responde melhor a elevadas intensidades luminosas. O ponto de saturação de luz é elevado e varia dependendo da cultivar, segundo Nickell (1975) citado por Lucchesi (1995). A radiação solar afeta todos os estágios de desenvolvimento da cultura. Assim, quando a cana-deaçúcar se desenvolve sob condições de baixa luminosidade, apresenta colmos finos e longos e as plantas menor acúmulo de matéria seca (Lucchesi, 1995).

O principal fator intrínseco à planta responsável pela elevada produção vegetal é o índice de área foliar (IAF), que varia entre as cultivares. A arquitetura foliar da canade-açúcar apresenta uma disposição vertical das folhas em relação ao colmo, refletindo em maior capacidade fotossintética, pois proporciona maior incidência da luz no dossel da cultura que geralmente possui uma alta densidade populacional (Magalhães, 1987).

A cana-de-açúcar, ao atingir seu estágio máximo de desenvolvimento apresenta, aproximadamente, um índice de área foliar 7, o que corresponde a uma área foliar 7 vezes maior que a área de solo ocupada. Isto confere à cultura uma grande capacidade fotossintética e de troca de substâncias (água, nutrientes e gases) com o ambiente (Fauconnier \& Bassereau, 1975).

A cultura da cana-de-açúcar é cultivada em larga escala dentro do território nacional, distribuindo-se em diferentes regiões e ocupando uma grande variabilidade de solos e ambientes de produção (Casagrande, 1991).

Locais de precipitação pluviométrica acima de $1.000 \mathrm{~mm}$ bem distribuídos ao longo do ano, são suficientes para garantir o desenvolvimento da cultura (Fauconnier \& Bassereau, 1975; Magalhães, 1987).

Além da distribuição adequada da chuva, deve ser ressaltado o potencial de armazenamento de água do solo cultivado com a cultura, que é bastante variado 
dependendo do tipo e quantidade de porosidade do mesmo. Apesar do solo ser apenas um dos componentes de um conjunto complexo de fatores de produção, se destaca pelo seu importante papel de fornecer às plantas suporte físico, água e nutrientes. Portanto, o conhecimento dos fatores edáficos, ou seja, das características inerentes a cada solo, é importante para julgar o potencial de produção agrícola (Lepsch, 1987).

Joaquim et al. (1994b) define ambiente de produção como sendo a junção de uma unidade de mapeamento de solos, uma determinada cultivar num dado estágio de corte sob um determinado regime climático (quantidade e distribuição de precipitação, temperatura, evapotranspiração, etc). Tais autores elucidam que é possível estabelecer uma classificação preliminar do potencial de produtividade dos solos e separá-los de acordo com seu nível de produção, numa escala que vai de A (ambientes melhores) à E (ambientes piores). Atualmente, os conceitos de ambientes de produção são de domínio comum no setor sucroalcooleiro.

A cana-de-açúcar no decorrer do seu ciclo atravessa dois períodos distintos com relação ao teor de sacarose: o primeiro é assinalado por um intenso crescimento vegetativo acompanhado por uma gradual formação de sacarose, enquanto que no segundo ocorre um predominante acúmulo de sacarose, motivado pela escassez dos principais fatores de desenvolvimento vegetativo, como temperatura e água disponível (Magalhães, 1987). Lucchesi (1995) relata que o teor de sacarose nos colmos aumenta no momento em que a cana-de-açúcar cessa seu crescimento, fenômeno favorecido principalmente pela queda de temperatura e/ou umidade.

A maturação é um processo fisiológico afetado por vários fatores naturais, como a própria variedade, condições climáticas, tipo de solo e tratos culturais. As variedades comerciais de cana-de-açúcar têm comportamentos distintos, apresentando níveis diferentes de sacarose mesmo quando cultivadas nas mesmas condições, constituindo a base para o planejamento agrícola (Nunes Junior et al., 1998). Tal estratégia possibilita a moagem da matéria-prima de bom teor de sacarose no decorrer de toda a safra, garantindo, desta maneira, um bom rendimento em todos os meses de processamento (Cesar \& Silva, 1993). 
O estádio de maturação é verificado, principalmente pelos teores de sacarose, de açúcares redutores e umidade que os colmos apresentam no decorrer do período da safra (Casagrande, 1991; Stupiello, 1987).

\subsubsection{Qualidade da matéria-prima}

A composição química da cana-de-açúcar é muito variável, em função das condições climáticas, das propriedades físicas, químicas e microbiológicas do solo, do tipo de cultivo, da variedade, do estádio de maturação, da idade, bem como de muitos outros fatores (Stupiello, 1987). A composição químico-tecnológica média da cana-deaçúcar se encontra resumida na Figura 2.

A qualidade da cana para a indústria, não é avaliada simplesmente pelo seu teor de sacarose que, para as condições do centro-sul do Brasil, deve possuir um valor mínimo ideal de $13 \%$. Uma série de outras variáveis são responsáveis pelo êxito da indústria, como o teor de fibra, responsável pela produção de bagaço e equilíbrio térmico da unidade industrial. Ainda que o teor de fibra ideal seja da ordem de 12,5\%, a média das variedades cultivadas na região centro-sul do Brasil está ao redor de 12 \% e cerca de $14 \%$ no norte-nordeste (Stupiello, 1987).

No caldo, cuja composição depende da cana, interessa ao tecnologista o teor de sacarose, de açúcares redutores e de cinzas, bem como de alguns componentes anormais como a dextrana. A quantidade de sacarose presente no caldo é fundamental para um bom processamento e rendimento e, os açucares redutores (glicose e frutose), quando em teores elevados, indicam um estádio pouco adiantado da maturação da cana-de-açúcar. No entanto, em canas maduras, os açúcares redutores contribuem para uma maior cristalização da sacarose, desde que se apresentem como fatores positivos de cristalização pela redução da solubilidade da sacarose (Cesar \& Silva, 1993; Stupiello, 1987).

São considerados açúcares redutores todos aqueles que, como a glicose e a frutose, são capazes de reduzir o cobre presente em soluções cupro-alcalinas, passando da forma $\mathrm{Cu}^{2+}$ para a forma $\mathrm{Cu}^{+}$. Os açúcares por sua vez, são oxidados à ácidos orgânicos (Cesar \& Silva, 1993). 


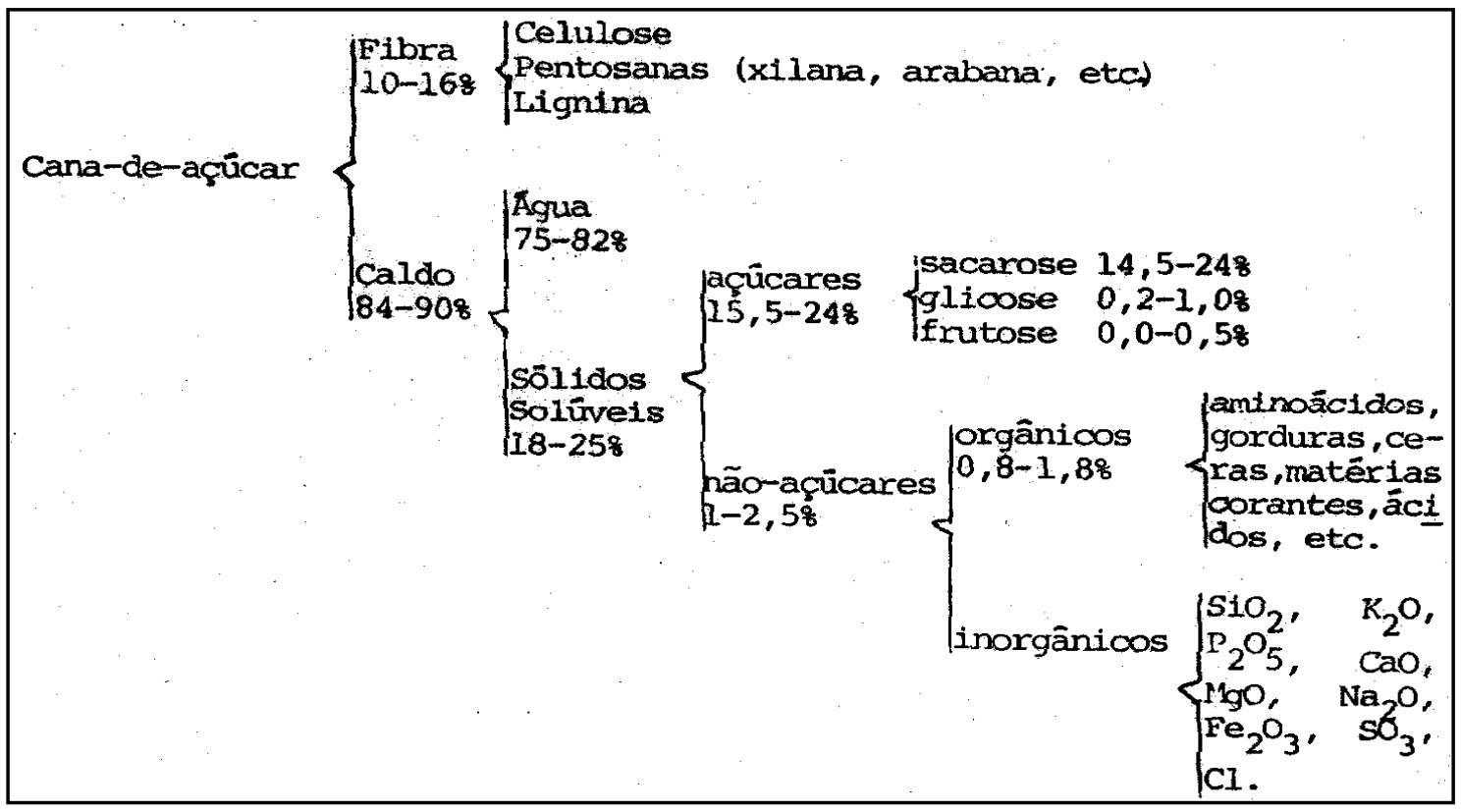

Figura 2 - Composição químico-tecnológica da cana-de-açúcar. Fonte: Stupiello (1987)

Para caracterizar o período em que uma cana pode ser processada, foi determinado o "período útil de industrialização" (PUI), com base no critério que estabelece o mínimo de 13 para a pol \% cana, como satisfatório para a industrialização de diferentes variedades, divididas em três grupos distintos. Geralmente as variedades ricas alcançam este valor de pol \% cana logo no início da safra e possuem um PUI longo (mais de 150 dias), existindo exceções. As variedades médias alcançam o valor fixado no meio da safra, apresentando PUI médio (120 - 150 dias) e, as pobres possuem PUI curto (70 - 100 dias), não apresentando grande interesse industrial (Cesar \& Silva, 1993). A riqueza é entendida como o teor de sacarose das variedades (Stupiello, 1987).

Segundo Lucchesi (1995), a adubação e nutrição da cana-de-açúcar têm influência na qualidade e na maturação da matéria-prima. O autor destaca que o nitrogênio (N) provoca diminuição no teor da pol \% pelo aumento da atividade bioquímica das células meristemáticas, favorecendo o desenvolvimento vegetativo da cana-de-açúcar e conseqüentemente ocorre a diluição da sacarose no caldo. O potássio (K) é responsável pela translocação da sacarose para o local de armazenamento e 
fundamental no processo de evapotranspiração. O fósforo (P) é responsável pelo metabolismo energético no desenvolvimento vegetal e formação da sacarose. O teor de fósforo no caldo também tem influência na clarificação deste na indústria (Stupiello, 1987; Cesar \& Silva, 1993).

Para avaliar o estádio de maturação da cana-de-açúcar existe o "índice de maturação" (eq. 1), que é a relação entre o teor de sólidos solúveis presentes no caldo dos entrenós da parte superior da cana sobre o teor dos entrenós da base da cana (Stupiello, 1987).

$$
I M=\frac{\text { Brix_entrenós_da_ponta }}{\text { Brix_entrenós_da_base }}
$$

Tais avaliações de maturação são realizadas geralmente logo no início da safra através de refratômetros de campo ou de laboratório e os padrões utilizados para a relação acima se encontram na tabela 1 .

Tabela 1. Índice de maturação da cana-de-açúcar

\begin{tabular}{cccc}
\hline \multicolumn{3}{c}{ Limites do índice } & Interpretação \\
\hline & $I M$ & $<0.7$ & verde \\
$0.71<$ & $I M$ & $<0.8$ & imatura \\
$0.81<$ & $I M$ & $<0.9$ & madura \\
$0.91<$ & $I M$ & $<1$ & excelente \\
& $I M$ & $>1$ & ultrapassado \\
\hline
\end{tabular}

Fonte: Cesar \& Silva (1993); Stupiello (1987).

As demais análises tecnológicas são realizadas em laboratório, onde o material vegetal (amostra) previamente desfribrado é prensado a uma pressão de $250 \mathrm{Kgf} / \mathrm{cm}^{2}$ por 1 minuto, obtendo-se desta forma a quantidade de caldo e o peso do bolo úmido (PU).

Para estimar a Pol \% caldo e a fibra \% existente na cana, utiliza-se a leitura do Brix $^{0}$ diretamente no refratômetro laboratorial e do sacarímetro, colocando-se uma amostra de caldo no prisma do aparelho, e substituindo os valores de leitura nas equações 2 e 3 (Cesar \& Silva, 1993). 


$$
\begin{aligned}
& \text { Pol\% caldo }=\frac{0,26 L}{d} \\
& \text { Fibra \% cana }=\frac{100 P S-P U \times b}{5 \times(100-b)}
\end{aligned}
$$

Nota-se que o teor de açúcares redutores (AR) presentes no caldo apresenta comportamento inverso ao teor de sacarose (Pol) que tende a aumentar com o decorrer dos meses de safra. O comportamento tecnológico da cana de açúcar ao longo da safra pode ser observado na Figura 3.

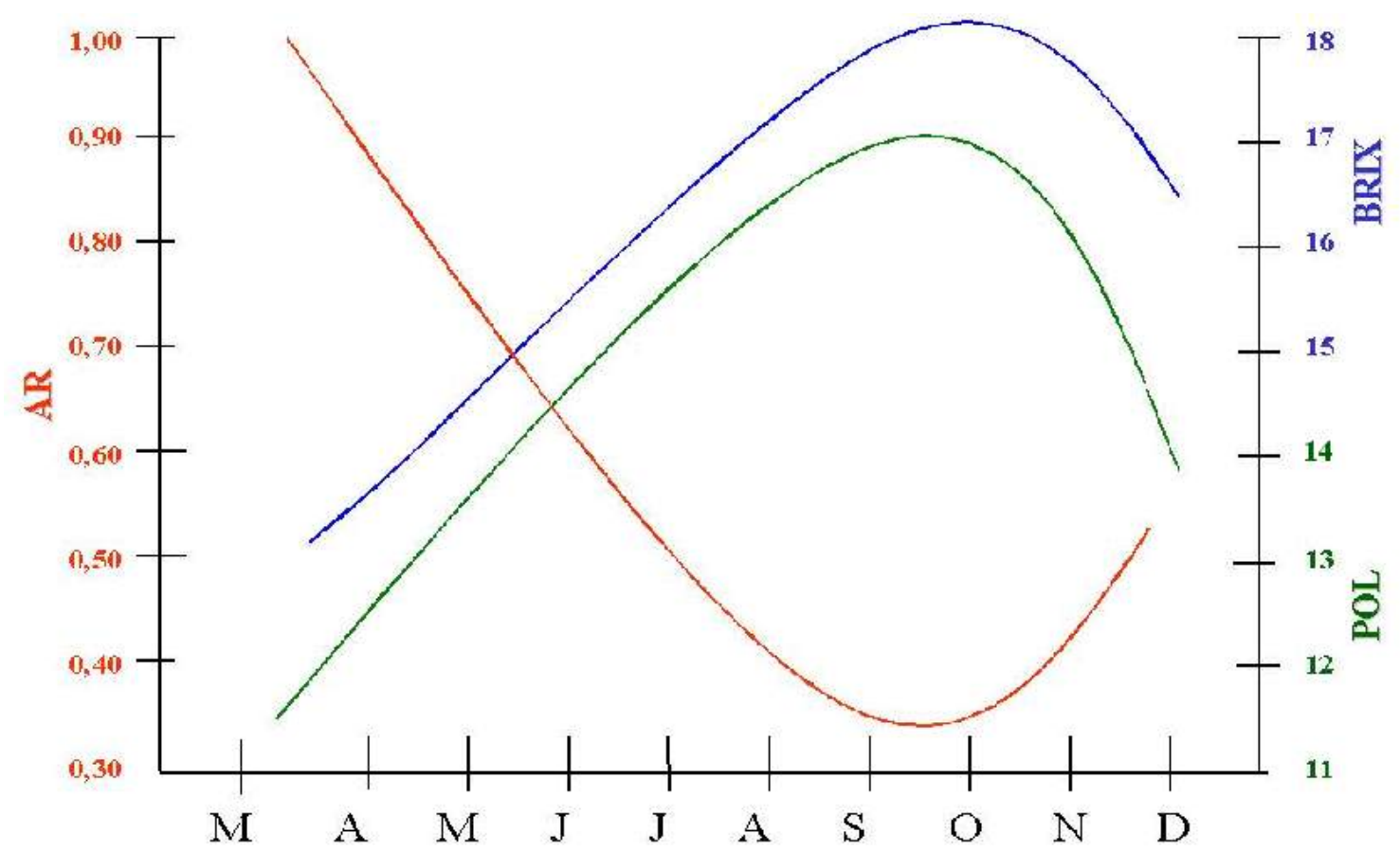

Figura 3 - Comportamento tecnológico da cana-de-açúcar ao longo da safra. (Fonte: Adaptado de Cesar \& Silva, 1993)

A Pol \% cana (eq. 4) é obtida através da Pol \% caldo e do teor de fibra. A pureza \% do caldo (eq. 5) é a relação entre o Pol \% caldo e o teor total de sólidos solúveis (Brix) presente no caldo. As metodologias de análises tecnológicas da cana-de-açúcar encontram-se melhor descritas em Cesar \& Silva (1993). 


$$
\begin{aligned}
& \text { Pol\% cana }=\text { Pol\% caldo } \times(1-0,01 F) \\
& P \%=\frac{\text { Pol caldo }}{\text { Brix caldo }} \times 100 \\
& U \% \text { cana }=100-(\text { Brix } \% \text { cana }+ \text { fibra } \% \text { cana })
\end{aligned}
$$

nas quais:

$L$ = Leitura sacarimétrica;

$d=$ Densidade do caldo em função do Brix ${ }^{\circ}$;

$F=$ Porcentagem de fibra na cana;

$P S=$ Peso seco da amostra (resíduo da prensagem);

$P U=$ Peso úmido da amostra (bolo úmido);

$b=$ Brix do caldo e;

$P \%=$ Pureza do caldo.

Antigamente a cana-de-açúcar era remunerada através da produção agrícola (Mg/ha) o que nem sempre correspondia à máxima produção industrial (Stupiello, 1987). O sistema proposto atualmente para o pagamento de cana pela qualidade em açúcar teórico recuperável (ATR), utiliza como base a Pol \% cana e a pureza do caldo e, seu resultado é expresso em quilogramas de sacarose por tonelada de cana-de-açúcar, como indicado pelas fórmulas a seguir (Consecana, 1999):

$$
\begin{aligned}
& \text { ATR }=9,26288 \times \text { PCC }+8,8 \times \text { ARC } \\
& \text { AR }=(3,641-0,0343 \times P) \times(1-0,01 \times F) \times(1,0313-0,00575 \times F)
\end{aligned}
$$

Nas quais: $\mathrm{PCC}=$ Pol \% cana; $\mathrm{P}=$ Pureza \% do caldo; $\mathrm{F}=$ Fibra $\%$ cana $\mathrm{e}$ $\mathrm{AR}=$ Açúcares redutores na cana.

Isto significa que o ATR, como função principal da PCC, atingirá o pico quando esta também atingir, resultando numa entrega de cana de fornecedores concentrada nos meses de julho a setembro. Considerando a necessidade da unidade industrial ter uma 
moagem constante, é necessário que esta utilize muito mais cana própria no início e final de safra, exigindo uma estrutura adequada e perdendo o ponto ótimo de maturação deste contingente de cana. (Consecana, 1999). Para minimizar este inconveniente ocorre a introdução de correções na tentativa de se eliminar as distorções existentes no sistema Consecana e, uma delas, seria efetivamente distribuir a entrega de cana de fornecedores durante toda a safra, em parcelas proporcionais à cana total da usina e à participação dos fornecedores. Mais detalhes da metodologia e do pagamento da cana-de-açúcar pelo teor de ATR são discutidos no manual do Consecana (1999).

A organização da lavoura em setores é outro aspecto que visa otimizar a oferta de matéria-prima e seu processamento na indústria, de maneira que não ocorram descontinuidades de fornecimento durante a safra e com menores custos operacionais. A setorização da lavoura é realizada no sentido de produzir uma matéria-prima de melhor qualidade à indústria, possibilitando um planejamento agrícola e industrial mais coerente e melhor dimensionado (Planalsucar/IAA, 1986).

\subsection{Sensoriamento remoto (SR)}

“Sensoriamento remoto pode ser definido como a ciência e a arte de se obter informações sobre um determinado objeto, área ou fenômeno, através de dados coletados por um equipamento, que não entra em contato direto com o objeto, área ou fenômeno estudado” (Crepani, 1993).

O recente desenvolvimento de novos sensores de alta resolução espacial e espectral abre a perspectiva de aplicação de técnicas de sensoriamento remoto no estudo das características e da variabilidade espacial de solos e vegetação, gerando subsídios para a prática da AP (Fritz, 1996).

Koffler (1992) destaca que a utilização de sensores orbitais em estudos agroambientais apresenta vantagens, pois permite a análise de grandes áreas em apenas uma imagem, fornece imagens da superfície terrestre continuamente e em intervalos regulares que dispensam a realização de levantamentos aerofotogramétricos e permite a obtenção de dados multiespectrais, multitemporais e em diferentes resoluções espaciais. 
Clevers (1999) elucida que a potencialidade da utilização de SR em aplicações agrícolas pode ser demonstrada pela estimativa de características das culturas como a cobertura do solo e o índice de área foliar (IAF). O autor ressalta que este último está muito relacionado com a produção agrícola e constitui uma das principais variáveis de modelos de produtividade das culturas.

Huete (1996) observou que sensores terrestres proporcionam informações básicas para a calibração e entendimento de dados orbitais para fins de avaliação de solos e Demattê et al. (2001) demonstraram que a utilização de dados radiométricos de sensores terrestres em combinação com fotografias aéreas e levantamentos planialtimétricos promove um maior número de informações para levantamentos detalhados de solos e/ou para a revisão de mapas de solos já existentes.

Atualmente os satélites de observação da terra possuem sensores de bandas largas como o Enhanced Thematic Mapper (ETM+), Thematic Mapper (TM) e o Mutispectral Scanner (MSS) da série LANDSAT, o High Resolution Visible (HRV) do SPOT, o Linear Imaging Self-Scanning (LISS) do Indian Remote Sensing (IRS), entre outros. Estes sensores apresentam limitações em proporcionar estimativas precisas de características biofísicas, produtividade das culturas e identificação de espécies vegetais (Thenkabail et al., 2002). Por outro lado, Almeida et al. (2002), Rudorff \& Batista (1990), Joaquim (1998) e Wiegand et al. (1996) verificaram que imagens orbitais são capazes de discriminar e quantificar características da cana-de-açúcar.

Com o desenvolvimento de sensores orbitais especialmente desenhados para aplicações agrícolas, sugere-se que o método será utilizado mais extensivamente (Stafford, 2000). O autor ainda discute a questão da resolução espacial que, em princípio, deve ser a melhor possível (da ordem de 1 metro) e a freqüência ideal de passagens de um sensor orbital deve ser suficiente para acompanhar a evolução da plantação ao longo de um ciclo produtivo anual.

Almeida et al. (2002), comparando dados espectrais dos sensores ETM+ do LANDSAT 7 e do ASTER (Advanced Spaceborne Thermal Emission and Reflection Radiometer) do satélite EOS - Terra, acrescentam que a resolução espectral deve permitir, no mínimo, abordar feições espectrais relativas aos principais grupos de 
informação de vegetação detectáveis por sensoriamente remoto, o que ampliaria de forma considerável a faixa de comprimento de onda necessária, uma vez que os sensores anteriores utilizavam essencialmente o visível e infravermelho próximo. Estes autores enumeram que a resolução espectral mínima para a abordagem pretendida é a do sensor ETM+, com bandas no visível, infravermelho próximo, ondas curtas e termal. Em comparação com o sensor ASTER, a existência de uma banda na região do azul nas imagens ETM+ é uma vantagem que, entretanto, é superada pelas cinco bandas do ASTER na região espectral entre 2.100 e $2.400 \mathrm{~nm}$. Estas bandas mais discretas podem permitir abordar, por exemplo, a presença relativa nas folhas de amido contra lignina ou amido contra lignina + celulose, ou seja, verificar o estágio de maturação das culturas. Ambos sensores estão aquém do ideal em relação a resolução espacial e temporal (freqüência de revisita).

Thenkabail et al. (2002) ressaltam que o desenvolvimento de sensores de altíssimas resoluções radiométricas irão gerar grande volumes de dados, sendo necessário estudos mais aprofundados em índices de vegetação para determinar quais as porções específicas do espectro que oferecem melhores informações quali-quantitativas sobre a vegetação e culturas.

Schmidt et al. (2001) concluíram que o uso de videografia aérea multiespectral, juntamente com o emprego de NIRS (Near Infrared Reflectance Spectrometry) em solos e folhas apresenta bons resultados para identificar áreas canavieiras com problemas de stress hídrico, encharcamento e mudanças ocorridas nas folhas devido a maturação da cana-de-açúcar, imperceptíveis a olho nú.

\subsubsection{Comportamento espectral de alvos agrícolas}

A medida dos valores de reflectância de um corpo ou alvo ao longo do espectro eletromagnético é definida como o seu comportamento espectral. Os alvos agrícolas em geral apresentam respostas espectrais características e distintas, devido sua constituição química, física e biológica (Sabins Junior, 1987).

O sistema NIRS (Near-Infrared Reflectance Spectroscopy) foi inicialmente desenvolvido na década de 70 para determinar a umidade de grãos (Ben-Gera \& Norris, 
1968) e atualmente é utilizado para vários fins como determinação da qualidade de grãos e forragens, identificação e caracterização de produtos químicos e farmacêuticos (Chang et al., 2001) e avaliações da qualidade tecnológica de produtos agrícolas como o caldo da cana-de-açúcar, apesar de seu uso ser restrito e limitado por questões operacionais e custo dos equipamentos (Fernandes \& Souza, 1997).

A utilização do espectro eletromagnético, na faixa do visível ao infravermelho, vem se mostrando eficaz, pois permite analisar vários constituintes de um material ao mesmo tempo, em uma análise rápida, de baixo custo e com pouca ou nenhuma preparação das amostras (Chang et al., 2001). Estes autores concluíram que a tecnologia NIRS - PCR (Near-Infra Red Reflectance Spectroscopy - Principal Component Regression) é uma ferramenta com acurácia suficiente para levantamentos pedológicos e avaliação de ambientes de produção, com grande potencial para o manejo localizado do solo e AP.

Os diferentes solos também apresentam determinados comportamentos e feições espectrais devido sua constituição mineralógica, teor de matéria orgânica, teores de óxidos de Fe e Mn e umidade. A denominada "linha do solo" descrita por Baret et al. (1993) e estudada por diversos autores (Galvão \& Vitorello, 1998; Gitelson et al., 2002; Huete et al., 1985 e Huete, 1989) tem se mostrado eficaz na avaliação de solos. Segundo os autores, os dados das bandas 4 e 3 do TM de um solo, sem interferência da vegetação, dispõem-se ao longo de uma linha imaginária a $45^{\circ}$ do eixo, dependendo de suas características químicas e mineralógicas (textura, cor, brilho rugosidade, teores de matéria orgânica e óxidos de Fe e Mn).

A energia refletida pelos alvos terrestres representa a média da energia refletida por todos os elementos que estão na superfície de forma que, se as culturas não estiverem cobrindo totalmente a superfície, maior será a contribuição do solo como parte constituinte na radiância detectada pelo sensor (Rondeaux et al., 1996; Todd \& Hoffer, 1998).

O espectro de reflectância de um dossel vegetal é influenciado por diversos fatores como a área foliar, a porcentagem de cobertura do solo, a reflectância do solo e as propriedades ópticas das folhas (Machado et al., 1985). Dessa forma, as diferenças 
que ocorrem nestes fatores podem estar relacionadas com o ambiente e/ou com as próprias culturas (Ponzoni, 2001). Outros fatores influenciam nas propriedades espectrais das folhas como deficiências minerais (Al-Abbas et al., 1974; Chapelle et al., 1992; Mariotti et al., 1996 e Ponzoni \& Gonçalves, 1999), stress hídrico (Masoni et al., 1993 e Wiegand et al.,1996) e senescência das folhas (Masoni et al., 1994 e Nutter et al., 2000).

Formaggio \& Epiphanio (1988) afirmam que o conhecimento das relações existentes entre os parâmetros físicos das culturas (IAF, fitomassa, cobertura do solo e vigor vegetativo) e seu comportamento espectral é um passo importante para se avaliar o desempenho e desenvolvimento das culturas utilizando modelos de dados de sensoriamento remoto, como os índices de vegetação que serão discutidos posteriormente. Na Figura 4 são apresentadas as curvas espectrais das culturas do feijão e do trigo, em diferentes estágios de desenvolvimento.
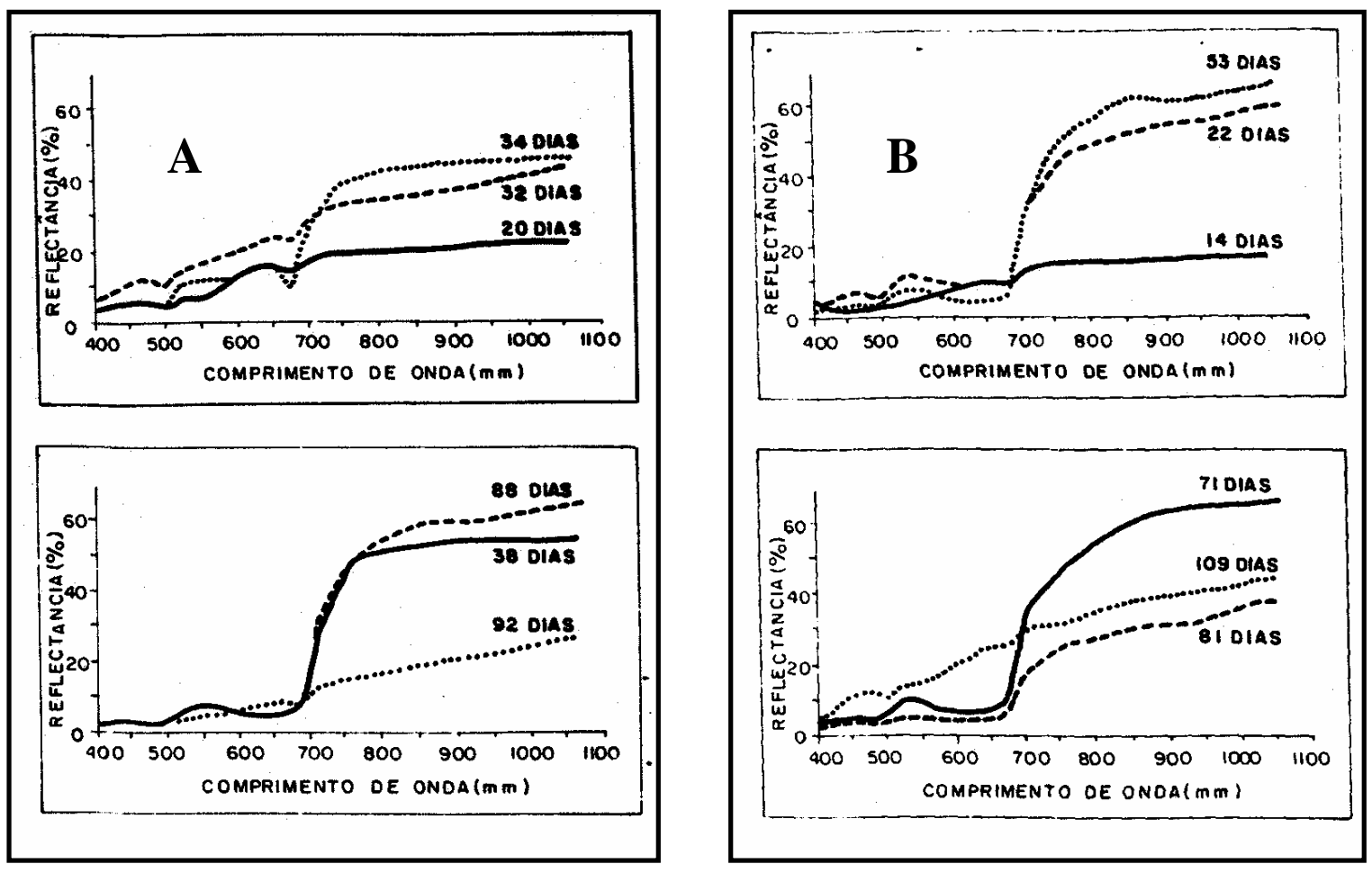

Figura 4 - Curvas espectrais de feijão (A) e trigo (B), com diferentes idades. (Fonte: Formaggio \& Epiphanio, 1988) 
Segundo Datt (1999), os sinais de reflectância de folhas verdes são resultado do espalhamento e da absorção da radiação pela folha. O espalhamento é causado por imperfeições ópticas da superfície das folhas e pela estrutura celular interna, incluindo tamanho e formato das células e organelas e o espaço ocupado pelo ar entre as células. A absorção desta radiação é causada pelos pigmentos fotossintetizantes nos comprimentos de onda do visível, pela água e outros compostos bioquímicos como a celulose/lignina, nos comprimentos de onda do infravermelho.

As pesquisas também revelam que através da espectrometria de laboratório, algumas feições de absorção específicas podem ser captadas e então correlacionadas a compostos orgânicos presentes nas folhas como celulose, lignina, proteínas, açúcares e amido (Curran, 1989; Curran et al., 2001; Fourty \& Baret, 1998; Kokaly \& Clark, 1999).

A presença de água nos tecidos vegetais vivos é o principal responsável pelo mascaramento das feições de absorção, quando se trata de sensores de bandas largas, ressaltando-se a importância de avaliações hiperespectrais com radiômetros portáteis. A absorção é mais pronunciada abaixo de $400 \mathrm{~nm}$ e acima de $2.400 \mathrm{~nm}$ e, entre estes valores, a absorção é baixa (Clevers, 1999; Datt, 1999). Em termos pontuais, Ponzoni (2001) ressalta que a absorção da radiação devido a água líquida ocorre suavemente em $1100 \mathrm{~nm}$ e fortemente em 1450, 1950, 2700 e $6300 \mathrm{~nm}$, ou seja, na região do infravermelho de ondas curtas (SWIR).

A mais promissora ferramenta para detectar stresses na vegetação é a avaliação do pico de reflectância no comprimento de onda que divide o espectro do visível e do infravermelho próximo (670-780 nm), a feição de absorção chamada “red-edge” (Horler et al., 1983; Curran et al., 1991). Segundo estes autores, o pico de reflectância de uma folha ocorre em comprimentos de onda de 680 a $740 \mathrm{~nm}$ e, a posição desta banda, pode ser alterada para comprimentos de onda menores (visível 400-700 nm) com a mudança do conteúdo de clorofilas e carotenóides (Chapelle et al., 1992; Gitelson \& Merzliak, 1997). Portanto, qualquer alteração fisiológica nas plantas interfere na posição da "red edge” e, quando a vegetação está sob algum tipo de stress, esta posição é alterada. 
Clevers (1999) e Datt (1999) ressaltam que feições compreendidas na chamada "red-edge” (aproximadamente $717 \mathrm{~nm}$ ) não são cobertas por sensores remotos orbitais e aerotransportados, devendo ser calibrado por sensores de maior resolução espectral.

Goel \& Strebel (1984) ressaltam que a arquitetura foliar tem uma grande influencia nas respostas espectrais captadas pelos sensores remotos, uma vez que a distribuição foliar dos dosséis afeta qualitativamente a reflectância da vegetação. Os autores dividem as plantas segundo os ângulos das folhas em relação ao solo (arquitetura foliar) em grupos a saber: planófilas ( 25 a $30^{\circ}$ ), plagiófilas (30 a $45^{\circ}$ ), extremófilas (45 a $\left.60^{\circ}\right)$ e erectófilas $\left(>65^{\circ}\right)$.

Thenkabail et al. (2002) ressaltam que vegetais de arquitetura foliar planófila como as leguminosas, contribuem significativamente em maior reflectância no infravermelho próximo e maior absortância no vermelho visível em relação à vegetais de arquitetura erectófila como as gramíneas.

No caso específico da cana-de-açúcar as diferenças espectrais entre os dosséis estão relacionadas a variedades, arquitetura foliar, absorção de radiação fotossinteticamente ativa, diferenças em biomassa além da concentração de água e de nutrientes nas folhas (Joaquim, 1998).

\subsubsection{Utilização de sensores remotos para avaliação da vegetação}

Uma das mais promissoras aplicações do sensoriamento remoto é a estimativa da biomassa vegetal natural ou das culturas agrícolas (Todd \& Hoffer, 1998; Machado et al., 2002; Thenkabail et al., 2002), mas para que isso seja possível, é importante conhecer as interações que ocorrem entre os alvos agrícolas (dosséis e solos) e a energia eletromagnética que é captada pelos sensores (Lillesand \& Kiefer, 2000).

A utilização de técnicas de sensoriamento remoto vem sendo preconizada no monitoramento de áreas agrícolas e estimativas de produtividade embora seja uma área carente de pesquisas (Stafford, 2000). Trabalhos demonstram que este sistema tem grande potencial de uso na avaliação das condições, mapeamento de áreas e estimativas de produção de biomassa das culturas (Singh et. al, 1992; Rudorff \& Batista, 1994; Pellegrino, 2000; Schmidt et al., 2001; Machado et al., 2002). 
O sensoriamento remoto óptico é uma ferramenta de importância crescente na agricultura extensiva e tecnologicamente competitiva, pela possibilidade de gerar informação sinóptica sobre diversas propriedades da lavoura, como crescimento e produtividade das culturas, informações essenciais ao planejamento agrícola e industrial, com reflexos no processo de formação de preços e implantação de programas de AP (Stafford, 2000).

Os dados espectrais dos alvos agrícolas podem ser extraídos de pontos amostrais e então serem relacionados à variáveis medidas nos mesmos locais, como produtividade, água disponível, teor de nutrientes do solo e das plantas, além de outros parâmetros para gerar mapas de atributos. Wiegand et al. (1996) demonstraram tais relações em áreas canavieiras impactadas por excesso de sais no solo, através de amostragem de solo e tecidos vegetais, correlacionando-os a dados espectrais do satélite SPOT.

Existem várias metodologias para quantificar parâmetros biofísicos de dosséis vegetais. Entre eles destacam-se o índice de área foliar, os índices de vegetação, biomassa úmida e seca, altura de plantas e conteúdo de N (Thenkabail et al., 2002).

Ponzoni \& Gonçalvez (1999) utilizaram um radiômetro de laboratório e análises de regressão simples e múltiplas para identificar deficiências nutricionais em seedlings de eucalipto. Concluíram que a influência maior foi encontrada nos comprimentos de onda do verde e do infravermelho próximo e que o estudo das variáveis em combinação estimam melhor o sinergismo entre os nutrientes e seus sintomas de deficiências nas plantas.

Para estudar o conteúdo de clorofila das plantas e fazer inferências sobre o estado nutricional, efeitos de senescência ou outros tipos de stress, Clevers (1999) e Datt (1999) ressaltam que são necessários trabalhos de interpretação de imagens, levantamentos de campo e laboratório para calibração das metodologias.

Rudorff \& Batista (1990), Rudorff \& Batista (1994) e Moran et al. (1997) sugerem que dados de imagens obtidas em estádios avançados de desenvolvimento das culturas podem ser utilizados para mapear a produtividade em combinação de modelos agrometeorológicos e de crescimento das culturas. 
O comportamento espectral dos vários componentes foliares é estudado em laboratório a décadas e há poucas controvérsias no que tange a caracterização de pigmentos na região do visível, de 400 a 700 nm (Chapelle et al., 1992; Curran, 1989; Fourty \& Baret, 1998; Gitelson \& Merzlyak, 1997). Entretanto, compostos bioquímicos como amido, açúcares, lignina, celulose e proteínas, cujas feições espectrais são proeminentes na região espectral do infravermelho de ondas curtas (SWIR - 1.300 a $2.500 \mathrm{~nm}$ ) e controladas pelas ligações $\mathrm{O}-\mathrm{H}$, são difíceis de serem estudadas devido à interferência da resposta espectral dominante da água neste mesmo intervalo (Fourty \& Baret, 1998; Kokaly \& Clark, 1999). As feições de absorção geralmente encontradas nos tecidos de vegetais estão exemplificados na Figura 5.

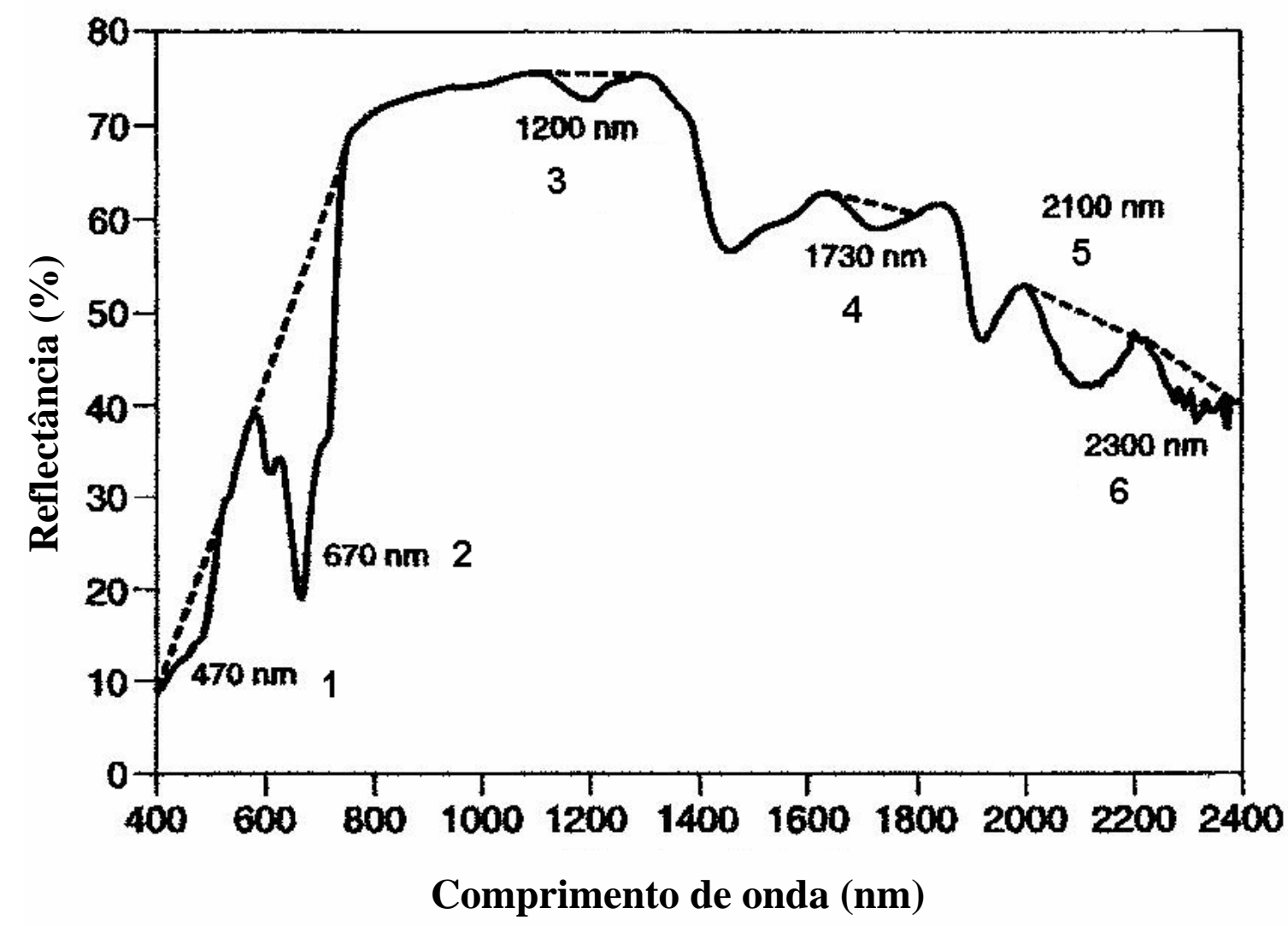

Figura 5 - Feições de absorção da clorofila (1 e 2), água (3), lignina (4), nitrogênio (5) e celulose (6). Fonte: Adaptado de Curran et al. (2001) 
Clevers (1999) ressalta que um desafio da utilização de sensores multi e hiperespectrais na espectrometria e imageamento da vegetação está no fato que as variáveis “observáveis” são as respostas individuais das bandas espectrais, enquanto que os fatores "inobserváveis" podem se constituir de variações no conteúdo de clorofila, estrutura foliar, teor de água, compostos bioquímicos, índice de área foliar, ângulos foliares e distribuição foliar no dossel. Este autor elucida que a combinação entre dados do sensor AVIRIS (Airborne Visible/Infrared Imaging Spectrometer) aliados a espectrometria terrestre de alta resolução espectral (largura de bandas até $10 \mathrm{~nm}$ ) auxilia no entendimento dos fatores "inobserváveis".

Segundo Almeida et al. (2002), as fontes de informação de origem foliar com resposta espectral detectável por sensores de baixa resolução podem ser resumidas a quatro: evapotranspiração, conteúdo relativo de clorofila, água e traços de informação da proporção entre os compostos bioquímicos. Destas, três não suscitam discussão (evapotranspiração, clorofila e água) e a quarta, dada pelos compostos bioquímicos, tem detecção ainda controversa, pois suas feições de absorção são mascaradas pelas bandas de absorção da água, segundo Curran (1989), Curran et al. (2001) e Fourty \& Baret (1998). Almeida et al. (2002) ressaltam que estudos de espectrometria de folhas in vivo de cana-de-açúcar mostram a presença de respostas independentes da água na região de 2.200 a $2.500 \mathrm{~nm}$.

Ceccato et al. (2001) citado por Almeida et al. (2002) discutem que a evapotranspiração é uma importante fonte adicional de informações sobre o status da plantação uma vez que sob stress hídrico, a atividade fotossintética está quase paralisada, embora a concentração de clorofila permaneça estável. Com respeito à correlação destas informações com o status da vegetação, sabe-se da relação da clorofila e da água com o metabolismo vegetal, pois entre os pigmentos foliares, é o responsável pela fotossíntese além de ser o primeiro a se degradar na senescência (Masoni et al., 1994). O mesmo ocorre com a água foliar, que além de se relacionar com o funcionamento da planta, também tem relação com a absorção de N. Este dado é de grande importância, pela correlação entre nitrogênio e produtividade. Já a informação relativa às proporções de compostos bioquímicos foliares pode tender para duas 
vertentes: o simples status de vigor da planta ou a maturação e concentração de açúcar no colmo (Almeida et al., 2002).

Segundo Curran et al. (2001), o pico de reflectância das folhas que ocorre a partir de $1.775 \mathrm{~nm}$ é possivelmente relacionado a reflectância de açúcares que ocorre na região de 1.800 a $1.850 \mathrm{~nm}$. Outra região do espectro de absorção dos compostos bioquímicos foliares, na região de $2.200 \mathrm{~nm}$, é largamente dominada por amido, principalmente entre 2.070 e $2.260 \mathrm{~nm}$. A baixa absorção da radiação pelo açúcar entre 2.050 e $2.250 \mathrm{~nm}$ pode fornecer uma resposta diagnóstica do processo de maturação, já que neste processo há aumento da razão açúcares/demais compostos bioquímicos. Isso deve ser considerado em culturas como a cana-de-açúcar, uma vez que esta é naturalmente pobre em amido e as folhas também tem seus teores de açúcares aumentados, a medida que a cultura entra em processo de maturação (Casagrande, 1991).

Em pesquisas recentes, Broner et al. (2002) visaram utilizar dados de sensoriamento remoto multiespectral aerotrasportado e orbital como um módulo para efetuar recomendações de $\mathrm{N}$, em conjunto com um sistema de apoio à tomada de decisão (Decision Support System - DSS) já existente. Para tanto, os autores pretendiam identificar deficiências de $\mathrm{N}$ através do conteúdo de clorofila, estimar o $\mathrm{N}$ total absorvido pelas culturas, realizar o balanço de $\mathrm{N}$ no solo para então predizer a quantidade de fertilizante nitrogenado que deveria ser empregada em cada situação. Segundo os autores, os modelos são preliminares e devem ser melhor calibrados, ou seja, possuírem maior banco de dados disponível.

Mariotti et al. (1996) elucidam que deficiências nutricionais usualmente decrescem a absortância e aumentam a reflectância e transmitância nos comprimentos de onda do visível e ressaltam que a reflectância é a propriedade espectral mais adequada para detectar anomalias, enquanto que a absortância representa a radiação teoricamente utilizada pela folha para a fotossíntese. Tais autores verificaram que a deficiência de ferro (Fe) em folhas de milho e girassol mudou a posição da "red-edge" de reflectância, absortância e transmitância para comprimentos de onda menores e encontraram boas correlações entre o conteúdo de Fe, conteúdo de clorofila e propriedades espectrais das 
folhas. Em folhas normais de milho e girassol, a posição da "red edge” está em torno de $713 \mathrm{~nm}$.

Almeida (2000) elucida que devido este proeminente aumento de reflectância da ordem de 10 vezes ocorrido na "red-edge" é que foram desenvolvidos os primeiros sensores MSS da série LANDSAT na década de 60. O autor ressalta ainda que este comportamento ocorre em torno de $700 \mathrm{~nm}$, concordando com as citações anteriores.

No caso da cana-de-açúcar, a população de colmos e o seu peso médio são os principais componentes da cultura possíveis de serem medidos, pois apresentam maior correlação com a produtividade e podem ser utilizados para estimar a produtividade dos ensaios de melhoramento e de talhões comerciais (Gheller et al., 2002). Porém, este método exige equipes treinadas, tem alto custo e demanda muito tempo no caso de áreas extensas. Rudorff \& Batista (1990) também concordam que é muito importante estimar a produção de colmos a serem processados antes da colheita começar e que, geralmente, a acurácia desta estimativa depende de pessoal tecnicamente experiente.

Vários são os métodos de calibração que relacionam as respostas espectrais de alvos agrícolas com propriedades medidas destes materiais como por exemplo, a análise de componentes principais (Chang et al., 2001), regressão linear múltipla (Kokaly \& Clark, 1999), redes neurais (Lillesand \& Kiefer, 2000; Moran et al., 1997), entre outros.

Robbins \& Daneman (1999) comentam que a análise de regressão múltipla é um método utilizado para relacionar duas ou mais variáveis independentes a uma variável dependende. No caso, estes autores utilizam o procedimento stepwise para predizer e estimar os custos e número de horas de trabalho para contratos de defesa do Departamento de Defesa (DoD) da força aérea americana e elucidam que, para tal análise, o primeiro passo deve ser a construção de uma matriz de correlação para a escolha das variáveis adequadas.

Beauclair \& Scarpari (2002) também utilizaram análise de regressão stepwise para gerar um modelo de maturação de cana-de-açúcar em uma usina do estado de São Paulo, através de dados de produção (Mg/ha e kg ATR/Mg cana) de três safras, valores de horas-frio e de precipitação, parâmetros que, segundo os autores, estão altamente relacionados a maturação da cana-de-açúcar. Obtiveram um coeficiente de determinação 
$\left(\mathrm{R}^{2}\right)$ de 0,69, para Kg de ATR/Mg de cana, concluindo que é possível estimar os valores de ATR com até dois meses de antecedência da colheita das canas de ano, na usina estudada.

Rudorff (1985) afirma que a melhor época de obtenção de imagens orbitais para fins de estimativa de produtividade da cana-de-açúcar é o mês de fevereiro, devido a cultura apresentar completo desenvolvimento de biomassa. Joaquim (1998) por sua vez, elucida que a melhor época de obtenção de imagens deve coincidir com o ínicio da safra, ou seja, abril-maio. Nesta época as imagens apresentam menor cobertura por nuvens e a cana-de-açúcar apresenta máxima cobertura do solo e desenvolvimento vegetativo.

Almeida (2000) ressalta que embora o satélite LANDSAT 7 tenha uma periodicidade de 16 dias, a disponibilidade de imagens sem cobertura de nuvens pode se restringir a apenas uma por ano, como demonstrou na região de Barra Bonita/SP. O autor ainda elucida que as imagens sem cobertura de nuvens correspondem, em sua maioria, aos meses de inverno de junho a setembro principalmente.

Almeida et al. (2002) indicam ser possível obter dados confiáveis das condições dos canaviais com imagens precoces, isto é, obtidas até 6 meses antes da colheita.

\subsection{3 Índices de vegetação}

Os índices de vegetação foram desenvolvidos para avaliar coberturas vegetais quantitativamente e qualitativamente utilizando-se dados espectrais (Huete, 1988; Jackson \& Huete, 1991). Estes índices têm sido utilizados com sucesso para monitorar e estudar temporalmente as mudanças na vegetação em escala regional, continental e global (Bannari et al., 1995; Moran et al., 1997; Rondeaux et al., 1996). O sucesso desta técnica se deve a reflectância diferencial da clorofila nos comprimentos de onda do visível (400 a $740 \mathrm{~nm}$ ) e infravermelho (740 a $1.400 \mathrm{~nm})$.

Ponzoni (2001) elucida que os índices de vegetação servem como indicadores do crescimento e vigor da vegetação e podem ser utilizados para diagnosticar vários parâmetros biofísicos com os quais apresentam altas correlações, incluindo IAF, biomassa, \% de cobertura do solo, atividade fotossintética e produtividade. 
Rudorff (1985) ressalta que os dados do LANDSAT, quando transformados em índices de vegetação, podem ser usados para expressar o efeito coletivo dos vários fatores de produtividade de culturas como a cana-de-açúcar.

Clevers (1999) afirma que a reflectância nos comprimentos de onda do verde, vermelho e infravermelho próximo são as variáveis mais utilizadas para estimativas de índice de área foliar e que os efeitos combinados destas variáveis constituem os índices de vegetação. Este autor alerta que, para não perder sensibilidade à variações de índice de área foliar após o completo fechamento do solo pelas culturas, o infravermelho próximo deve compor o papel principal nestas combinações.

Segundo Jackson \& Huete (1991), dentre os índices de vegetação que exploram fatores dependentes da superfície e do comprimento de onda, tem-se o Índice de Taxa de Vegetação (RVI - Ratio Vegetation Index) e Índice de Diferença de Vegetação Normalizado (NDVI - Normalized Difference Vegetation Index). O RVI foi o primeiro índice de vegetação proposto, entretanto, o seu uso para a quantificação de biomassa iniciou-se com o surgimento do NDVI. O RVI baseia-se na razão de bandas do vermelho e infravermelho próximo, representados respectivamente pelas bandas 3 e 4 do TM e ETM+, bandas 4 e 2 do MSS e as bandas XS 2 e XS 3 do SPOT.

O RVI é definido pela razão simples entre R/NIR, onde, $\mathrm{R}$ = vermelho visível e NIR = infravermelho próximo, segundo Pearson \& Miller (1972) citados por Rudorff et al. (1995). A aplicação prática desse índice para quantificação de biomassa vegetal ou cobertura do solo exige precaução com relação aos princípios físicos que o regem, pois, devido à intensa absorção do vermelho (600-740 nm) pela vegetação, sua reflectância é mínima. Portanto, em áreas de vegetação esparsa, faz-se necessário a utilização de índices mais precisos e de maior sensibilidade para que haja registro dos baixos valores de reflectância no comprimento de onda referente ao vermelho. Caso contrário, o denominador da equação do RVI pode assumir valores próximos ou iguais a zero e seu cálculo torna-se impreciso (Todd \& Hoffer, 1998).

O NDVI (Rouse et al., 1974 citados por Bannari et al., 1995), embute em seu cálculo um procedimento que evidencia a reflectância do comprimento de onda vermelho pela vegetação permitindo, portanto, a quantificação de biomassa vegetal em 
áreas de vegetação esparsa e desuniforme. O NDVI é definido de acordo com a equação 9.

$$
\mathrm{NDVI}=\frac{(\mathrm{NIR}-\mathrm{R})}{(\mathrm{NIR}+\mathrm{R})}
$$

Embora ambos os índices sejam funcionais, o NDVI torna-se pouco sensível à variações da reflectância no vermelho em áreas de vegetação muito densa, onde essa grandeza radiométrica é mais expressiva (Jackson \& Huete, 1991). Nesses casos os autores apontam uma melhor sensibilidade do RVI.

Thenkabail et al. (2002) elucidam que o NDVI é um índice que normaliza os efeitos da topografia, é sensível à radiação fotossinteticamente ativa e é uma técnica simples e confiável de mensurar o vigor da vegetação. Os autores ainda ressaltam que o NDVI pode superestimar a vegetação em solos mais escuros, em comparação a solos mais claros. Kokaly \& Clark (1999) também ressaltam a importância da aplicação dos índices de vegetação em dados de sensores de bandas largas como o LANDSAT, para a redução e normalização de efeitos topográficos e atmosféricos.

Vários trabalhos apontam altas correlações entre os índices de vegetação RVI e NDVI com parâmetros associados ao vigor e produtividade da vegetação, como densidade e cobertura vegetal (Moran et al., 1997; Todd \& Hoffer, 1998), conteúdo de clorofila (Chapelle et al., 1992), compostos bioquímicos (Curran et al. 2001; Gitelson \& Merzlyak, 1997), estado de vigor das culturas (Wiegand et al.,1996) além da possibilidade de seu emprego em modelos de estimativa de produtividade de culturas (Almeida et al., 2002; Machado et al. 2002; Pellegrino, 2000; Rudorff \& Batista, 1990; Rudorff \& Batista, 1994; Singh et al.,1992).

Gitelson \& Merzlyak (1997), estudando a estimativa do conteúdo de clorofila de várias espécies vegetais concluíram que a sensibilidade do NDVI aumenta cerca de cinco vezes, quando utilizaram as bandas do verde e vermelho mais próximo a $700 \mathrm{~nm}$, a chamada "red edge". Os autores elucidam que mudanças nas respostas espectrais nesta faixa do espectro podem indicar alterações fisiológicas nas plantas, uma vez que o pico da curva se movimenta em direção ao infravermelho próximo, quanto mais sadia estiver a vegetação. 
Gitelson et al. (1996) apresentam o “Green NDVI” (eq. 10) que incorpora na fórmula do NDVI o comprimento de onda do verde, ou seja, a banda 2 do ETM+.

$$
\text { GNDVI }=\frac{(\mathrm{NIR}-\mathrm{G})}{(\mathrm{NIR}+\mathrm{G})} \text { onde } \mathrm{G}=\text { verde, } \mathrm{ETM}+2
$$

Os índices de vegetação se correlacionam bem com a densidade foliar dos dosséis, porém estão sujeitos a interferências de fatores externos como o ângulo e geometria solar, ângulo de visada dos sensores, reflectância do solo e efeitos atmosféricos (Ponzoni, 2001; Rondeaux et al., 1996). Para minimizar estas interferências foram desenvolvidos nas duas últimas décadas mais de quarenta índices derivados do NDVI como, por exemplo, o SAVI (Soil Adjusted Vegetation Index) e o ARVI (Atmospherically Resistant Vegetation Index). Detalhes sobre os índices de vegetação atualmente utilizados, bem como seus respectivos autores, encontram-se na revisão de Bannari et al. (1995).

Thenkabail et al. (2002) utilizaram o módulo máximo $\mathrm{R}^{2}$ do SAS (Statistical Analysis System, 1999) para determinar combinações de bandas ótimas para estimar biomassa verde e seca, índice de área foliar e altura do dossel de seis culturas e consideram que os modelos de três bandas são os que melhor se adaptam a índices de vegetação para sensores de bandas largas (satélites) e estreitas (radiômetros terrestres) e para quantificação de parâmetros biofísicos dos dosséis. Os autores ressaltam ainda que dependendo da altura da cultura, a influência do solo é maior e os dados de satélite não conseguem captar determinadas variações na vegetação.

Segundo Huete (1988), o índice de vegetação SAVI leva em consideração as variações de solos quanto a cor, textura e brilho, sendo o mais sensível quando a vegetação é esparsa, embora não aumente a intensidade de reflectância dos dosséis. O SAVI foi escolhido para utilização neste trabalho e insere um fator que visa minimizar a influencia do solo na resposta espectral do dossel (eq. 11).

$$
\mathrm{SAVI}=\frac{(\mathrm{NIR}-\mathrm{R})}{(\mathrm{NIR}+\mathrm{R}+L)} *(1+L) \text { onde } L=0,5
$$

A área fotossinteticamente ativa total ou GLAI (Green leaf area index) é, segundo Nutter et al. (2000), a variável que mais está relacionada à produção agrícola, 
uma vez que esta é função da quantidade de radiação interceptada pelos dosséis das culturas. Os autores enumeram que através do uso do GLAI, GPS, SIG e geoestatística, os dados de sensoriamento remoto podem ser analisados e interpretados para identificar e quantificar stresses na vegetação, avaliar o desenvolvimento e a produtividade das culturas e compor prescrições sobre manejo, que irão aumentar a rentabilidade e o retorno do investimento pelos produtores. Outras pretensões dos autores foram estabelecer níveis de dano e controle para pragas e doenças através de dados de sensoriamento remoto.

Um índice atualmente utilizado para avaliação da vegetação é o "Tasseled cap" que decompõe os efeitos espectrais das bandas do LANDSAT em três componentes a saber: "Wetness", "Greeness" e o "Brightness", segundo Crist \& Cicone (1984) e Thenkabail et al. (2002). A componente "Greeness" é o índice de vegetação GVI e segue a equação 12. Os outros componentes encontram-se nas equações 13 e 14.

$$
\begin{aligned}
& \mathrm{GVI}=-0,24717 * \mathrm{TM} 1-0,16263 * \mathrm{TM} 2-0,40639 * \mathrm{TM} 3+0,85468 * \mathrm{TM} 4+ \\
& \text { 0,005493*TM5 - 0,11749*TM7 } \\
& \text { Brightness }=0,1446 * \mathrm{TM} 1+0,1761 * \mathrm{TM} 2+0,3322 * \mathrm{TM} 3+0,3396 * \mathrm{TM} 4- \\
& 0,6210 * \text { TM5 - 0,4186*TM7 } \\
& \text { Wetness }=0,2909 * \mathrm{TM} 1-0,2728 * \mathrm{TM} 2+0,1446 * \mathrm{TM} 3+0,8461 * \mathrm{TM} 4+ \\
& \text { 0,00549*TM5 + 0,1706*TM7 }
\end{aligned}
$$

onde TM são as bandas do satélite LANDSAT.

Zullo Júnior (1994) cita que a presença da atmosfera proporciona alguns efeitos observados nas imagens de satélite como, por exemplo, a diminuição da faixa de valores digitais possíveis de serem registrados pelo sensor, o que resulta na diminuição do contraste entre superfícies adjacentes e alteração do brilho de cada ponto da imagem. Os gases (vapor d'água, oxigênio, dióxido de carbono e ozônio) e os aerossóis (partículas em suspensão) refletem, refratam, absorvem e espalham a radiação desde quando ela atinge a atmosfera até quando a deixa após ser refletida pelo solo. Segundo o mesmo 
autor, os valores de NDVI, de uma maneira geral, são subestimados devido aos efeitos atmosféricos e observou em uma área de cana-de-açúcar valores do NDVI de 0,6 e 0,4 na imagem corrigida e na original, respectivamente.

Song et al. (2001) ressaltam que para algumas aplicações que utilizem razões de bandas, como o cálculo do NDVI, os valores da imagem devem ser corrigidos em relação aos efeitos atmosféricos, uma vez que estes atuam de maneira desigual ao longo de todo espectro e são mais pronunciados nos comprimentos de onda menores (visível).

\subsection{Utilização de geotecnologias na cultura da cana-de-açúcar}

Atualmente a agricultura é um mercado consumidor potencial das chamadas geotecnologias, como os sistemas de posicionamento global (GPS), sensores remotos terrestres, aéreos e orbitais, programas para armazenamento de dados georreferenciados (SIG), sistemas informatizados de medição e coleta de dados além de outros como controles e acionamento automático de máquinas (Stafford, 2000).

O sistema GPS - NAVSTAR (Navigation Satellite Time and Ranging) é um sistema de posicionamento baseado em satélites e possui alta confiabilidade. Foi criado pelo departamento de Defesa dos Estados Unidos e é constituído por 24 satélites, sendo 3 de reserva, segundo Rocha \& Lamparelli (1998). Em agricultura, o sistema GPS tem basicamente o seguinte modo de funcionamento: os equipamentos de campo enviam sinais para os satélites e estes são retransmitidos para uma base na terra que armazena os dados com a latitude e longitude do ponto. Isso possibilita a coleta de amostras pontuais de solos e culturas ou, quando instalado em maquinários agrícolas, permite a visualização da movimentação destes. Estes autores afirmam que o GPS é o elo de ligação entre as informações referenciadas de dados de campo e sensoriamento remoto, podendo ser então trabalhadas num SIG. O uso do GPS para captura e edição de dados faz com que o gerenciamento e manipulação destes se torne mais eficiente, uma vez que o acesso a informações espaciais (mapas) atualizadas é um dos pontos críticos para utilização de SIG's (Rocha, 1995). 
Muitas empresas do setor agroindustrial utilizam bancos de dados para controlar e planejar suas operações agrícolas como preparo do solo, adubação, plantio e colheita. A existência de um banco de dados informatizado e mapas em formato digital criam condições favoráveis à implantação de um gerenciamento com a utilização de um SIG (Aronoff, 1989).

O início das pesquisas para utilização de SIG's na agroindústria canavieira nacional é recente e se iniciou em meados da década de 90, como relatam Joaquim et al. (1994a) que, utilizando o programa SGI (Sistema Geográfico de informações) do INPE, pretendiam integrar, em uma única base de dados, informações espaciais provenientes de mapas, dados de censos, imagens de satélite, modelos numéricos de terreno e combinar estas informações através de algoritmos de manipulação, para geração de mapas derivados, além de visualizar e plotar tais informações georeferenciadas. Nestes estudos preliminares já se pensava na possibilidade de uso do SIG para estimar a porcentagem de áreas e a localização das fazendas com declividade favorável para colheita mecanizada, planejamento de colheita, reforma, transporte além de inventariamento varietal através de imagens de satélite.

A implantação de SIG's no gerenciamento de operações agrícolas em agroindústrias deve ser encarada como um pacote tecnológico que envolve desenvolvimento de programas específicos e configurações voltadas ao usuário, modernização do trabalho topográfico para atualização da mapoteca através do GPS, integração de bancos de dados agrícolas e de rendimento industrial, além de dados de sensoriamento remoto (Rocha, 1995).

Outro aspecto relevante na gerência de unidades agroindustriais é que o aumento no preço dos insumos, a maior oferta e a queda dos preços dos produtos agrícolas vêm forçando as agroindústrias canavieiras a buscar competitividade através de maior eficiência e produtividade (Almeida et al., 1994). Para tanto, os autores ressaltam que muitos investimentos em programas computacionais de bancos de dados vem sendo realizados como forma de se obter maior controle da parte agrícola das usinas, desde o mais simples, como controle da produção agrícola e de qualidade tecnológica por 
variedade, até o mais completo, ou seja, controle da produção, frota, funcionários, frentes de colheita, sistemas de carregamento e capacidade de moagem da indústria.

Os talhões, juntamente com fazenda e/ou setor, são as unidades-chave do banco de dados das usinas e é a partir deles que se faz a ligação com todas as outras informações consideradas no gerenciamento agrícola (Rocha, 1995). O autor ainda observa que, pela sua logística e natureza dinâmica, as operações agrícolas no setor canavieiro requerem decisões rápidas e eficazes, o que dificilmente pode ser atingido a partir de bancos de dados sobrecarregados e informações em formato de papel. Aponta também que a modificação constante dos mapas de talhões e fazendas e, portanto a sua rápida desatualização, constitui um problema gerencial rotineiro em agroindústrias em geral. A ligação GPS-SIG faz com que a topografia, um ponto crítico na atualização de mapas em agroindústrias, passe a ser mais ágil e eficaz. O autor enumera algumas vantagens da utilização de SIG's para o gerenciamento de agroindústrias de cana-deaçúcar:

1. Importação, leitura e edição digital de mapas: Geralmente os dados digitalizados são em formato DXF (Drawing Exchange Format), um padrão Autocad de desenho muito utilizado em agroindústrias em geral;

2. Interface com bancos de dados existentes: A maioria das agroindústrias possuem banco de dados informatizados (ex: Oracle, Access e Dbase) e não apresentam dificuldades em exportar os dados para um SIG sendo que alterações no banco de dados são somente para se melhorar a sua estrutura e a dinâmica de consultas;

3. Execução de programas externos: Os SIG's possibilitam a execução de programas de otimização, roteirização e simulação de rotinas específicas desenvolvidas na empresa e, através da lógica de dados históricos, é possível realizar simulações e projeções para as safras seguintes;

4. Multiusuários com diferenciados níveis de consulta: SIG's são sistemas projetados para trabalhar principalmente em rede, pois as informações devem ser compartilhadas e, para funcionar de maneira eficiente, o sistema deve ter níveis diferenciados de acesso. 
No campo do sensoriamento remoto orbital, os primeiros estudos realizados no Brasil para identificação e o mapeamento de áreas ocupadas com cana-de-açúcar foram realizados no município de Jardinópolis, SP, em 1975, por Batista et al. (1976). Estes autores compararam resultados obtidos do satélite LANDSAT-2 com fotografias aéreas para o mapeamento da cultura.

Após estes primeiros estudos, vários outros utilizando técnicas de sensoriamento remoto em cana-de-açúcar foram desenvolvidos no intuito de mapear e identificar a cultura (Mendonça et al., 1978; Batista et al., 1978; Mendonça, 1980 e Mendonça et al., 1981). Os autores ressaltam que a precisão dos levantamentos realizados através de dados LANDSAT é influenciada por diferenças nas respostas espectrais dos dosséis, devido a fatores relacionados a própria cultura, como a variedade, o estádio de desenvolvimento e a época de plantio e colheita.

Mendonça et al. (1989) iniciaram o projeto CANASATE, para estimar a área e a distribuição da cana-de-açúcar a nível nacional utilizando técnicas de sensoriamento remoto e obtiveram uma média de $91 \%$ de precisão devido a metodologia adotada utilizar constantemente informações de campo como complemento das análises dos dados orbitais.

Rudorff (1985) avaliou o uso potencial de dados LANDSAT em conjunto com dados de um modelo agrometeorológico na previsão de produtividade de cana-deaçúcar. Das imagens orbitais de áreas canavieiras foram extraídos os níveis de cinza que foram transformados em valores de reflectância e estes utilizados em índices de vegetação. O estudo comprovou que os melhores resultados foram aqueles alcançados com o uso dos dois componentes do modelo em conjunto, o agrometeorológico e o índice de vegetação. Embora os resultados tenham mostrado a viabilidade do uso de dados LANDSAT na estimativa de produtividade da cana-de-açúcar, o modelo proposto neste trabalho foi considerado como preliminar.

Outros estudos de caso confirmam a possibilidade do uso de sensoriamento remoto para previsão de safras de cana-de-açúcar, como por exemplo, Rudorff \& Batista (1990) na região de Lençóis Paulista, SP. Os autores utilizaram dados espectrais do sensor MSS/LANDSAT além de dados meteorológicos de três safras (1984/85, 85/86 e 
86/87) e observaram que a utilização conjunta do índice de vegetação Ratio Vegetation Índice (RVI - bandas MSS4/MSS2) derivado das imagens e dos dados meteorológicos num único modelo melhoraram significativamente os coeficientes de determinação $\left(R^{2}\right)$, passando de 0,59, 0,24 e 0,14 para 0,69, 0,54 e 0,50, para os referidos anos agrícola, respectivamente.

Rudorff et al. (1995) ressaltam que o emprego de variáveis qualitativas sobre os modelos como a variedade e o estádio de corte melhoram a relação entre a produtividade observada e os índices de vegetação obtidos das imagens de satélite.

Além de cana-de-açúcar, Rudorff \& Batista (1994) também desenvolveram um modelo para estimar o rendimento de trigo em regiões tritícolas do sul de São Paulo através do índice de vegetação RVI gerado de imagens TM/LANDSAT (bandas TM4/TM3) e dados agrometeorológicos. Observaram novamente maiores coeficientes de determinação e menores erros de estimativa de rendimento quando os componentes do modelo foram utilizados em conjunto.

Wiegand et al. (1996), estudando áreas de cana-de-açúcar sobre solos afetados por sais, reconhecem o sensoriamento remoto juntamente com observações de campo como ferramentas importantes na identificação e mapeamento de áreas sob algum tipo de stress. Estes autores utilizaram dados espectrais do satélite SPOT - HRV e de videografia aérea multiespectral e correlacionaram a produtividade da cana-de-açúcar com índices de vegetação, amostragem de solos e de material vegetal.

Noonan (1999), citado por Schmidt et al. (2001), demonstrou que através de técnicas modernas de processamento de imagens e da utilização de índices de vegetação como o NDVI foram bem sucedidos na estimativa de produtividade de cana-de-açúcar em duas safras e em dois locais na Austrália.

Almeida (2000) ressalta que o sensoriamento remoto se apresenta heterogêneo no diagnóstico quando se pretende levantar o estado de vigor de culturas como a cana-deaçúcar. Esta variação é função dos solos, presença de pragas, variedade plantada e idade da cana. O autor elucida que este diagnóstico, quando feito em grandes áreas, permite um exame agronômico de detalhe em campo, rápido e dirigido a áreas com potenciais 
problemas de pragas e/ou insumos. Outro ponto levantado pelo autor é que tais avaliações de vigor devem ser restritas a talhões de mesma idade e variedade.

Moran et al. (1997) comentam que o uso de sensoriamento remoto orbital para fins de Agricultura de Precisão (AP) depende do objetivo e aplicação que se deseja, devendo se considerar a resolução de pixels (espacial), tempo de processamento das imagens e ciclo de repetição (resolução temporal). Estes autores também apontam que as limitações dos sensores orbitais são devido a instrumentação, pois bandas espectrais fixas podem ser impróprias para certas aplicações, resoluções espaciais muito grosseiras não permitem avaliações detalhadas de campo e o tempo para aquisição, processamento e entrega aos usuários pode ser muito extenso.

Almeida et al. (2002) elucidam que estimativas de produtividade de cana-deaçúcar por sensores orbitais ASTER e ETM+ foram mais precisas que as realizadas pela usina no método convencional, chegando a erros de estimativa da ordem de 3,09 e 5,65 \% respectivamente para os dois sensores, contra 9,96 \% da usina. Os autores ainda comentam que o uso da técnica é de baixo custo dependendo da área estudada e indicam que o uso de imagens precoces podem indicar a produtividade da cana-de-açúcar. Os autores lembram que apesar de estar sendo abordado recentemente, o assunto é raro nos principais periódicos internacionais.

Schmidt et al. (2001) enumeram várias utilizações do sensoriamento remoto na cultura da cana-de-açúcar na África do Sul como a identificação de variedades, mapeamento das áreas, estimativa de produtividade e monitoramento das condições da cultura, gerando subsídios para implantação da AP.

O manejo adequado das culturas é de importância crítica para a sustentabilidade agroambiental e, os sistemas de suporte a decisão (DSS), podem elevar o nível de controle sobre as culturas sem afetar substancialmente os custos associados ao uso intensivo de recursos (Broner et al., 2002). Em sua pesquisa preliminar, os autores objetivaram combinar e ajustar um sistema de suporte a decisão já existente a um ambiente SIG (ArcGIS), para receber dados de sensoriamento remoto e gerar mapas de decisões de manejo. 
Almeida (2000) discute um método de diagnóstico do vigor de áreas canavieiras através de interpretação de imagens de sensoriamento remoto orbital LANDSAT e enumera os seguintes objetivos: geração de diagnóstico comparativo anual de toda área plantada, identificação de talhões e áreas com falhas e outros problemas, otimizar e direcionar ações de equipes de campo, facilitar a decisão por reformas precoces ou adoção de insumos direcionados, tudo isso visando principalmente à economia de recursos, aumento da relação benefício-custo e aumento da produtividade média por hectare. 


\section{INFORMAÇÕES BÁSICAS DO TRABALHO}

Este item tem a intenção de descrever o sensor orbital ETM+ do LANDSAT 7 e as variedades de cana-de-açúcar utilizadas para o desenvolvimento deste trabalho. Estas informações são básicas para ambos os capítulos (itens 5 e 6) e esta configuração visa facilitar o entendimento do leitor. As metodologias dos estudos serão descritas com maiores detalhes nos seus respectivos itens.

\subsection{Características do sensor orbital utilizado}

O sensor orbital utilizado neste trabalho foi o ETM+ (Enhanced Thematic Mapper Plus) que se encontra a bordo do satélite LANDSAT 7. Este satélite foi lançado em abril de 1999, financiado pelo Governo Americano. A operação do satélite em órbita é administrada pela National Aeronautics and Space Administration (NASA, 2002)

Uma imagem LANDSAT 7 ETM+ é composta por 8 bandas espectrais que podem ser combinadas em diversas possibilidades de composições coloridas e opções de processamento. Entre as principais melhorias técnicas se comparado ao seu antecessor, o satélite LANDSAT 5, destacam-se a adição de uma banda espectral (banda pancromática) com resolução de $15 \mathrm{~m}$, melhorias nas características geométricas e radiométricas, e o aumento da resolução espacial da banda termal para $60 \mathrm{~m}$. Esses avanços tecnológicos permitem aplicações diretas de imagens de satélites até a escala 1:25.000, principalmente em áreas agrícolas, mesmo em grandes extensões de território, como acontece freqüentemente no Brasil. O LANDSAT 7 pode adquirir imagens numa área que se estende desde $81^{\circ}$ de latitude norte até $81^{\circ}$ de latitude sul e em todas as longitudes do globo terrestre. Outra melhoria em relação ao LANDSAT 5 é o 
aprimoramento no sistema de calibração radiométrica dos sensores, o que garante uma precisão radiométrica absoluta de $+/-5 \%$ (NASA, 2002). As características do sensor ETM+ se encontram na Tabela 2.

Uma órbita do LANDSAT 7 é realizada em aproximadamente 99 minutos, permitindo ao satélite dar 14 voltas na Terra por dia, ou seja, a cobertura total do planeta é completada em 16 dias. A órbita é descendente, isto é, de norte para sul e o satélite cruza a linha do Equador entre 10:00 e 10:15 (hora local) em cada passagem. O LANDSAT 7 é heliosincronizado, ou seja, sempre passa num mesmo local dado ao mesmo horário solar (NASA, 2003).

Outro fato importante é que o satélite LANDSAT 7 tem o mesmo período de revisita que o LANDSAT 5 (16 dias), e a sua órbita é de tal maneira que resultou na mesma grade de referência do LANDSAT 5 (WRS2 - World Reference System) e tem a mesma área imageada (185 x 185 km por cena). A conservação destes parâmetros técnicos facilita o processo de pesquisa de imagens e pode ser feito com a mesma grade de referência e a perfeita integração no processamento das imagens do LANDSAT 7. Com os dados históricos do LANDSAT 5 existentes desde 1985, no caso de utilização dos dois tipos de dados simultaneamente para a mesma área, é possível realizar estudos multitemporais (NASA, 2003). 
Tabela 2. Características Espectrais e Espaciais do Sensor ETM+ do LANDSAT - 7 (Fonte: Adaptado de NASA (2002)

\begin{tabular}{|c|c|c|c|c|}
\hline BANDAS & $\begin{array}{c}\text { FAIXA } \\
\text { ESPECTRAL } \\
(\mathbf{n m})\end{array}$ & $\begin{array}{l}\text { REGIÃO DO } \\
\text { ESPECTRO }\end{array}$ & $\begin{array}{l}\text { RESOLUÇÃO } \\
\text { ESPACIAL } \\
\text { (m) }\end{array}$ & $\begin{array}{c}\text { PRINCIPAIS } \\
\text { APLICAÇÕES }\end{array}$ \\
\hline 1 & $450-520$ & AZUL & 30 & $\begin{array}{l}\text { Mapeamento de águas } \\
\text { costeiras, diferenciação } \\
\text { entre solo e vegetação, } \\
\text { absorção pela clorofila e } \\
\text { carotenóides. }\end{array}$ \\
\hline 2 & $520-600$ & VERDE & 30 & $\begin{array}{l}\text { Reflectância da vegetação } \\
\text { verde sadia, presença de } \\
\text { sedimentos em suspensão. }\end{array}$ \\
\hline 3 & $630-690$ & VERMELHO & 30 & $\begin{array}{l}\text { Absorção pela clorofila, } \\
\text { diferenciação de espécies } \\
\text { vegetais, identificação e } \\
\text { delimitação de áreas } \\
\text { urbanas e agrícolas. }\end{array}$ \\
\hline 4 & $770-900$ & IV Próximo & 30 & $\begin{array}{l}\text { Levantamentos de } \\
\text { biomassa, áreas agrícolas, } \\
\text { delineamento de corpos } \\
\text { d’água, alta reflectância } \\
\text { pela vegetação sadia. }\end{array}$ \\
\hline 5 & $1550-1750$ & IV Médio & 30 & $\begin{array}{l}\text { Medidas de umidade e } \\
\text { stress hídrico da } \\
\text { vegetação, alta absorção } \\
\text { pela água e espessura das } \\
\text { folhas. }\end{array}$ \\
\hline 6 & $10400-12500$ & IV Termal & 60 & $\begin{array}{l}\text { Detecção de propriedades } \\
\text { termais de rochas, solos, } \\
\text { vegetação e água. }\end{array}$ \\
\hline 7 & $2090-2350$ & IV Médio & 30 & $\begin{array}{l}\text { Mapeamento hidrotermal, } \\
\text { identificação de minerais } \\
\text { com íons hidroxila. }\end{array}$ \\
\hline 8 (PAN) & $520-900$ & VIS/IV & 15 & Idem 2,3 e 4. \\
\hline \\
\hline \multicolumn{3}{|c|}{ RESOLUÇÃO TEMPORAL: } & \multicolumn{2}{|c|}{ RESOLUÇÃO RADIOMÉTRICA: } \\
\hline \multicolumn{3}{|c|}{16 dias } & \multicolumn{2}{|c|}{8 bits (256 NC) } \\
\hline
\end{tabular}




\subsection{Variedades de cana-de-açúcar avaliadas}

As variedades escolhidas para o desenvolvimento dos trabalhos foram as de maiores áreas colhidas na safra em questão (2000/01) e mais representativas da região de estudo. São elas: RB835486 (1121,27 ha - 42,17 \% da área), RB855536 (176,97 ha 6,66 \%), RB855113 (433,78 ha - 16,31 \%) e SP81-3250 (173,52 ha - 6,53 \%). Somente a RB835486 foi utilizada nos dois estudos, o de discriminação e o de estimativa de produtividade agroindustrial, por isso será descrita com maior detalhamento. Abaixo estão as descrições resumidas das variedades, segundo as instituições de melhoramento que as desenvolvem.

\subsubsection{RB835486}

A variedade de cana-de-açúcar mais estudada foi a RB835486, dada a sua importância na região e ser bem adaptada aos ambientes edáficos de produção da área de estudo. É uma variedade de alta produtividade em cana planta e soca, altíssimo teor de sacarose, alta precocidade, média exigência em solos, ampla adaptabilidade, perfilhamento médio, bastante tombamento, florescimento médio e pouca isoporização (UFSCar, 2001).

Quanto às características botânicas, a RB835486 apresenta touceiras ralas, decumbentes na fase adulta, colmos medianamente empalhados e de fácil despalha, diâmetro médio a grosso e de elevado peso, cor arroxeada com cera abundante; entrenós médios, dispostos em leve ziguezague; gemas arredondadas; capitel médio, folhas de largura e comprimento médios, eretas, geralmente dispostas em leque, com leve curvatura na ponta e bainha sem joçal (Figura 8).

Esta variedade apesar de muito rústica e ter sido a mais plantada na safra em questão (2000/01), apresenta como inconveniente uma susceptibilidade intermediária a ferrugem (Puccinia melanocephala) porém sem acarretar danos a sua produtividade,

desde que plantada e manejada nas épocas corretas e em áreas menos favoráveis ao aparecimento da doença (Giglioti et al., 1999). Na maioria das áreas de produção contempladas neste trabalho, o plantio da RB835486 ocorreu em meados de abril e maio 
e foi colhida em junho e julho, com cerca de 14,5 meses em cana-planta, evidenciando seu caráter precoce.

Considerando-se todos os seus aspectos botânicos e tecnológicos, a RB835486 é a variedade precoce de maior retorno econômico de diversas empresas desde que colhida de junho a agosto, embora nessa época possa brotar devagar e irregularmente. Outro aspecto importante é que devido ao seu alto vigor vegetativo e intenso tombamento, possui baixa densidade de carga na forma de cana inteira, devendo-se desta maneira evitar plantios a longas distâncias da indústria (Arizono et al., 2000).

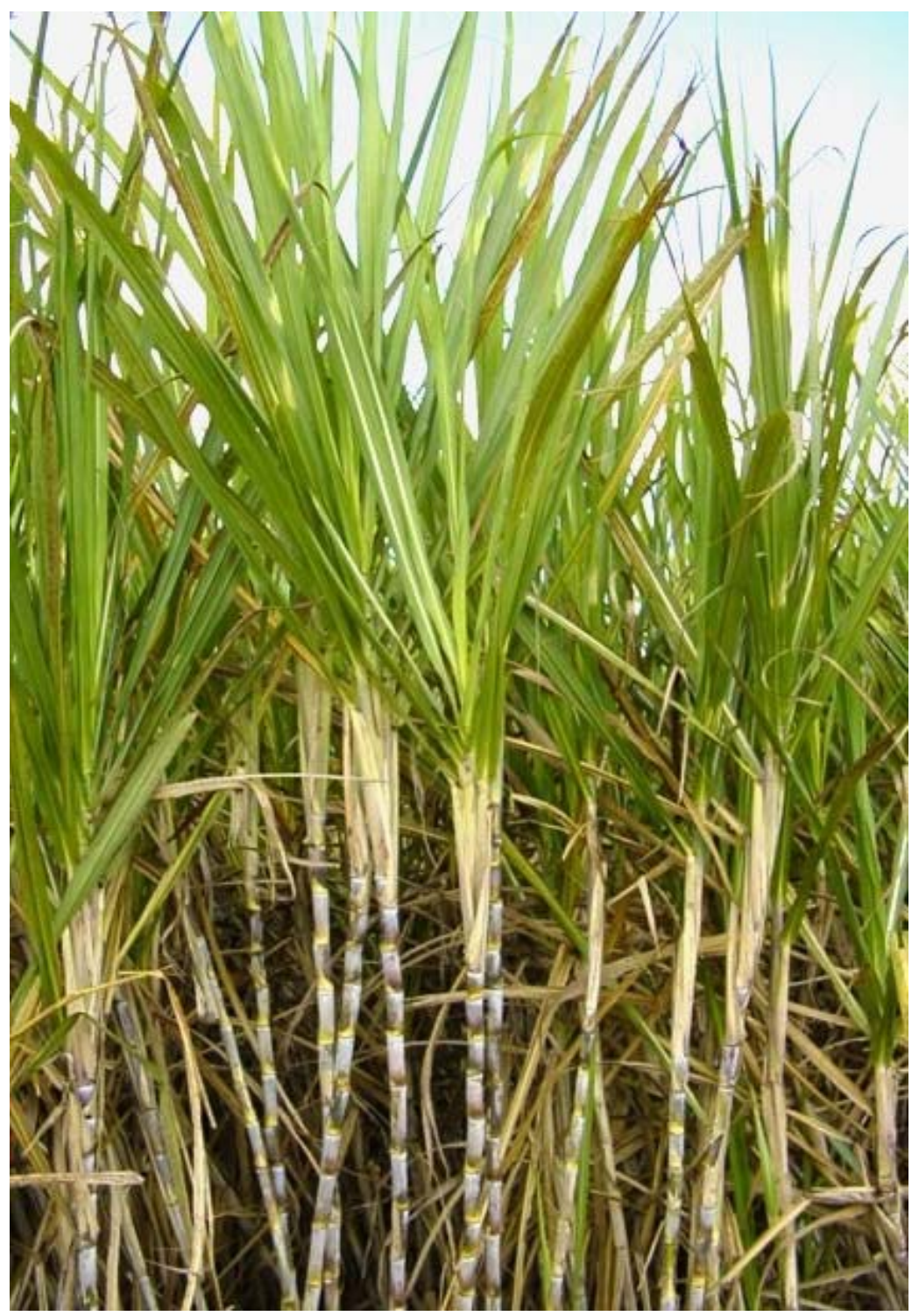

Figura 8 - Variedade de cana-de-açúcar RB835486 


\subsubsection{RB855536}

É uma variedade de alta produtividade agrícola e industrial, porte alto, ótima brotação de soqueira mesmo sob palha, ampla adaptabilidade, alta estabilidade e uniformidade do canavial. O touceiramento é bom, os colmos são eretos, de fácil despalha, diâmetro médio, e de cor arroxeada; entrenós médios, alinhados em leve ziguezague, e com média quantidade de cera; capitel médio com folhas espetadas e com pouco joçal (UFSCar, 2001).

Segundo Arizono et al. (2000) é uma variedade que deve ser plantada preferencialmente em solos de médio a alto potencial produtivo devido sua área foliar ser muito grande e o consumo de água muito elevado. Não apresenta florescimento nem isoporização e apresenta alta resposta a maturadores.

\subsubsection{RB855113}

É uma variedade de alta produção agroindustrial, porte ereto e com alta densidade de carga. A característica marcante desta variedade é seu crescimento inicial lento e sua maturação tardia. É menos exigente em solos que a RB855536, porém é altamente sensível a herbicidas pós-emergentes. Em solos infestados de nematóides é necessário algum tipo de controle (Arizono et al., 2000).

Segundo a UFSCar (2001), o touceiramento é intenso, os colmos são eretos, empalhados, de diâmetro médio, e de cor verde amarelada, com manchas de cera; entrenós médios, alinhados em leve ziguezague; folhas verdes escuras de largura e comprimento médios, as novas espigadas e dobradas nas pontas, com margem serrilhada agressiva e média quantidade de joçal agressivo.

\subsubsection{SP81-3250}

Esta variedade tem hábito levemente decumbente, pouco acamamento, despalha média, alta uniformidade e perfilhamento médio. Os entrenós são de cor verde arroxeada ao sol e verde amarelada sob a palha, de comprimento e diâmetro médios, cilíndrico e com zigue-zague suave. Como característica marcante esta variedade possui 
florescimento intenso, isoporização média, ótima brotação de soqueiras e fechamento de entrelinhas. É uma variedade de ampla adaptabilidade, porém é direcionada a ambientes de médio potencial produtivo. Possui alta produtividade agrícola e industrial e é uma variedade recomendada para colheita no meio e final de safra. Assim como a RB855113, é muito susceptível ao ataque de nematóides, sendo necessário medidas de controle em altas infestações (Copersucar, 1995). 


\section{DISCRIMINAÇÃO DE VARIEDADES DE CANA-DE-AÇÚCAR POR DADOS ESPECTRAIS ORBITAIS ETM+/LANDSAT 7}

\section{Resumo}

O estudo da energia eletromagnética refletida das plantas tem aumentado a sua importância, na medida que se apresenta como método alternativo e auxiliar no planejamento agrícola. A caracterização e identificação de variedades de cana-de-açúcar pelo sensoriamento remoto orbital são atualmente estudados visando diminuir o tempo de avaliação e identificação de campo. Além disso serve para direcionar as instituições de melhoramento de variedades de cana-de-açúcar para cobrança de royalties sobre a utilização e propagação do material genético por elas desenvolvido, além de políticas de mercado e logística das unidades produtoras. Este trabalho teve como objetivo caracterizar e discriminar variedades de cana-de-açúcar através de dados espectrais do sensor orbital ETM+ do LANDSAT 7. A hipótese baseia-se no fato que as variedades de cana-de-açúcar possuem dosséis com diferentes características físicas e morfológicas podendo-se então identificar diferenças e discriminar as variedades de cana-de-açúcar através de dados espectrais. Para tanto, obteve-se uma imagem da região de Paraguaçu Paulista, localizada a oeste do estado de SP e avaliou-se talhões de quatro variedades de cana-de-açúcar de primeiro corte (cana-planta) a saber: RB835486, RB855536, RB855113 e SP81-3250. Os dados foram todos georeferenciados e inseridos em um banco de dados. As técnicas utilizadas na discriminação foram: análise de bandas individuais, gráficos de dispersão (bandas B3 e B4) e equações discriminantes. A observação das curvas espectrais orbitais permite discriminar as variedades sendo a banda B4 a mais adequada. O gráfico de dispersão entre B4 e o GNDVI auxilia na 
separação destas variedades. Concluiu-se que é possível discriminar as variedades de cana através das equações discriminantes com 100\% de acerto para a RB855536 com as outras variedades. O erro geral médio foi de 6,45 \%, ou seja, 93,55 \% de acerto na discriminação varietal.

\section{DISCRIMINATION OF SUGARCANE VARIETIES THROUGH SPECTRAL DATA OF ETM+/LANDSAT 7}

\section{Summary}

The study of reflected electromagnetic energy by plants is increasing its importance because it works as an alternative and auxiliary method in agricultural planning. The characterization and identification of sugarcane varieties through the orbital remote sensing are studied attempting to reduce evaluation time and field identification efforts. Besides it also directs the sugarcane varieties breeding institutions for royalties charge about the usage and propagation of the genetic material for them developed, helps in market politics and in the producing units logistics. This work had as objective the characterization and discrimination of sugarcane varieties through spectral data of the orbital sensor ETM+ of LANDSAT 7. The hypothesis is based on the fact that sugarcane varieties have different canopies due to their particular physical and morphologic characteristics, then it might be possible to identify such differences and to discriminate the sugarcane varieties through spectral data. Thus, it has been obtained an image of a sugarcane producing area at Paraguaçu Paulista, on western São Paulo state, Brazil, where fields of four sugarcane varieties in the first cut (cane-plant) were evaluated as well: RB835486, RB855536, RB855113 and SP81-3250. The data were all georeferenced and inserted in a database. The used discrimination techniques were: individual bands analysis, dispersion plots (bands B3 and B4) and the discrimination equations. The observation of the orbital spectral plots allows discriminating the varieties and the B4 band is the most appropriate. The dispersion plot between B4 and GNDVI aids in the separation of these varieties. It has been concluded that is possible to discriminate the sugarcane varieties through the discriminating equations with $100 \%$ of 
accuracy for RB855536 among the other varieties. The medium general error was of $6,45 \%$, in other words, it has been reached $93,55 \%$ of accuracy in the varieties discrimination. 


\subsection{Introdução}

A identificação varietal e o inventariamento das áreas de produção de cana-deaçúcar são práticas utilizadas para diversos fins, desde censos quantitativos, logística de transporte de matéria-prima, políticas de compra e venda de açúcar e álcool e tomada de decisão quanto à abertura de novas unidades e expansão da lavoura (Joaquim, 1998; Schmidt et al., 2001).

O sensoriamento remoto óptico e o desenvolvimento de sensores orbitais multiespectrais são ferramentas de grande importância para agricultura extensiva e tecnologicamente competitiva, pela possibilidade de gerar informações sobre diversas propriedades das lavouras como crescimento e produção de biomassa. Além disso pode tornar possível a realização de levantamentos de variabilidade espacial e diversos tipos de mapeamento das culturas agrícolas em grandes extensões de área (Koffler, 1992; Stafford, 2000).

Na área canavieira, a utilização de sensores remotos em tais avaliações é tema de pesquisa no Brasil e em outros países, como a identificação de variedades, sintomas de stress, anomalias e mapeamento das áreas de produção (Almeida et al., 2002; Batista et al., 1978; Joaquim, 1998; Mendonça et al., 1978; Schmidt et al., 2001; Wiegand et al., 1996).

Formaggio \& Epiphanio (1988) afirmam que o conhecimento das relações existentes entre os parâmetros físicos das culturas (IAF, fitomassa, cobertura do solo e vigor vegetativo) e seu comportamento espectral é um passo importante para se avaliar o desempenho e desenvolvimento das culturas utilizando modelos de dados de sensoriamento remoto, como os índices de vegetação ou razões de banda.

Ponzoni (2001) afirma que, além das interações da radiação eletromagnética com as folhas (fotossíntese), outros fatores também influenciam na resposta espectral dos dosséis como espécie vegetal, tamanho, distribuição, arquitetura e ângulos foliares, maturação e senescência das folhas, efeitos de stresses, estado nutricional, \% de cobertura (IAF) e classe de solo. 
Muchow et al. (1994) ressaltam a importância de estudos relacionados a interação da radiação solar com variedades de cana-de-açúcar de diferentes ciclos e tipos (planta e soca) quando se pretende gerar modelos de produtividade, quantificar eficiência fotossintética e a conversão de biomassa em sacarose.

Joaquim (1998), utilizando as variedades SP70-1143, SP71-1406 e SP71-6163 elucida que para a cultura da cana-de-açúcar a textura do solo não tem influencia na identificação de variedades e obteve boa separação destas, através de dados orbitais do sensor TM/LANDSAT 5.

Atualmente a pretensão de se identificar variedades e áreas de cana de açúcar se justifica pela lei de proteção de cultivares, $n^{0} 9.456$ de 25 de abril de 1997, que visa proteger aqueles que investem no contínuo desenvolvimento de variedades de cana (Joaquim \& Donzelli, 1999). Estes autores relatam que até o momento, o uso de imagens de satélite LANDSAT para identificar variedades de cana é viável e obtiveram um índice de acerto médio de $87 \%$. Os autores ressaltam também a importância de continuidade destes estudos devido a necessidade de avaliar as áreas plantadas das variedades em tempo real e ao longo dos anos agrícolas.

Nota-se que a cana-de-açúcar tem importância fundamental no setor energético e ambiental. É uma cultura que abrange grandes áreas e necessita de agilidade e planejamento no processo produtivo. As técnicas de sensoriamento remoto podem proporcionar subsídios na avaliação desta cultura (Almeida, 2000). Por outro lado, raros são os trabalhos que efetivamente caracterizam o comportamento espectral desta cultura ao nível orbital, assim como a metodologia de discriminantes também têm sido pouco explorada nestas avaliações. Tais indicadores mostram a necessidade de estudos que apresentem as características espectrais de diferentes variedades e o potencial orbital na sua discriminação.

Dessa forma, o objetivo deste trabalho foi caracterizar e discriminar variedades de cana-de-açúcar através de dados orbitais do ETM+/LANDSAT 7. Como hipótese tem-se que as diferentes variedades de cana-de-açúcar possuem particularidades botânicas, ou seja, físicas e morfológicas, que influenciarão diferenças espectrais orbitais, permitindo sua discriminação. 


\subsection{Material e Métodos}

\subsubsection{Localização e caracterização da área de estudo}

A área de estudo localiza-se a oeste do estado de São Paulo, no retângulo envolvente $22^{\circ} 15^{\prime} \mathrm{S} / 51^{\circ} 15^{\prime} \mathrm{W}$ e $22^{\circ} 45^{\prime} \mathrm{S} / 50^{\circ} 30^{\prime} \mathrm{W}$, com altitude média de $410 \mathrm{~m}$, e abrange os municípios de Paraguaçu Paulista, Borá, Iepê, Agicê, Maracaí, Cruzália, Gardênia, Sapezal, João Ramalho, São José das Laranjeiras e Rancharia (Figura 1). Trata-se de uma grande região canavieira que apresenta contínua expansão agrícola.

Na geologia predomina a Formação Adamantina (Grupo Bauru) e em algumas áreas a Formação Serra Geral (Grupo São Bento), segundo o IPT (1981). As rochas eruptivas básicas ocorrem principalmente nos vales dos principais rios como o Paranapanema e, sobre estas é comum a ocorrência de material sedimentar ou do Arenito Bauru.

Os solos dos talhões avaliados são os LATOSSOLOS VERMELHOS de textura média e os NEOSSOLOS QUARTZARÊNICOS (Embrapa, 1999), sendo os mais representativos da região, segundo França \& Demattê (1993).

Climaticamente a área é caracterizada por apresentar um verão quente e úmido com as precipitações maiores ocorrendo de novembro a março e decrescendo no mês de abril. O inverno apesar de seco pode apresentar algumas precipitações, inclusive em junho. Os meses de julho e agosto são os mais secos. A precipitação média anual é da ordem de 1.400 a $1.600 \mathrm{~mm}$ e a temperatura média é de 22,5 $\mathrm{C}$. O déficit hídrico corresponde aos meses de junho a meados de setembro, com uma evapotranspiração da ordem de 1.050 mm (Apêndices 1 e 2).

\subsubsection{Variedades de cana-de-açúcar avaliadas}

As variedades de cana-de-açúcar avaliadas foram as de maior representatividade em relação à área de plantio na safra 2000/01 da área de estudo e também são bastante cultivadas no estado de São Paulo. As variedades, instituições de melhoramento que as desenvolvem, a área cultivada (em ha e \%) e suas características principais se encontram 
na tabela 1. Detalhes das variedades encontram-se no item 4.2 e/ou em Copersucar (1995), Arizono et al. (2000) e UFSCar (2001).

\subsubsection{Processamento digital da imagem e obtenção dos índices de vegetação}

Foi utilizada a imagem obtida do sensor ETM+ do LANDSAT 7, órbita ponto WRS 222/76, bandas 1, 2, 3, 4, 5 e 7 de 6 de junho de 2000. As características espectrais e espaciais do sensor estão descritas no item 4.1.

Efetuou-se a correção atmosférica, através do modelo “5S” - Simulation of Satellite Signal in the Solar Spectrum, presente no programa computacional SCORADIS - Sistema de Correção de Imagens de Satélite - Versão LITE - LANDSAT 7 ETM+, desenvolvido por Zullo Junior (1994). Para execução do algoritmo de correção atmosférica são necessários alguns parâmetros de entrada como localização geográfica do centro da cena (latitude e longitude), data e hora de aquisição e o modelo atmosférico dos componentes gasosos, principalmente vapor d’água e ozônio, determinados pelo programa SCORADIS - Versão LITE - ETM+/LANDSAT 7. Obteve-se a partir disso uma imagem de reflectância real, ou seja, exoatmosférica.

A correção geométrica ou registro de imagem (georreferenciamento) foi realizada no software Environment for Visualizing Images 3.6 (ENVI, 2003) e para tanto, foram coletados pontos de controle na região de abrangência da área de estudo com um GPS Trimble PRO-XR, de erro submétrico e pós-processado, de acordo com procedimentos descritos por Crosta (1992). O sistema de projeção e o datum utilizados para localização e georeferenciamento foram o UTM e SAD-69, respectivamente (Figura 2). O interpolador utilizado foi o vizinho mais próximo (nearest neighbor) que, segundo Crosta (1992) é o mais utilizado por não alterar o valor dos níveis de cinza dos pixels da imagem.

Epiphanio \& Formaggio (1988), Thenkabail et al. (2002) e Demattê \& Nanni (2003) comentam que, para realizar análises quantitativas sobre os comportamentos espectrais de alvos em imagens, devem ser feitas transformações dos NC para dados de reflectância por esta ser uma grandeza física intrínseca dos alvos, ao passo que números 
digitais (níveis de cinza) são valores transformados para a obtenção das imagens orbitais.

Segundo Luiz et al. (2003), a transformação dos NC’s de imagens ETM+ do LANDSAT 7 em radiância é obtido pela resolução de uma regressão linear simples cujos parâmetros de entrada são fornecidos e atualizados pelos responsáveis pelo satélite. Os mesmos autores elucidam que para o cálculo da reflectância, é necessário conhecer o valor de diversas variáveis, porém apenas o NC do pixel varia dentro da imagem, as demais variáveis são constantes e variam em função da data e da banda utilizada. Os valores de NC devem ser convertidos em radiância e em reflectância exoatmosférica para as posteriores avaliações de bandas e obtenção dos índices de vegetação (Thenkabail et al., 2002).

Os dados da imagem foram convertidos e normalizados em fatores de reflectância como descrito por Epiphanio \& Formaggio (1988) e após este processo, o nível de cinza zero presente na imagem passou a corresponder à reflectância real 0 \% e o nível 255 à reflectância real 100 \%.

\subsubsection{Aquisição de dados espectrais e análise estatística}

Os dados espectrais utilizados foram referentes a talhões de quatro variedades distintas de cana-de-açúcar, no estágio de primeiro corte no ano de passagem. São elas: RB835486 - 36 ha (14 talhões), RB855536 - 16 ha (6 talhões), RB855113 - 43 ha (19 talhões) e SP81-3250 - 18 ha (7 talhões), todos de cana-planta ( $1^{\circ}$ corte). Isso se deve ao fato que para reconhecimento de variedades, deve-se dar preferência aos cortes mais novos, como elucida Joaquim (1998). Atentou-se para a escolha de setores de datas de plantio (março-abril) e idade próximas, para que este fator não fosse o predominante nas diferenças espectrais das variedades (Figura 2).

Os limites dos talhões da área de interesse foram vetorizados no programa Autocad 2000 e montou-se um banco de dados detalhado no SIG ArcView 3.2 (ESRI, 1996), com os limites e informações de cada talhão como data de plantio, colheita e produtividade agroindustrial. No SIG foi feita a seleção das áreas de interesse e os dados foram exportados para o software ENVI 3.6 onde foram criadas as regiões de interesse 
(ROI's) para proceder a coleta dos dados espectrais dos pixels referentes às variedades de cana-de-açúcar.

Além dos valores espectrais das bandas foram criadas seis imagens índice vegetação, a saber: NDVI, GVI, SAVI, RVI, RATIO e GNDVI de acordo com Bannari et al. (1995), Crist \& Ciccone (1984), Thenkabail et al. (2002), Huete (1988), Baret \& Guyot (1991) e Gitelson et al. (1996). As observações foram os valores dos pixels, ou “picture element cells” (Crosta, 1992) das imagens das bandas e dos IV’s.

Realizou-se uma interpretação visual prévia das áreas das variedades buscando demarcar as ROI's em locais homogêneos dentro dos talhões, evitando manchas que indicassem alguma anomalia ou falha no dossel (Figura 3).

Coletados os dados espectrais das seis bandas do sensor ETM+/LANDSAT 7 e os seis índices de vegetação derivados destas, procedeu-se os métodos de avaliação discriminante.

Primeiramente, foram obtidos os dados espectrais dos solos da região e das variedades estudados para a geração de um gráfico de dispersão entre as bandas B3 (vermelho) e B4 (infravermelho) com o objetivo de comparar os dois alvos através da linha do solo (Baret et al. 1993). A interpretação deste gráfico também indica a presença de vegetação permitindo visualizar a distribuição dos valores espectrais entre as variedades.

Posteriormente foi realizada a comparação de médias dos valores espectrais (bandas e IV's) das variedades pelo teste de Tukey ao nível de $5 \%$, no Statistical Analysis System (SAS, 1999). Tal método permite verificar qual ou quais as melhores variáveis espectrais para diferenciar as variedades.

Finalmente foi realizado o método de análise discriminante. Para tanto, os dados das observações de cada variedade foram exportados para o Excel e randomizados, para evitar qualquer efeito local dos talhões. Utilizou-se sessenta observações de cada variedade para a geração dos modelos no Statistical Analysis System (SAS, 1999).

O procedimento DISCRIM do SAS, através da rotina "Stepdisc", escolhe as variáveis que melhor irão compor o modelo, com um nível de significância de 15 \%. Neste caso, todas as variáveis (bandas e IV’s) entraram na composição das equações. 
Para validar os modelos quanto sua capacidade de discriminar as variedades, as observações que não foram utilizadas para a geração do modelo foram usadas para testar as equações.

\subsection{Resultados e Discussão}

\subsubsection{Discriminação espectral das variedades por bandas e índices de vegetação}

A discriminação das variedades de cana pode ser observada pelas curvas espectrais obtidas pelo sensor orbital que apresentam diferenças quanto à forma e intensidades de reflectância (Figura 4) assim como pelo resultado do teste de Tukey que foi realizado para as quatro variedades em cada banda do sensor (Tabelas 2 e 3).

Ponzoni (2001) ressalta que as folhas são o principal elemento da vegetação sob o ponto de vista do processo de interação com a radiação eletromagnética e, as curvas de reflectância de folhas verdes sadias, quando comparadas com medições espectrais de dosséis apresentam formas muito semelhantes. Isto indica haver relação entre as diferenças morfológicas apresentadas pelas variedades estudadas (Tabela 1) e suas respostas espectrais captadas pelo sensor (Figura 4).

Dentre as variedades estudadas, a RB855536 foi a que mostrou maior intensidade de reflectância nas bandas B1 a B5 sendo que na banda B4 apresentou as maiores diferenças entre os fatores de reflectância para todas as variedades, concordando com Joaquim \& Donzelli (1999).

A RB835486 apresentou as menores intensidades de reflectância, principalmente na B4. Porém, na banda B2 a resposta é maior nesta variedade do que na RB855113. Isso pode ser atribuído a maior largura das folhas da primeira e maior quantidade de palha na segunda, o que interfere nas respostas espectrais captadas pelo sensor orbital (Tabela 1).

A variedade RB855113 apresentou características intermediárias na banda B4. Trata-se de uma variedade tardia com folhas eretas médias e levemente arqueadas, por isso seu comportamento é intermediário em relação a RB855536 e RB855486. A SP813250 foi a única variedade de outra instituição estudada (variedade SP) e tem ligeira 
semelhança com a variedade RB855113, em relação a seu dossel e coloração dos colmos, embora a primeira seja de ciclo médio (Tabela 1).

A banda B3 também discriminou as variedades RB em relação aos seus ciclos. Da variedade precoce para a média e para a tardia houve aumento da intensidade de reflectância (Figura 4). O ciclo da planta está intimamente relacionado aos processos fotossintéticos (Masoni et al., 1994). Neste aspecto, a banda B3 tem por característica medir a absorção da energia luminosa pelas folhas das plantas para a realização da fotossíntese. Neste caso, a resposta espectral das folhas é influenciada principalmente pelos pigmentos existentes nos cloroplastos encontrados no mesófilo (Curran et al., 2001; Gitelson \& Merzliak, 1997). A variedade precoce, RB835486 apresentou maior intensidade de reflectância nesta banda por se encontrar em fase adiantada de maturação (sensescência) na data de passagem do sensor.

A banda B4 é influenciada pela estrutura celular interna das folhas. Além disso, a arquitetura e distribuição das folhas nos dosséis vegetais também influenciam no comportamento espectral das espécies vegetais (Ponzoni, 2001). Para variedades com alto IAF e folhas eretas como a RB855536 (Tabela 1) a intensidade de reflectância tende a ser maior nesta banda e a medida que a vegetação entra em senescência esta resposta decresce, assim como observado na RB835486. Outro fator responsável por esta baixa intensidade de reflectância desta variedade pode ser atribuído ao intenso acamamento que ocorre em seus primeiros cortes, o que também aumenta a contribuição do solo, colmos e da palha na resposta espectral captada pelo sensor (Tabela 1).

A absorção da B5 está relacionada à absorção de radiação pela água nas folhas e por sua vez é função do teor de umidade de da espessura das folhas (Joaquim, 1998) porém, na data de passagem do sensor houve seca prolongada, o que diminui esse efeito. Por outro lado, pode-se observar a maior intensidade de reflectância na RB855536, passando para a RB835486 e RB855113 com menores intensidades. Outro fator de absorção e reflexão desta banda está relacionado a estrutura foliar e quantidade de palha presente na vegetação (Masoni et al, 1993 e 1994). A RB855536 apresenta folhas abundantes e conseqüentemente alta absorção e transpiração, enquanto que a RB835486 já se encontrava na ocasião em maturação (folhas secas). Já a RB855113 embora tardia, 
apresenta grande quantidade de palha aderida ao colmo durante o seu ciclo, o que interfere na umidade e reposta espectral nesta banda (Tabela 1).

A banda B4, o NDVI, RVI e GVI foram os parâmetros que apresentaram maiores diferenças estatísticas significativa entre as médias das quatro variedades estudadas (Tabelas 2 e 3). Isso concorda com Joaquim (1998) e Joaquim \& Donzelli (1999), que descrevem a banda B4 como a única que conseguiu separar adequadamente a maioria das variedades estudadas. No presente trabalho verifica-se que para as RB's, um maior número de bandas auxilia nesta discriminação, no caso, as bandas 1, 2, 3, 4 e 5. Na tentativa de se discriminar a variedade SP81-3250, a banda 4 passa a ser a dominante.

O trabalho de Joaquim (1998) visou identificar diferentes variedades SP de canade-açúcar em diferentes classes texturais de solos do estado de São Paulo. O autor concluiu que é possível identificar variedades de cana-de-açúcar através dos NC's das bandas B3, B4 e B5 do TM/LANDSAT 5. Entretanto, autor não observou interferência do solo na discriminação varietal, como foi concluído no presente trabalho.

Segundo Joaquim \& Donzelli (1999), a variedade RB855536 foi a variedade mais plantada na safra 1998/99 (juntamente com a SP80-1842) e também obteve grande precisão na sua separação entre outras variedades de cana-de-açúcar de primeiro corte. Foi a única variedade que se separou significativamente, isto é, sem sobreposição de NC's nas três bandas (3, 4 e 5) devido suas particularidades morfológicas referentes à arquitetura (espetada) e ao número de folhas abundantes (Tabela 1). A metodologia utilizada por estes autores levou em consideração somente as médias e os desvios padrões dos NC's das variedades nas bandas espectrais do TM/LANDSAT 5. Isto foi feito com o intuito de definir intervalos de ocorrência dos valores dos NC's das variedades nas três bandas utilizadas, ou seja, definir níveis de intensidade dos pixels das variedades para que estas se situem entre um máximo e um mínimo. Para este trabalho utilizou-se o valor radiométrico de todas as bandas do sensor (B1 a B7) e índices de vegetação derivados, buscando um maior detalhamento na caracterização espectral das variedades. Porém, neste trabalho acredita-se que pode haver informações espectrais importantes para discriminação varietal com a utilização das demais bandas do sensor. 
Na banda B1 as quatro variedades de cana-de-açúcar estudadas apresentaram o mesmo comportamento estatísticamente ocorrido na B2 (Tabela 2). Embora a primeira sofra grande influência de espalhamento atmosférico (Zullo Junior, 1994), ainda sim pode-se observar diferenças espectrais das variedades RB's nesta banda. No comprimento de onda da B1 (450 - $520 \mathrm{~nm}$ ) ocorre absorção pela clorofila e na B2 (520 - $600 \mathrm{~nm}$ ) a reflectância verde da vegetação (Ponzoni, 2001). Estudos da interação entre pigmentos fotossintetizantes dos dosséis e a radiação eletromagnética apresentam características semelhantes para folhas de espécies distintas e em diferentes zonas climáticas (Chapelle et al. 1992; Fourty \& Baret, 1998; Gitelson \& Merzliak, 1997; Machado et al., 1985). Neste trabalho é possível notar que as variedades apresentam curvas semelhantes e as variações destas são resultado das características morfológicas e bioquímicas das folhas.

A variedade RB855536 apresentou a maior intensidade de reflectância média na banda B4, concordando com Joaquim \& Donzelli (1999) e nos índices de vegetação NDVI, RATIO, GVI, e SAVI. Isso ocorre porque esta variedade apresenta folhas espetadas e dossel com grande índice de área foliar (IAF), segundo Arizono et al. (2000). O IAF é um parâmetro que possui alta correlação com o infravermelho próximo e IV’s de uma forma geral (Formaggio \& Epiphanio, 1988; Pellegrino, 2000). Já a arquitetura da vegetação é definida como a distribuição espacial e a densidade dos seus elementos, ou seja, folhas e colmos no caso da cana-de-açúcar (Ponzoni, 2001). Esta variedade também apresentou o maior valor médio de intensidade de reflectância na B2, correspondente ao comprimento de onda do verde visível, confirmando tais afirmações. A RB855536 foi uma das variedades que apresentou maior intensidade de reflectância média também para a banda B5, juntamente com a SP81-3250 e este fato pode ser atribuído a alta exigência desta variedade em água e seu teor foliar ser geralmente alto (UFSCar, 2001).

A RB835486 foi a que apresentou menores valores médios de intensidade de reflectância na banda B4 e nos IV's de uma forma geral, somente sendo maior no RVI. Este fato pode ser atribuído ao ciclo desta variedade ser precoce (UFSCar, 2001) e na data de passagem, em junho de 2000, esta já se encontrava num estádio adiantado de 
maturação, ou seja, em senescência. Outro aspecto relevante nesta variedade é seu hábito decumbente, pois os colmos se acamam com facilidade principalmente em condições de primeiro corte e/ou alta fertilidade do solo, o que interfere na resposta espectral, no IAF e \% de cobertura do solo. As bandas B5 e B7 estão associadas a quantidade de água presentes na vegetação e indicam haver uma intensidade de reflectância significativamente maior da variedade SP81-3250 do que para a RB835486 e esta maior que a RB855113 nestes comprimentos de onda (Tabela 2 e Figura 4). Joaquim (1998) ressalta que o desenvolvimento vegetativo da cana-de-açúcar está associado à quantidade de nutrientes que é colocado na adubação e água disponível durante o ciclo da cultura e que as diferenças no crescimento da cana também interferem na resposta espectral captada pelo satélite assim como arquitetura foliar, conteúdo de água e clorofila nas folhas.

A variedade RB855113 é caracterizada pelo seu ciclo tardio e apresentou a maior média no GNDVI que é um índice que intensifica a resposta do comprimento de onda do verde (B2 520-600 nm), seguido pela RB855536 e SP81-3250, embora tenha apresentado a menor intensidade de reflectância na B2 (Tabela 2). Tal comportamento está relacionado a variedade apresentar-se em fase de desenvolvimento vegetativo e início de maturação na data de passagem do sensor, ou seja, as folhas ainda estavam verdes e em atividade fotossintética. Gitelson et al. (1996) elucidam que a intensidade de coloração da vegetação é bem relacionada com o GNDVI, o que explica o maior valor espectral desta variedade neste índice (Tabelas 1 e 3). Outro fato é que esta variedade apresentou baixos valores de reflectância média nas bandas B1 e B3, que são os comprimentos de onda da absorção pelos carotenóides e clorofila. Apesar da RB855113 ter apresentado o menor valor de intensidade de reflectância nas bandas B5 e B7, sabe-se que embora os efeitos do stress hídrico interfiram nas respostas espectrais das variedades nestes comprimentos de onda, o conteúdo dos pigmentos e compostos bioquímicos tendem a permanecerem constantes durante o período vegetativo independente da quantidade de água das folhas (Almeida et al., 2002). Já a umidade não permanece constante, decrescendo nas folhas e colmos durante o período de maturação e concentração de sacarose (Lucchesi, 1995), o que interfere na resposta espectral nestes 
comprimentos de onda relativos aos infravermelhos médios B5 (1550 - 1750 nm) e B7 $(2080-2350 \mathrm{~nm})$.

A SP81-3250 é uma variedade de maturação média e que na ocasião da data de passagem do satélite estava sendo colhida (dados não apresentados). Pode-se perceber que a SP81-3250 e a RB835486, apresentaram o mesmo comportamento nas bandas B1 e B2 e isto pode estar relacionado a estas variedades já estarem em fase de maturação/senescência, na referida época. No entanto, apresentou a maior intensidade de reflectância média significativa na B5 juntamente com a RB855536 e maior isoladamente na B7, embora tenha se comportado intermediariamente nas outras bandas

e IV’s (Figura 4). Tais bandas estão melhor relacionadas com a umidade da vegetação. É uma variedade que apresenta boa uniformidade do canavial e grande área foliar (Copersucar, 1995), estando posicionada como a segunda maior média de intensidade de reflectância na B4 e nos IV's GVI, SAVI e RVI. Os dados que proporcionam melhor visualização das diferenças espectrais das variedades são a B4 e o GNDVI, quando plotados num gráfico de dispersão (Figura 5b).

\subsubsection{Discriminação espectral das variedades por gráficos de dispersão}

A reflectância das plantas e dos solos é governada por diversos fatores e suas propriedades físico-químicas influenciam sua assinatura espectral pelos processos de absorção (Huete et al., 1985). Correções de dados de sensoriamento remoto são portanto, necessárias para sua correta avaliação e alguns índices foram desenvolvidos para minimizar o efeito do solo na vegetação (Baret et al., 1993; Huete, 1988), que geralmente referem-se a uma combinação das intensidades de reflectância de bandas (Gitelson et al., 2002). Alguns dos IV's baseiam-se no fato de que solos expostos ocorrem numa linha gerada por bandas, a linha do solo e que os IV's são comumente uma simples medida dos dados observados nesta linha usando a distância euclidiana ou angular (Huete, 1989).

Gitelson et al. (2002) definem a linha dos solos e vegetação como um espaço bidimensional para cada par de intensidades de reflectância e ressaltam que ambas não tendem a ser paralelas pois a inclinação da linha da vegetação é um pouco menor que a 
da linha do solo (Figura 5a e 5b). Ressalta-se que os autores utilizaram radiometria de campo para obtenção de dados sobre dosséis de trigo para posterior calibração de dados espectrais orbitais.

Dessa forma, a posição do valor espectral de determinado pixel num gráfico de dispersão entre as bandas B3 e B4 nos auxilia na avaliação das características dos alvos (Tabela 1; Figura 5a). Amostras de pixels com solo exposto apresentam variações de posição no gráfico de dispersão (Figura 5). Os solos mais argilosos (> $350 \mathrm{~g} \mathrm{Kg}^{-1}$ argila) e avermelhados (2,5 YR) como os LATOSSOLOS VERMELHOS apresentam-se numa posição inferior do gráfico, enquanto os solos arenosos como os NEOSSOLOS QUARTZARÊNICOS estão bem acima (Huete et al., 1985; Huete, 1989). Por outro lado, todos os pontos apresentam-se deslocados da denominada linha do solo, o que concorda com Galvão \& Vitorello (1998).

Segundo Huete et al. (1985), na medida em que ocorrem diferenças nas características do solo, ocorre deslocamento de valor espectral ao longo do eixo próximo à $45^{\circ}$. Os autores chamaram de "greeness line” a linha deslocada da linha do solo devido a presença da vegetação. Com o aumento da vegetação (crescimento da planta) ocorre decréscimo significativo da intensidade reflectância na banda B3 (vermelho) e automaticamente um grande aumento na intensidade de reflectância na B4 (Huete et al., 1985).

Quando aparece vegetação (crescimento da planta) ocorre alteração da posição espectral do pixel no gráfico (Figura 5a). Isso ocorre porque a reflectância na banda B4 tende a aumentar mais que a banda B3 e quem define a resposta espectral dos dosséis são as folhas e seus pigmentos (Chapelle et al., 1992; Gitelson et al., 2002; Ponzoni, 2001). Isso ocorreu quando o pixel estava totalmente coberto pela cana-de-açúcar e a posição no gráfico foi deslocada do eixo de $45^{\circ}$ para o vértice superior esquerdo (Figura 5a). Próximo a este vértice ocorrem as informações espectrais relativas a vegetação e conseqüentemente as diferentes variedades de cana-de-açúcar avaliadas neste trabalho. Devido a diferenças morfológicas entre as variedades de cana (Tabela 1) e conseqüentemente sua influencia nas respostas espectrais das bandas de sensores orbitais, é possível determinar nuvens de pixels padrões das variedades. Quando a 
vegetação cobre de 20 a 75 \% do solo, esta linha greeness fica fortemente dependente do efeito do brilho do solo. Solos claros possuem maiores valores para mesmas quantidades de vegetação, e diferenças de “greenness” entre solos escuros e claros se tornam maiores para coberturas menores que $60 \%$.

Gitelson et al. (2002) ressaltam a importância de incluir outros comprimentos de onda nos estudos de posicionamento de observações em gráficos de linha de solo e vegetação. Os autores descrevem técnicas de estimar a fração vegetal baseada na reflectância no verde (550 nm), na “red edge” (700 nm), no azul (500 nm) e no vermelho $(660$ - $680 \mathrm{~nm})$. Tais dados podem se apresentar robustos em estimar a cobertura vegetal quando dispostos em gráficos de linhas de dispersão, além das razões entre vermelho e infravermelho, comumente utilizadas em estudos de solos/vegetação. Para este trabalho, encontrou-se visualização adequada dos dados de solos e variedades no gráfico da B3 e B4 e B4 e GNDVI. Este último substitui a banda B3 (vermelho) no cálculo do NDVI pela B2 (verde), a qual está bem relacionada a coloração da vegetação (Gitelson et al., 1996).

Observa-se tendência definida na separação de cada variedade no referido vértice, principalmente as variedades RB (Figura 5a), embora ocorram sobreposições entre pixels das variedades, principalmente RB835486 e RB855113. A variedade SP ocorre principalmente em posição intermediária, também se sobrepondo a dados de outras variedades. Este fato também pode ser observado pelo gráfico de dispersão obtido a partir da banda B4 X GNDVI (Figura 5b). Este gráfico atua como ferramenta auxiliar na discriminação das variedades. Gitelson et al. (2002) elucidam que a inclinação e comprimento da linha da vegetação dependem do IAF, da coloração verde da vegetação (pigmentos e composição), da densidade e da estrutura do dossel. Quanto maior for a variação destes fatores mais comprida é a linha e, reflectâncias no azul (500 nm) e vermelho $(600 \mathrm{~nm})$ decrescem com o aumento do IAF de 8 até 12. O IAF médio de um dossel de cana-de-açúcar é 7 segundo Magalhães (1987) e Lucchesi (1995).

Medidas a campo de IAF e outros parâmetros biofísicos são difíceis de serem executados e exigem equipamentos e pessoal altamente capacitado (Pellegrino, 2000; Machado, 2003), para gerar os dados e calibrar as metodologias. Outro aspecto é que 
alguns sensores hiperespectrais aliados a outros sensores geram grande volume de dados, o que torna necessário investimentos em recursos computacionais (hardware e softwares) e pessoais (Gitelson et al., 2002). Este trabalho descreve um método relativamente simples e eficaz quando se pretende diferenciar variedades, espécies e diferentes usos da terra através de dados orbitais, uma vez que índices de vegetação podem ser gerados a partir de fórmulas e/ou em programas específicos para o manipulação de imagens. Através deste método pode-se chegar a padrões espectrais dos dosséis vegetais e de diferentes variedades da mesma espécie como no presente trabalho.

\subsubsection{Análise discriminante}

Cada variedade de cana-de-açúcar apresenta uma informação espectral padrão. Estas informações foram inseridas num único modelo estatístico (Tabela 4). No caso, cada variedade possui uma equação que a representa. Esta é derivada da múltipla relação entre todas as bandas espectrais com as características das variedades.

A equação que apresenta o maior resultado terá a maior probabilidade de caracterizar as variedades desconhecidas. Usando os dados das intensidades de reflectância espectrais, estas equações foram testadas e obteve-se na discriminação 100 \% de acerto somente para a RB855536 (Tabela 5). O valor das observações (pixels) quando inseridos nas equações, proporcionaram a discriminação da referida variedade.

Nota-se que todas as variáveis espectrais obtidas, as seis bandas e os seis índices de vegetação entraram na composição das equações discriminantes, ressaltando a importância de se utilizar outros dados espectrais além daqueles preconizados na literatura, ou seja, as bandas B3, B4 e B5 (Joaquim \& Donzelli, 1999). As fontes de variação nas equações foram os diferentes pesos das variáveis espectrais para cada variedade de cana-de-açúcar em particular.

A RB835486 obteve 95,24 \% de acerto (4,76 \% de erro geral) na discriminação dentre as suas observações. Houve confusão com algumas observações de outras variedades, 3,17 \% com a RB855113, justamente aquela que apresentou proximidade de valores nos gráficos de dispersão e na curva espectral e 1,59 \% da SP81-3250. Isso se deve ao fato de sensores orbitais de bandas largas não captarem feições sutis da 
vegetação, principalmente em relação a mesma espécie, no caso, cana-de-açúcar (Moran et al. 1997; Thenkabail et al. 2002), uma vez que as variedades mencionadas possuem muito pouca semelhança, em relação ao hábito e disposição do dossel (Tabela 1).

A RB855113 foi discriminada com 89,77 \% de acerto (10,23 \% de erro geral), havendo 1,14 \% de confusão com dados da RB835486 e 9,09 \% com os da SP81-3250. Isso se deve ao fato de haver certa semelhança morfológica entre a RB855113 e a SP813250, que apresentam elevada quantidade de folhas arqueadas além de colmos amarelados e bem empalhados (Tabela 1).

A SP81-3250 obteve 89,19 \% de acerto na sua discriminação e apresentou confusão com dados das variedades RB855113 (2,70 \%) e RB855536 (8,11 \%). Com a primeira existe certa semelhança morfológica, devido à coloração dos colmos e a própria conformação foliar (Tabela 1).

De maneira geral, o erro obtido na discriminação das variedades foi de 6,45 \% (Tabela 5) indicando que as equações descrevem e separam satisfatoriamente as variedades estudadas. As confusões entre as observações oscilaram de 1,14 a 9,09 \% e ocorreram somente entre observações de três variedades, nunca com as quatro em conjunto. Muchow et al. (1994) ressaltam que estudos que envolvem interações da energia eletromagnética com os dosséis de cana-de-açúcar devem ser ajustados para cada local devido às diferenças de radiação, temperatura e regime hídrico que influem nas características morfo-fisiológicas das variedades.

Os resultados confirmam o potencial de discriminar variedades de cana-deaçúcar por dados orbitais e o acerto na discriminação se encontra acima dos 90 \%, maior do que os encontrados na literatura (Joaquim, 1998; Joaquim \& Donzelli, 1999). O método é interessante não só na discriminação de variedades da mesma espécie, mas pode ser empregado quando se pretende obter padrões de uso do solo com a intenção de realizar censos quantitativos de áreas de culturas e mapeamentos diversos.

\subsection{Conclusões}


A observação das curvas espectrais orbitais permite discriminar as variedades sendo a banda B4 a mais adequada. O gráfico de dispersão entre B4 e o Green NDVI auxilia na separação destas variedades.

É possível discriminar as variedades de cana com 93,55 \% de acerto, ou seja, um erro geral médio de 6,45 \%. Para a RB855536 o índice de acerto foi de 100\% na separação entre as outras variedades.

A utilização de todas as bandas do sensor ETM+/LANDSAT 7 (B1, B2, B3, B4, B5 e B7) mostrou-se importante na caracterização e discriminação varietal da cultura de cana-de-açúcar. 
Tabela 1. Características das variedades de cana-de-açúcar avaliadas no trabalho e área de cultivo, safra 2000/01

\begin{tabular}{|c|c|c|c|c|c|c|c|c|c|}
\hline \multirow[b]{2}{*}{ Variedade } & \multirow[b]{2}{*}{ Instituição $^{1}$} & \multicolumn{2}{|c|}{ Área Cultivada $^{2}$} & \multicolumn{6}{|c|}{ Características Gerais ${ }^{5}$} \\
\hline & & $\mathrm{ha}^{3}$ & $\%^{4}$ & $\begin{array}{l}\text { Exigência } \\
\text { em solos }\end{array}$ & $\begin{array}{c}\text { Ciclo/ } \\
\text { Teor de } \\
\text { Sacarose }\end{array}$ & $\begin{array}{l}\text { Florescimento/ } \\
\text { Perfilhamento }\end{array}$ & Entrenós/Colmos & Hábito e dossel & Particularidades \\
\hline RB835486 & UFSCar & 1121,3 & 42,2 & Média & $\begin{array}{c}\text { Precoce/ } \\
\text { Alto }\end{array}$ & Médio/Médio & $\begin{array}{c}\text { Médios em zigue-zague, } \\
\text { arroxeados,cera } \\
\text { abundante e fácil } \\
\text { despalha }\end{array}$ & $\begin{array}{c}\text { Decumbente, } \\
\text { folhas médias } \\
\text { dispostas em leque } \\
\text { com leve curvatura }\end{array}$ & $\begin{array}{l}\text { Tombamento, baixa } \\
\text { densidade de carga, } \\
\text { média resistência a } \\
\text { ferrugem }\end{array}$ \\
\hline RB855536 & UFSCar & 176,9 & 6,7 & Exigente & $\begin{array}{l}\text { Média/ } \\
\text { Alto }\end{array}$ & Ausente/Médio & $\begin{array}{l}\text { Médios em leve zigue- } \\
\text { zague, arroxeados,cera } \\
\text { média e fácil despalha }\end{array}$ & $\begin{array}{l}\text { Porte ereto, folhas } \\
\text { estreitas e } \\
\text { espetadas e em } \\
\text { grande número }\end{array}$ & $\begin{array}{c}\text { Susceptível a seca, } \\
\text { boa resposta a } \\
\text { maturadores }\end{array}$ \\
\hline RB855113 & UFSCar & 433,8 & 16,4 & Média & $\begin{array}{c}\text { Tardia/ } \\
\text { Alto }\end{array}$ & Raro/Intenso & $\begin{array}{l}\text { Médios em leve zigue- } \\
\text { zague, verde- } \\
\text { amarelados, mcnchas de } \\
\text { cera e despalha média }\end{array}$ & $\begin{array}{l}\text { Porte ereto, folhas } \\
\text { médias e arqueadas } \\
\text { de coloração verde } \\
\text { escuro }\end{array}$ & $\begin{array}{l}\text { Susceptível a } \\
\text { nematóides e } \\
\text { herbicidas pós- } \\
\text { emergentes }\end{array}$ \\
\hline SP81-3250 & Copersucar & 173,6 & 6,6 . & Média & $\begin{array}{l}\text { Média/ } \\
\text { Alto }\end{array}$ & Intenso/Médio & $\begin{array}{l}\text { Médios em leve zigue- } \\
\text { zague, verde- } \\
\text { amarelados, cera e } \\
\text { despalha média }\end{array}$ & $\begin{array}{c}\text { Levemente } \\
\text { decumbente, folhas } \\
\text { médias e } \\
\text { levemente } \\
\text { arqueadas. }\end{array}$ & $\begin{array}{c}\text { Susceptível a } \\
\text { nematóides, floresce e } \\
\text { isoporiza }\end{array}$ \\
\hline
\end{tabular}

${ }^{1}$ UFSCar - Universidade Federal de São Carlos; Copersucar - Cooperativa dos Produtores de Cana, Açúcar e Álcool do Estado de São Paulo;

${ }^{2}$ Fonte: Cocal Açúcar e Álcool; ${ }^{3}$ Área de primeiro corte colhida na safra 2000/01; ${ }^{4} \%$ do total da área da usina na safra 2000/01; ${ }^{5}$ Fonte: Copersucar (1995), Arizono (2000) e UFSCar (2001). 
Tabela 2. Análise estatística dos resultados de reflectância média das bandas do sensor ETM+/LANDSAT 7 para quatro variedades de cana-de-açúcar

\begin{tabular}{|c|c|c|c|c|c|c|c|}
\hline \multirow[b]{2}{*}{ Variedade } & \multirow[b]{2}{*}{$\mathrm{N}^{1}$} & \multicolumn{6}{|c|}{ Bandas (nm) } \\
\hline & & $\begin{array}{c}\text { B1 } \\
(450-520)\end{array}$ & $\begin{array}{c}\text { B2 } \\
(520-600)\end{array}$ & $\begin{array}{c}\text { B3 } \\
(630-690)\end{array}$ & $\begin{array}{c}\text { B4 } \\
(770-900)\end{array}$ & $\begin{array}{c}\text { B5 } \\
(1550-1750)\end{array}$ & $\begin{array}{c}\text { B7 } \\
(2080-2350)\end{array}$ \\
\hline RB835486 & 249 & $0,0040304 \mathrm{~B}^{2}$ & 0,0679122 B & $0,0620524 \mathrm{~A}$ & 0,331773 D & 0,177589 B & 0,0730608 B \\
\hline RB855536 & 83 & 0,0086919 A & $0,0776745 \mathrm{~A}$ & $0,057627 \mathrm{~B}$ & $0,466761 \mathrm{~A}$ & 0,204203 A & $0,0745100 \mathrm{~B}$ \\
\hline RB855113 & 148 & $0,0009535 \mathrm{C}$ & 0,0560146 C & $0,0487285 \mathrm{C}$ & $0,370827 \mathrm{C}$ & 0,166481 C & 0,0625597 C \\
\hline SP81-3250 & 97 & 0,0042034 B & 0,0668304 B & $0,0560733 \mathrm{~B}$ & 0,394785 B & $0,200687 \mathrm{~A}$ & $0,0794816 \mathrm{~A}$ \\
\hline
\end{tabular}

${ }^{1}$ Número de observações (pixels) de cada variedade; ${ }^{2}$ Teste de Tukey aplicado entre as médias de reflectância das variedades para as seis bandas do ETM+/LANDSAT 7, letras iguais na coluna não diferem estatisticamente ao nível de 5\%. 
Tabela 3. Análise estatística dos resultados de índices de vegetação médios (IV’s) derivados das bandas do sensor ETM+/LANDSAT 7 para quatro variedades de cana-de-açúcar

\begin{tabular}{cccccccc}
\hline & & \multicolumn{7}{c}{ Indices de Vegetação $^{2}$} \\
\cline { 3 - 8 } Variedade & $\mathrm{N}^{1}$ & NDVI & RATIO & GVI & SAVI & RVI & GNDVI \\
\cline { 3 - 8 } RB835486 & 249 & $0,685232 \mathrm{D}^{2}$ & $5,3940 \mathrm{C}$ & $64,2144 \mathrm{D}$ & $0,452241 \mathrm{C}$ & $0,187042 \mathrm{~A}$ & $0,660749 \mathrm{C}$ \\
RB855536 & 83 & $0,781338 \mathrm{~A}$ & 8,2143 A & $92,6384 \mathrm{~A}$ & $0,599702 \mathrm{~A}$ & $0,122870 \mathrm{D}$ & $0,714557 \mathrm{~B}$ \\
RB855113 & 148 & $0,767704 \mathrm{~B}$ & $7,8716 \mathrm{~A}$ & $73,3930 \mathrm{C}$ & $0,525076 \mathrm{~B}$ & $0,131968 \mathrm{C}$ & $0,737408 \mathrm{~A}$ \\
SP81-3250 & 97 & $0,750071 \mathrm{C}$ & $7,1431 \mathrm{~B}$ & $77,5788 \mathrm{~B}$ & $0,533452 \mathrm{~B}$ & $0,143160 \mathrm{~B}$ & $0,709792 \mathrm{~B}$
\end{tabular}

${ }^{1}$ Número de observações (pixels) de cada variedade; ${ }^{2}$ Teste de Tukey aplicado entre as médias dos índices de vegetação (IV's) das variedades, letras iguais na coluna não diferem estatisticamente ao nível de 5\%.

${ }^{2}$ Fórmulas dos Índices de Vegetação (Bannari et al., 1995): Red = B3, NIR = B4 e Green = B2 do ETM+/LANDSAT 7

NDVI = (NIR - Red) / (NIR + Red);

RATIO = Red/NIR;

$\mathrm{GVI}=-0,24717 * \mathrm{TM} 1-0,16263 * \mathrm{TM} 2-0,40639 * \mathrm{TM} 3+0,85468 * \mathrm{TM} 4+0,005493 * \mathrm{TM} 5$ - 0,11749*TM7;

$\mathrm{SAVI}=(1+L)(\mathrm{NIR}-\mathrm{Red}) /(\mathrm{NIR}+\mathrm{Red}+L), L=0,5$;

$\mathrm{RVI}=\mathrm{NIR} / \mathrm{Red}$;

GNDVI = (NIR - Green) / (NIR + Green). 
Tabela 4. Equações discriminantes para quatro variedades de cana-de-açúcar por dados espectrais ETM+/LANDSAT 7

\begin{tabular}{|c|c|c|}
\hline Variedade & $\mathrm{N}^{1}$ & Equação Discriminante $^{2}$ \\
\hline RB835486 & 60 & $\begin{array}{c}-4160772+213314 * \mathrm{~B} 4+101164 * \mathrm{GNDVI}+3919 * \mathrm{~B} 5+339347 * \mathrm{~B} 2-586863 * \mathrm{SAVI}+687364 * \mathrm{~B} 3- \\
35480 * \mathrm{RATIO}+9327192 \mathrm{NDVI}+148,22207 * \mathrm{GVI}+11600073 * \mathrm{RVI}-54131 * \mathrm{~B} 1+44524 * \mathrm{~B} 7\end{array}$ \\
\hline RB855536 & 60 & $\begin{array}{c}-4164226+216282 * \mathrm{~B} 4+102322 * \mathrm{GNDVI}+4340 * \mathrm{~B} 5+343372 * \mathrm{~B} 2-590432 * \mathrm{SAVI}+682616 * \mathrm{~B} 3- \\
35502 * \mathrm{RATIO}+9331137 \mathrm{NDVI}+147,59088 * \mathrm{GVI}+11603719 * \mathrm{RVI}-53915 * \mathrm{~B} 1+44520 * \mathrm{~B} 7\end{array}$ \\
\hline RB855113 & 60 & $\begin{array}{c}-4163715+211475 * \mathrm{~B} 4+101756 * \mathrm{GNDVI}+4008 * \mathrm{~B} 5+340914 * \mathrm{~B} 2-584999 * \mathrm{SAVI}+689771 * \mathrm{~B} 3- \\
35496 * \mathrm{RATIO}+9329461 \mathrm{NDVI}+147,70220 * \mathrm{GVI}+11603286 * \mathrm{RVI}-54276 * \mathrm{~B} 1+44459 * \mathrm{~B} 7\end{array}$ \\
\hline SP813250 & 60 & $\begin{array}{c}-4162289+212538 * \mathrm{~B} 4+101741 * \mathrm{GNDVI}+4360 * \mathrm{~B} 5+340833 * \mathrm{~B} 2-586079 * \mathrm{SAVI}+688063 * \mathrm{~B} 3- \\
35494 * \mathrm{RATIO}+9328222 * \mathrm{NDVI}+147,48746 * \mathrm{GVI}+11601178 * \mathrm{RVI}-54152 * \mathrm{~B} 1+44601 * \mathrm{~B} 7\end{array}$ \\
\hline $\begin{array}{l}{ }^{1} \text { Número de } \\
\text { sensor ETM }\end{array}$ & obse & $\begin{array}{l}\text { rvações (pixels) de cada variedade estudada; }{ }^{2} \text { Equação discriminante obtida pela análise das seis bandas do } \\
\text { NDSAT } 7 \text { - B1 (450-520 nm), B2 (520-600 nm), B3 (630-690 nm), B4 (760-900 nm), B5 (1550-1750 nm) e }\end{array}$ \\
\hline
\end{tabular}


Tabela 5. Número de observações (pixels) e porcentagem de acerto na discriminação de quatro variedades de cana-de-açúcar através das equações discriminantes

\begin{tabular}{|c|c|c|c|c|c|}
\hline Variedade & RB835486 & RB855113 & RB855536 & SP813250 & Total $^{2}$ \\
\hline RB835486 & $\begin{array}{c}180^{1} \\
95,24^{3}\end{array}$ & $\begin{array}{c}6 \\
3,17\end{array}$ & $\begin{array}{c}0 \\
0,00\end{array}$ & $\begin{array}{c}3 \\
1,59\end{array}$ & $\begin{array}{c}189 \\
100,00\end{array}$ \\
\hline RB855536 & $\begin{array}{c}0 \\
0,00\end{array}$ & $\begin{array}{c}0 \\
0,00\end{array}$ & $\begin{array}{c}23 \\
100,00\end{array}$ & $\begin{array}{c}0 \\
0,00\end{array}$ & $\begin{array}{c}23 \\
100,00\end{array}$ \\
\hline RB855113 & $\begin{array}{c}1 \\
1,14\end{array}$ & $\begin{array}{c}79 \\
89,77\end{array}$ & 0,00 & $\begin{array}{c}8 \\
9,09\end{array}$ & $\begin{array}{c}88 \\
100,00\end{array}$ \\
\hline SP813250 & $\begin{array}{c}0 \\
0,00\end{array}$ & $\begin{array}{c}1 \\
2,70\end{array}$ & $\begin{array}{c}3 \\
8,11\end{array}$ & $\begin{array}{c}33 \\
89,19\end{array}$ & $\begin{array}{c}37 \\
100,00\end{array}$ \\
\hline $\begin{array}{l}\text { Total } \\
\%^{5}\end{array}$ & $\begin{array}{c}181^{4} \\
53,71\end{array}$ & $\begin{array}{c}86 \\
25,52\end{array}$ & $\begin{array}{c}26 \\
7,72\end{array}$ & $\begin{array}{c}44 \\
13,06\end{array}$ & $\begin{array}{c}337^{6} \\
100,00\end{array}$ \\
\hline $\begin{array}{l}\text { Erro Geral } \\
(\%)\end{array}$ & 4,76 & 10,23 & 0,00 & 10,81 & 6,45 \\
\hline
\end{tabular}

${ }^{1}$ Número de observações (pixels) classificadas para cada variedade; ${ }^{2}$ Total de observações para cada variedade; ${ }^{3} \%$ de acerto na discriminação da variedade; ${ }^{4}$ Total de observações classificadas para cada variedade; ${ }^{5} \%$ de observações em relação ao total de observações de todas as variedades; ${ }^{6}$ Número total de observações (pixels) analisados. 


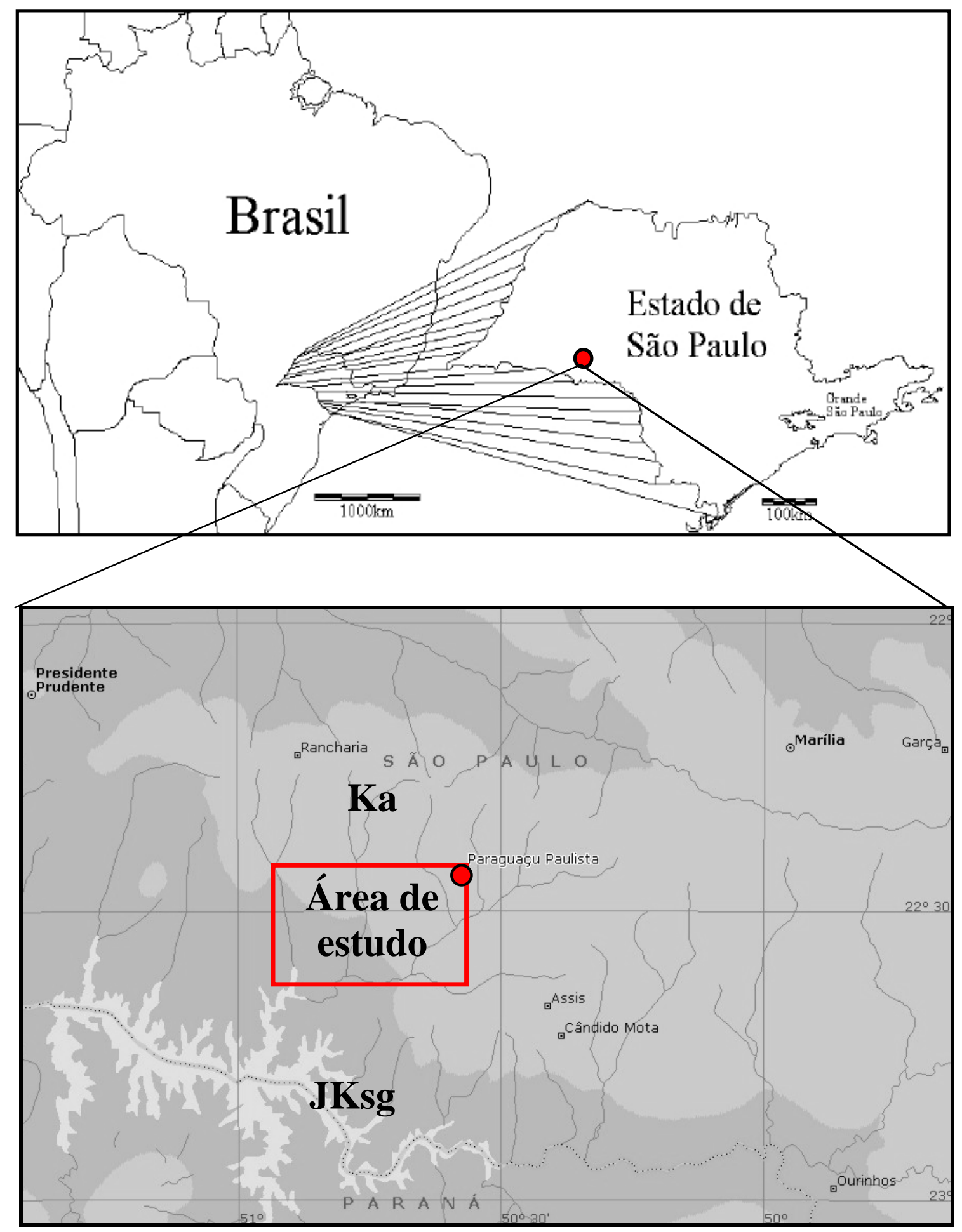

Figura 1 - Localização da área de estudo, município de Paraguaçu Paulista, SP e suas formações Geológicas Adamantina (Ka) e Serra Geral (JKsg) 


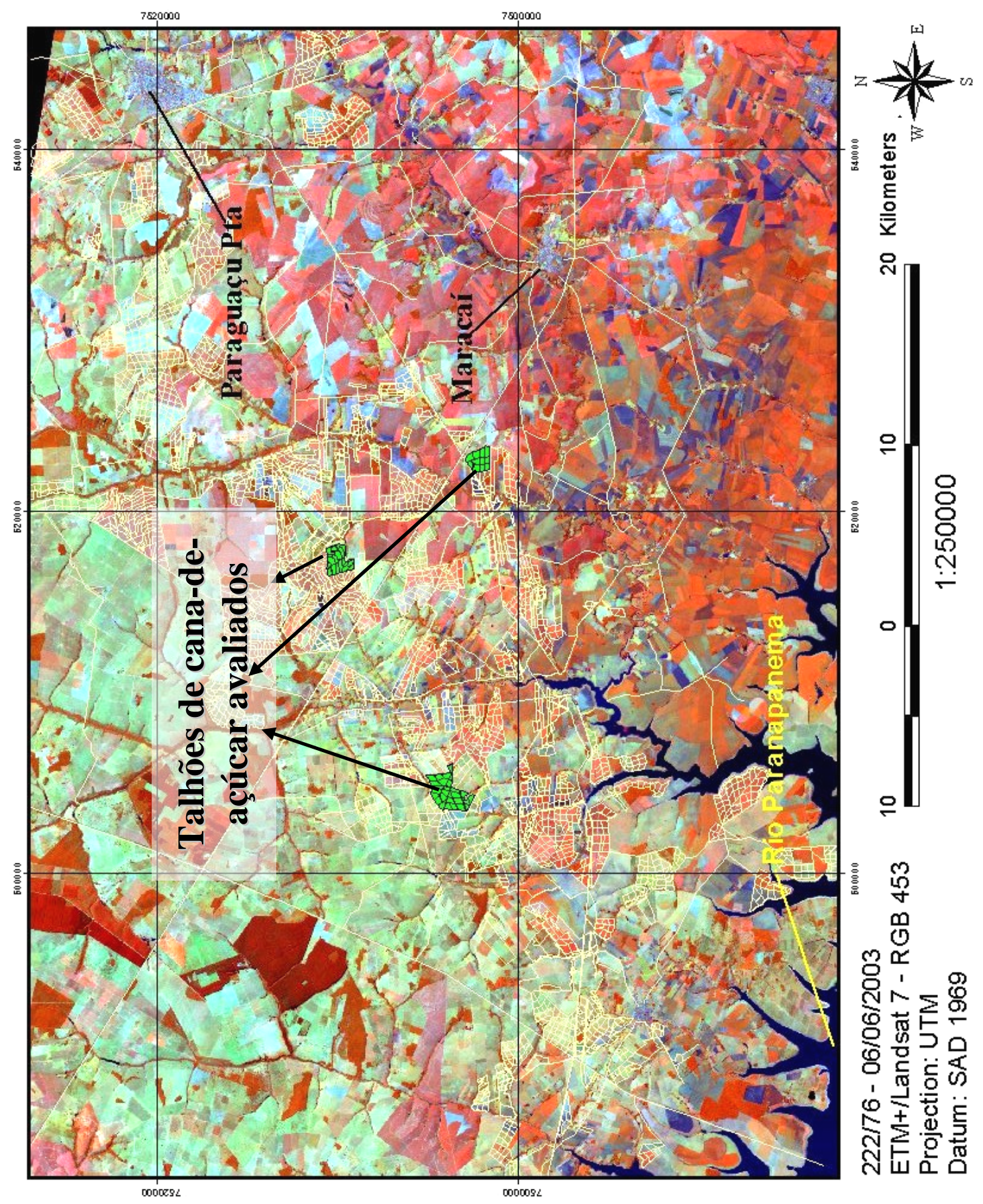

Figura 2 - Composição colorida 453 (RGB) da área de estudo. Talhões em verde são das variedades de cana de açúcar estudadas 


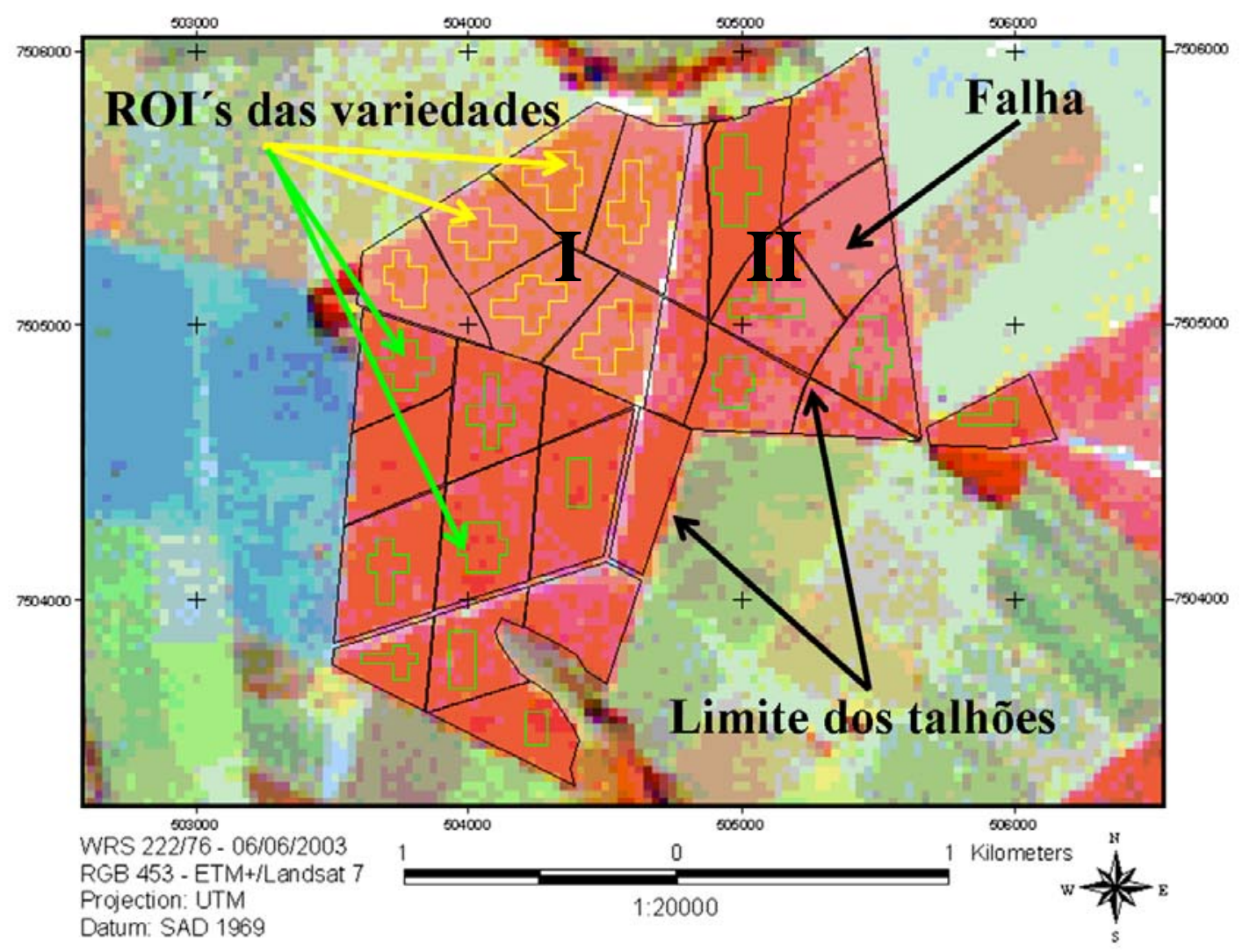

Figura 3 - Exemplo de regiões de interesse (ROI's) para coleta de dados espectrais das variedades de cana-de-açúcar, I-RB855536 e II-RB855113 


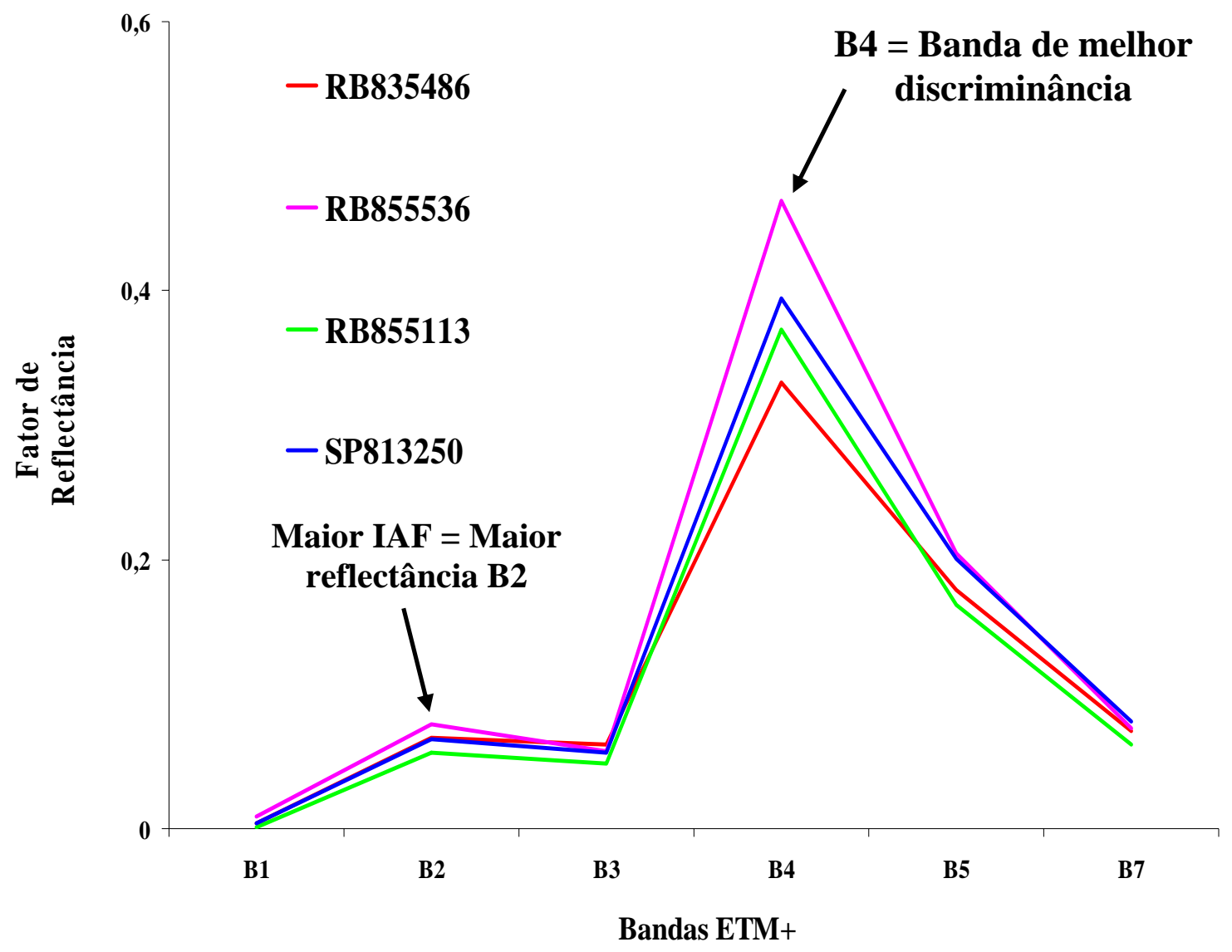

Figura 4 - Dados espectrais médios de seis bandas do sensor ETM+/LANDSAT 7 para quatro variedades de cana-de-açúcar 

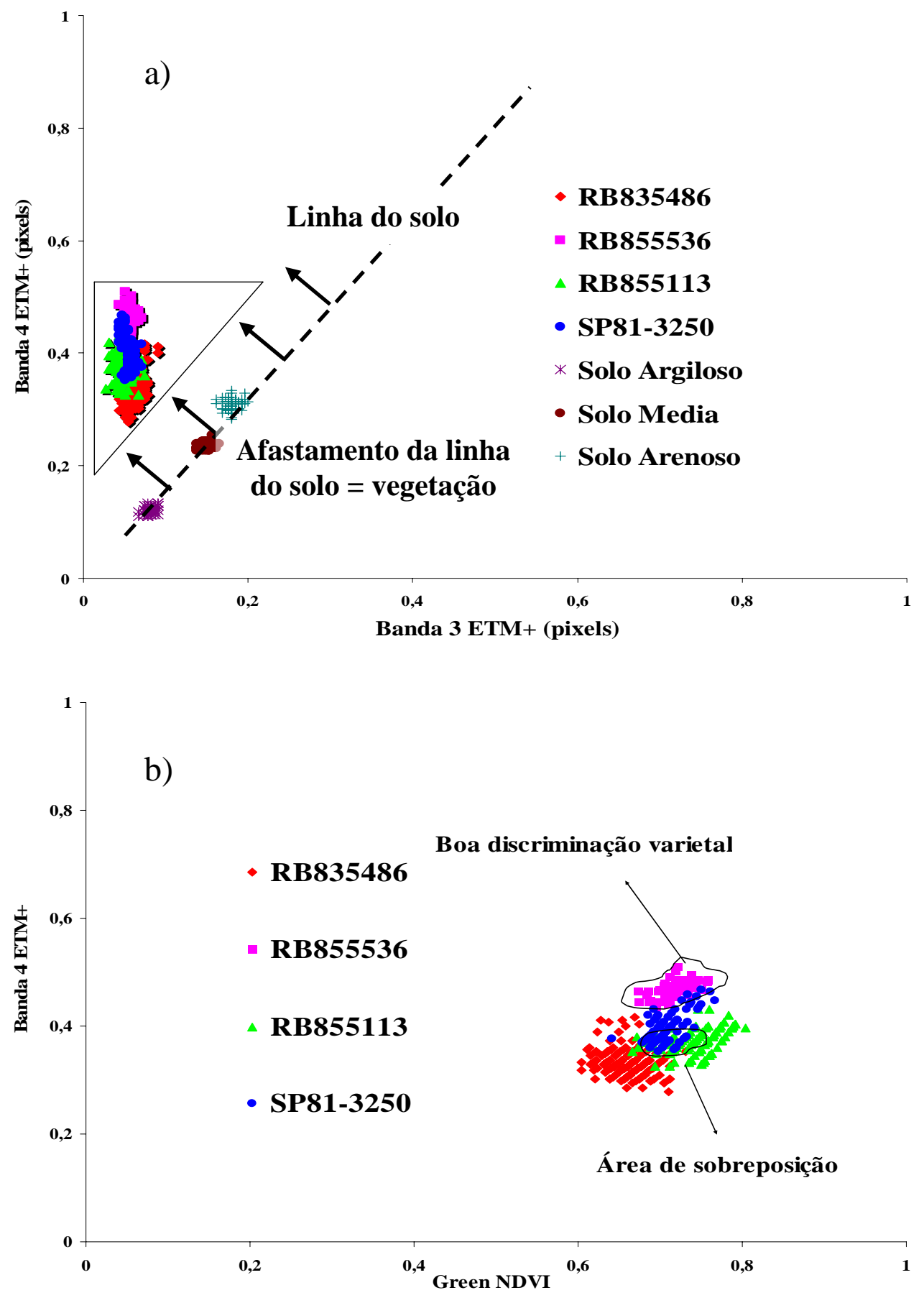

Figura 5 - a) Gráfico de dispersão B4 X B3 das observações das variedades da área de estudo; b) Gráfico de dispersão B4 x GNDVI das variedades da área de estudo $(\mathrm{GNDVI}=(\mathrm{NIR}-\mathrm{B} 2) /(\mathrm{NIR}+\mathrm{B} 2)$ 


\section{ESTIMATIVA DE PRODUTIVIDADE AGROINDUSTRIAL DE CANA-DE- AÇÚCAR POR DADOS ESPECTRAIS ORBITAIS ETM+/LANDSAT 7}

\section{Resumo}

A estimativa de safras agrícolas é uma das ferramentas fundamentais para o poder público, as empresas e agricultores pois proporciona um melhor planejamento de políticas de mercado e otimiza a tomada de decisões. Os sistemas de estimativa de safras são baseados em censos agropecuários que relacionam a área ocupada pelas culturas em diferentes escalas (municípios, estados e países) e seu rendimento médio. Devido à dificuldade de obtenção dos dados, devem ser desenvolvidos métodos alternativos para tal finalidade. O objetivo deste trabalho é determinar uma metodologia para estimar a produtividade da cana-de-açúcar $(\mathrm{Mg} / \mathrm{ha})$ dos talhões e outras propriedades industriais importantes como Brix ${ }^{\circ}$, Pol \% caldo, Pol \% cana, Fibra \%, Umidade \%, Pureza \% e Kg de ATR/Mg cana, pelo sensor orbital ETM+/LANDSAT 7. O comportamento espectral de dosséis vegetais reflete características importantes das culturas agrícolas quanto seu crescimento, vigor vegetativo e produção de biomassa e também devido ao efeito dos diversos fatores de produção, levanta-se a hipótese de que é possível estabelecer relações entre as características espectrais da cultura de cana-de-açúcar e sua produtividade agrícola e industrial. Para tanto, foram escolhidas áreas de produção de cana-de-açúcar localizadas na região de Paraguaçú Paulista, SP, da variedade RB835486 de primeiro corte. Foi montado um banco de dados através do qual foram escolhidos talhões representados pela mesma época de plantio. A imagem de satélite foi corrigida quanto aos efeitos atmosféricos e transformada em reflectância. Para a coleta de dados espectrais foram determinadas duas metodologias: na primeira estabeleceu-se áreas de 
coleta de dados espectrais dentro dos talhões, o qual foi representado pela média aritmética dos pixels. Outro método se baseou na classificação não supervisionada dos dados espectrais de cada talhão. Nesse caso cada talhão foi representado pela média ponderada do valor dos pixels em sete classes espectrais distintas. As bandas B1, B2, B3, B4, B5 e B7 e índices de vegetação foram utilizados para gerar modelos de regressão linear múltipla, visando selecionar as variáveis com maior potencial para quantificar características da cultura mencionadas anteriormente. Os resultados indicam que é possível estimar características agroindustriais da cana-de-açúcar através de dados espectrais orbitais, indicados por $\mathrm{R}^{2}$ de 0,6935 para produtividade agrícola ( $\mathrm{Mg} / \mathrm{ha}$ ) e em média 0,5807 para as características tecnológicas.

\section{SUGARCANE AGROINDUSTRIAL YIELD FORECAST BY ORBITAL SENSOR DATA ETM+ LANDSAT 7}

\section{Summary}

The forecast of agricultural harvests is one of the fundamental tools for the public power, the companies and farmers because it provides a better planning of market politics and it optimizes the decisions making. The production forecasts are based on agricultural censuses that relate the crops planted area in different scales (districts, states and countries) and its average yields. Due to the difficulty of data obtaining, alternative methods should be developed for such purpose. The objective of this work is to determine a methodology to foresee the productivity of the sugarcane $(\mathrm{Mg} / \mathrm{ha})$, and other important industrial properties like Brix ${ }^{\circ}$, Pol\% juice, Pol\% cane, Fiber\%, Humidity\%, Purity\% and $\mathrm{Kg}$ of ATR/Mg of cane, by orbital sensor ETM+/LANDSAT 7. The

spectral behavior of vegetable dossals reflects important characteristics of the agricultural crops as its growth, greeness and biomass production and also due to the effect of the several production factors, it gets up the hypothesis that it is possible to establish relationships between the spectral characteristics of the sugarcane crop and its agricultural and industrial yield. Thus, it has been chosen sugarcane production areas 
located in Paraguaçu Paulista County, on western São Paulo state, Brazil, of RB835486 variety on first cut. A database was set up and were chosen producing fields with the same planting date. The satellite image was corrected for the atmospheric effects and transformed in reflectance. The spectral data collection followed two methodologies: the first it has been settled down areas of spectral data collection, inside of the fields, which were represented by the arithmetic average of the pixels values. Another method was based on an unsupervised classification of the spectral data of each field. In that case each field was represented by the weighted mean of the value of the pixels in seven different spectral data classes. The bands B1, B2, B3, B4, B5 and B7 and vegetation indexes were used to generate multiple linear regression models, aiming the selection of variables with high potential to quantify the crop characteristics mentioned previously. The results indicate that it is possible to foresee agroindustrial characteristics of the sugarcane through orbital spectral data, suitable for $\mathrm{R}^{2}$ 0,6935 for agronomic yield (Mg/ha) and on average 0,5807 for the technological characteristics. 


\subsection{Introdução}

O açúcar e o álcool como fonte alimentícia e energética tem historicamente importância mundial. A cana-de-açúcar se apresenta como commodity ambiental por ser uma fonte de energia renovável, o álcool um combustível menos poluente e o açúcar um dos principais produtos de exportação do país. Neste contexto, o Brasil é o maior produtor mundial e nas últimas cinco safras gerou em média 310 milhões de toneladas de cana, 12 milhões de $\mathrm{m}^{3}$ de álcool e 20 milhões de toneladas de açúcar/safra. A área plantada no Brasil é estimada em 4,8 milhões de ha. O estado de São Paulo é responsável por 57 \% desta produção e participa com 52 \% da área canavieira nacional (Agrianual, 2003). Desta forma estudos relacionados a cultura de cana-de-açúcar tem grande importância e um dos passos importantes no planejamento é a estimativa de safras.

Atualmente os sistemas de previsão e estimativa de safras são baseados em censos agropecuários que relacionam a área ocupada pelas culturas em diferentes escalas (municípios, estados e países) e seu rendimento médio. Entretanto, a demora na publicação dos dados é a principal limitação deste método (Ipolliti-Ramilo et al., 1999). O principal método utilizado por agricultores e unidades produtoras é baseado na experiência de campo. Tal método é demorado e se relaciona principalmente com a estimativa de produtividade. Esses dados podem ser utilizados para diversos fins, entre eles especulação e regulagem de mercados interno e externo, intenções de plantio e políticas públicas em geral.

A cultura da cana-de-açúcar apresenta nível tecnológico dos mais elevados dentro da agricultura brasileira, lançando mão de técnicas como gerenciamento das áreas produtoras através de bancos de dados, setorização da produção agrícola em talhões e emprego de imagens de satélite no mapeamento de variedades (Joaquim, 1998). No Brasil a cana-de-açúcar é uma das maiores culturas de exportação, podendo ser considerada uma cultura de alto custo por área, com aplicações de até 800 kg/ha/ano de fertilizantes além de outros insumos (Corá \& Marques Junior, 2000). Portanto, pode-se 
dizer que a cana-de-açúcar é uma candidata potencial para o emprego da Agricultura de Precisão (AP).

Gitelson et al. (2002) definem a produtividade das culturas como o produto da energia solar captada pelo dossel e a eficiência deste em conversão de biomassa. Portanto, embora a produtividade agrícola da cultura de cana-de-açúcar seja importante, a remuneração do produto é feita com base na qualidade da matéria-prima quanto ao teor de sacarose (Consecana, 1999). Muchow et al. (1994) ressaltam que é importante realizar estudos que relacionem a conversão da energia solar em biomassa e ao acúmulo de sacarose, uma vez que este é o ponto crítico no retorno econômico da atividade.

A cana-de-açúcar no decorrer do seu ciclo atravessa dois períodos distintos com relação ao teor de sacarose: o primeiro é assinalado por um intenso crescimento vegetativo acompanhado por uma gradual formação de sacarose, enquanto que no segundo ocorre um predominante acúmulo de sacarose, motivado pela escassez dos principais fatores de desenvolvimento vegetativo, como temperatura e água disponível (Magalhães, 1987). Lucchesi (1995) relata que o teor de sacarose nos colmos aumenta no momento em que a cana-de-açúcar cessa seu crescimento, fenômeno favorecido principalmente pela queda de temperatura e/ou umidade.

A maturação é um processo fisiológico afetado por vários fatores naturais, como a própria variedade, condições climáticas, tipo de solo e tratos culturais (Fauconnier \& Bassereau, 1975; Stupiello, 1987). As variedades comerciais de cana-de-açúcar têm comportamentos distintos, apresentando níveis diferentes de sacarose mesmo quando cultivadas nas mesmas condições, constituindo-se na base para o planejamento agrícola (Nunes Junior et al., 1998). Tal estratégia possibilita a moagem da matéria-prima com alto teor de sacarose no decorrer de toda a safra, garantindo, desta maneira, um bom rendimento em todos os meses de processamento (Cesar \& Silva, 1993).

Dada a importância desta cultura, observa-se a necessidade de métodos alternativos na sua avaliação. Métodos que consigam obter informações mais ágeis e sem a necessidade de análises laboratoriais. Isso diminuiria o impacto ambiental e aumentaria a eficiência da cadeia produtiva. Neste aspecto o sensoriamento remoto demonstra grande potencial na avaliação do comportamento espectral da cana-de-açúcar 
em levantamentos e discriminação das áreas da cultura (Batista et al., 1978; Mendonça, 1980), reconhecimento de variedades (Joaquim, 1998; Joaquim \& Donzelli, 1999) e estimativas de produção (Almeida et al., 2002; Machado et al., 2002; Pellegrino, 2000; Rudorff, 1985; Rudorff \& Batista, 1990 e Schimidt et al., 2001).

A estimativa da biomassa vegetal natural ou das culturas agrícolas é uma das aplicações do sensoriamento remoto (Machado et al., 2002; Thenkabail et al., 2002; Todd \& Hoffer, 1998). Para que isso seja possível, é importante conhecer as interações que ocorrem entre os alvos agrícolas (dosséis e solos) e a energia eletromagnética que é captada pelos sensores (Lillesand \& Kiefer, 2000; Ponzoni, 2001).

A utilização de técnicas de sensoriamento remoto vem sendo preconizada no monitoramento de áreas agrícolas e estimativas de produtividade e surge como uma área inovadora na pesquisa (Stafford, 2000). Trabalhos demonstram que este sistema tem grande potencial de uso na avaliação do estado, mapeamento de áreas e estimativas de produção de biomassa das culturas (Singh et. al, 1992; Rudorff \& Batista, 1994, Schmidt et al., 2001; Pellegrino, 2000; Machado et al., 2002), por outro lado esta área é carente de estudos que visem determinar a qualidade industrial da cana-de-açúcar. Além disso, a determinação dos atributos de qualidade são realizados atualmente por métodos químicos caros e poluentes.

No caso da cana-de-açúcar, a população de colmos e o peso médio destes são os principais componentes da cultura possíveis de serem medidos, pois apresenta maior correlação com a produtividade e podem ser utilizados para estimar a produtividade dos ensaios de melhoramento e de talhões comerciais (Gheller et al., 2002). Porém, este método exige equipes treinadas, tem alto custo e demanda muito tempo no caso de áreas extensas. Rudorff \& Batista (1990) elucidam que é muito importante estimar a produção de colmos a serem processados antes do início da colheita começar e também concordam que a acurácia desta estimativa depende de pessoal tecnicamente experiente.

Portanto, este trabalho tem o objetivo de desenvolver uma metodologia para estimar a produtividade agrícola e características industriais de cana-de-açúcar através de dados obtidos do sensor orbital ETM+ do satélite LANDSAT 7. Para tanto serão 
utilizadas técnicas de processamento e interpretação de imagens num ambiente SIG, para organização e visualização dos dados georeferenciados.

O comportamento espectral de dosséis vegetais reflete características importantes das culturas agrícolas quanto seu crescimento, vigor vegetativo, produção de biomassa e também devido ao efeito dos diversos fatores de produção. Levanta-se a hipótese de que é possível estabelecer relações entre as características espectrais da cultura de cana-deaçúcar e sua produtividade agrícola e industrial. Espera-se que a presente metodologia possa orientar e direcionar trabalhos de campo na estimativa de produtividade, principalmente nas análises laboratoriais para determinação das características industriais, com diminuição do custo e com qualidade ambiental.

\subsection{Material e Métodos}

\subsubsection{Localização e caracterização da área de estudo}

A área de estudo localiza-se a oeste do estado de São Paulo, no retângulo envolvente $22^{\circ} 15^{\prime} \mathrm{S} / 51^{\circ} 15^{\prime} \mathrm{W}$ e $22^{\circ} 45^{\prime} \mathrm{S} / 50^{\circ} 30^{\prime} \mathrm{W}$, com altitude média de $410 \mathrm{~m}$, e abrange os municípios de Paraguaçu Paulista, Borá, Iepê, Agicê, Maracaí, Cruzália, Gardênia, Sapezal, João Ramalho, São José das Laranjeiras e Rancharia (Figura 1). Trata-se de uma grande região canavieira que apresenta contínua expansão agrícola.

Na geologia predomina a Formação Adamantina (Grupo Bauru) e em algumas áreas a Formação Serra Geral (Grupo São Bento), segundo o IPT (1981). As rochas eruptivas básicas ocorrem principalmente nos vales dos principais rios como o Paranapanema e, sobre estas é comum a ocorrência de material sedimentar ou do Arenito Bauru.

Os solos dos talhões avaliados são os LATOSSOLOS VERMELHOS de textura média e os NEOSSOLOS QUARTZARÊNICOS (Embrapa, 1999), sendo os mais representativos da região, segundo França \& Demattê (1993).

Climaticamente a área é caracterizada por apresentar um verão quente e úmido com as precipitações maiores ocorrendo de novembro a março e decrescendo no mês de abril. O inverno apesar de seco pode apresentar algumas precipitações, inclusive em 
junho. Os meses de julho e agosto são os mais secos. A precipitação média anual é da ordem de 1.400 a $1.600 \mathrm{~mm}$ e a temperatura média é de $22,5^{\circ} \mathrm{C}$. O déficit hídrico corresponde aos meses de junho a meados de setembro, com uma evapotranspiração da ordem de 1.050 mm (Apêndices 1 e 2).

\subsubsection{Variedade de cana-de-açúcar}

A variedade de cana-de-açúcar estudada foi a RB835486, dada a sua importância na região e ser uma variedade bem adaptada a tais ambientes edáficos de produção. É uma variedade de alta produtividade em cana planta e soca, altíssimo teor de sacarose, alta precocidade, média exigência em solos, ampla adaptabilidade, perfilhamento médio, bastante tombamento, florescimento médio e pouca isoporização (Arizono et al., 2000).

Quanto às características botânicas, a RB835486 apresenta (UFSCar, 2001): touceiras ralas, decumbentes na fase adulta, colmos medianamente empalhados e de fácil despalha, diâmetro médio a grosso e de elevado peso, cor arroxeada com cera abundante; entrenós médios, dispostos em leve ziguezague; gemas arredondadas; capitel médio, folhas de largura e comprimento médios, eretas, geralmente dispostas em leque, com leve curvatura na ponta e bainha sem joçal (Figura 8).

\subsubsection{Processamento digital da imagem e obtenção dos índices de vegetação}

Foi utilizada a imagem obtida do sensor ETM+ do LANDSAT 7, órbita ponto WRS 222/76, bandas 1, 2, 3, 4, 5 e 7 de 6 de junho de 2000. As características espectrais e espaciais do sensor estão descritas no item 4.1.

Efetuou-se a correção atmosférica, através do modelo "5S" - Simulation of Satellite Signal in the Solar Spectrum, presente no programa computacional SCORADIS - Sistema de Correção de Imagens de Satélite - Versão LITE - LANDSAT 7 ETM+, desenvolvido por Zullo Junior (1994). Para execução do algoritmo de correção atmosférica são necessários alguns parâmetros de entrada como localização geográfica do centro da cena (latitude e longitude), data e hora de aquisição e o modelo atmosférico dos componentes gasosos, principalmente vapor d’água e ozônio, determinados pelo 
programa SCORADIS - Versão LITE - ETM+/LANDSAT 7. Obteve-se a partir disso uma imagem de reflectância real, ou seja, exoatmosférica.

A correção geométrica ou registro de imagem (georreferenciamento) foi realizada no programa Environment for Visualizing Images 3.6 (ENVI, 2003) e para tanto, foram coletados pontos de controle na região de abrangência da área de estudo com um GPS Trimble PRO-XR, de erro submétrico e pós-processado, de acordo com procedimentos descritos por Crosta (1992). O sistema de projeção e o datum utilizados para localização e georeferenciamento foram o UTM e SAD-69, respectivamente (Figura 2). O interpolador utilizado foi o vizinho mais próximo (nearest neighbor) que, segundo Crosta (1992) é o mais utilizado por não alterar o valor dos níveis de cinza dos pixels da imagem.

Epiphanio \& Formaggio (1988), Thenkabail et al. (2002) e Demattê \& Nanni (2003) comentam que, para realizar análises quantitativas sobre os comportamentos espectrais de alvos em imagens, devem ser feitas transformações dos NC para dados de reflectância por esta ser uma grandeza física intrínseca dos alvos, ao passo que números digitais (níveis de cinza) são valores transformados para a obtenção das imagens orbitais.

Segundo Luiz et al. (2003), a transformação dos NC’s de imagens ETM+ do LANDSAT 7 em radiância é obtido pela resolução de uma regressão linear simples cujos parâmetros de entrada são fornecidos e atualizados pelos responsáveis pelo satélite. Os mesmos autores elucidam que para o cálculo da reflectância, é necessário conhecer o valor de diversas variáveis, porém apenas o NC do pixel varia dentro da imagem, as demais variáveis são constantes e variam em função da data e da banda utilizada. Os valores de NC devem ser convertidos em radiância e em reflectância exoatmosférica para as posteriores avaliações de bandas e obtenção dos índices de vegetação (Thenkabail et al., 2002).

Os dados da imagem foram convertidos e normalizados em fatores de reflectância como descrito por Epiphanio \& Formaggio (1988) e após este processo, o nível de cinza zero presente na imagem passou a corresponder à reflectância real 0 \% e o nível 255 à reflectância real 100 \%. 
Além dos valores espectrais das bandas foram criadas seis imagens índice vegetação, a saber: NDVI, GVI, SAVI, RVI, RATIO e GNDVI de acordo com Bannari et al. (1995), Crist \& Ciccone (1984), Thenkabail et al. (2002), Huete (1988), Baret \& Guyot (1991) e Gitelson et al. (1996). As observações foram os valores espectrais médios dos talhões nas imagens das bandas e dos IV's.

\subsubsection{Banco de dados agronômicos}

Em usinas e destilarias de uma forma geral, os setores são áreas de dimensão variável, com um determinado solo predominante, com plantio da cana ocorrido na mesma época e de preferência com uma mesma variedade, para ser colhida também na mesma época. O tamanho dos setores é muito variável em decorrência de acidentes geográficos, topografia, classes de solos e de áreas (próprias e de fornecedores) sendo o tamanho médio ideal da ordem de 200 a 300 ha. Preconiza-se que os setores sejam módulos agrícolas compatíveis com a unidade industrial e/ou que correspondam a uma produção que abasteça a indústria por um período de 5 a 10 dias (Planalsucar/IAA, 1986).

Foram utilizados dados da safra 2000/01 referentes aos setores 3, 4, 11, 361, 366 e 371, perfazendo um total de 70 talhões, numa área de 763,57 ha de cana-de-açúcar da mesma variedade (RB 835486), sobre a mesma classe de solo predominante, o LATOSSOLO VERMELHO textura média (Embrapa, 1999) e mesmo estádio de corte ( $1^{\circ}$ corte). A idade média dos canaviais avaliados foi de 13,5 meses evidenciando o caráter precoce da variedade.

Foi montado um banco de dados constituído de: mapas planimétricos do programa Autocad 2000 com a área dos talhões, classe de solos e variedade de cana-deaçúcar cultivada; planilhas do programa PIMS C/S - Pol Information Manager System Client/Server (SRI, 2003), contendo produtividade média (Mg/ha) estimada e real, produção total de cana $(\mathrm{Mg})$ estádio de corte e características tecnológicas (Brix ${ }^{0}$, Pol\% caldo, Pol \% cana, Fibra \%, Pureza \%, Umidade \% e Kg ATR/Mg cana) médias dos talhões referentes à safra 2000/01, idade dos canaviais em meses, datas de colheita e 
dados meteorológicos históricos de 1992 a 2003, contemplando o ano de aquisição da imagem e do banco de dados (Apêndices 1 e 2).

O banco de dados foi a base para a escolha dos setores com os talhões a serem analisados. Essa escolha teve como premissa talhões com cana de mesma variedade (RB835486), mesma data de plantio (meados de abril), mínimo de variações externas (pragas e doenças), mesmo ambiente de produção e solos. A Tabela 1 e o Apêndice 3 apresentam as características dos setores utilizados no trabalho.

\subsubsection{Obtenção das informações espectrais da cana-de-açúcar}

Os contornos dos talhões de cana-de-açúcar foram vetorizados no programa Autocad 2000 e sobrepostos às imagens e ao mapa de solos da região através do software ArcView GIS 3.2 (ESRI, 1996). Neste SIG foi confrontado o banco de dados de rendimentos agroindustriais (item 6.2.3) aos respectivos talhões.

Os talhões escolhidos foram plantados em meados de março até maio como ciclo de cana de ano-e-meio (18 meses). Os talhões foram considerados como repetições. A escolha da data da imagem também foi em função de aspectos climáticos. Almeida (2000) ressalta que embora o satélite LANDSAT 7 tenha uma periodicidade de 16 dias, a disponibilidade de imagens sem cobertura de nuvens pode se restringir a apenas uma por ano, como demonstrou na região de Barra Bonita, SP. O autor ainda elucida que as imagens sem cobertura de nuvens correspondem, em sua maioria, aos meses de inverno de junho a setembro principalmente.

Dois métodos foram utilizados para aquisição dos dados espectrais de cada talhão, o de médias aritméticas e de médias ponderadas. Para tanto, as bordas dos talhões foram desprezadas, pois sofrem grande influência espectral dos carreadores.

A primeira foi obtida a partir da média aritmética entre os valores espectrais dos pixels dos talhões em cada uma das seis bandas dividido pelo número de pixels contido nestes talhões.

No segundo método, as médias ponderadas foram obtidas através da técnica de classificação não supervisionada. Dentro de cada talhão existem diferenças espectrais relacionadas à umidade, estado nutricional e vegetativo da cultura. Visando mapear estas 
diferenças do dossel dentro dos talhões, utilizou-se o classificador "K-means" do programa ENVI 3.6 (ENVI, 2003), que calcula inicialmente as classes distribuindo uniformemente no espaço e então aglomera classe por classe em um processo iterativo, usando a técnica de distância mínima. Melhor será a classificação quanto melhor for agrupada a nuvem de pixels. A classificação se completa quando o número de iterações definido pelo usuário for concluído, ou quando for alcançado o critério de número de pixels que mudam de classe (Change Threshold); por exemplo, se escolhermos 5\%, e, se menos de 5\% dos pixels "migrarem" de uma classe para a outra, o critério estará alcançado. Para este trabalho definiu-se um número de sete classes e quatro iterações como razoável. Procedeu-se uma aferição visual entre as classes espectrais geradas e os mapas de produtividade ( $\mathrm{Mg} / \mathrm{ha}$ ) no software ArcView GIS 3.2, buscando correlacionar com a produtividade real dos talhões (TCH_Real) observada no banco de dados.

Cada talhão escolhido foi avaliado quanto aos valores médios de reflectância nas seis bandas do sensor e aos seis índices de vegetação médios (item 3.2.3). Os valores de reflectância final dos talhões foram obtidos e ponderados através do valor médio de cada classe e da porcentagem que estas ocupavam da área dos talhões. Portanto, cada talhão teve um valor espectral médio para as seis bandas e para os seis índices de vegetação e para as duas metodologias de coleta de dados.

\subsubsection{Metodologia tradicional para quantificação das características da cultura}

Atualmente as estimativas de produtividade dos talhões são realizadas por supervisores agrícolas em duas épocas, uma em meados de novembro, no final da safra (chamada de pré-estimativa) e outra em fevereiro a março, antecedendo o início da safra (chamada de estimativa oficial). Este levantamento é realizado através de amostragem dos talhões por variedades, onde geralmente são contadas as canas de 10 metros de linhas plantio e pesadas em feixes de 10 a 15 canas. Um aspecto importante é que são considerados os aspectos individuais de cada área, quanto ao seu histórico de fertilidade do solo, práticas culturais, épocas de plantio e colheita, presença de pragas, ou seja, o conhecimento global das áreas é fundamental. O erro máximo que se preconiza em tais levantamentos é de 3\%, o que denota uma necessidade grande de precisão da equipe e 
esta ser composta sempre pelos mesmos profissionais, concordando com Gheller et al. (2002) e Rudorff \& Batista (1990). As características tecnológicas são obtidas em laboratório antes (pré-análise) da queima dos talhões através de amostras de feixes de 10 a 15 canas/talhão. Isso é feito para acompanhamento da maturação e tomada de decisão quanto a ordem de queima e colheita da matéria prima. Após a colheita, as cargas dos caminhões são amostradas segundo as metodologias descritas pelo sistema Consecana (Consecana, 1999) procede-se a análise de laboratório para fins de PCTS (pagamento da cana pelo teor de sacarose).

A metodologia apresentada neste trabalho tem a intenção de direcionar e auxiliar nos trabalhos de campo das equipes de amostragem.

\subsubsection{Análise estatística}

Foram realizadas análises estatísticas de correlação entre os valores médios de reflectância das bandas do sensor ETM+ LANDSAT 7 e índices de vegetação com os valores de produtividade e de características tecnológicas médias dos talhões (Brixº , Pol $\%$ caldo, Pol \% cana, Fibra \%, Umidade \%, Pureza \%, Kg de ATR/Mg cana e Impureza \%), através de equações lineares de regressão múltipla realizados pelo Statistical Analysis System (SAS, 1999).

O procedimento REG, Stepwise do Statistical Analysis System (SAS, 1999) determina as variáveis bandas e índices de vegetação, verifica e analisa efeitos de colinearidade que possam existir entre as variáveis e enumera quais delas determinam maiores coeficientes de determinação $\left(\mathrm{R}^{2}\right)$ para modelos de estimativa de atributos. Somente as variáveis que determinarem equações com um $\mathrm{R}^{2}$ adequado é que deverão fazer parte dos modelos (Robbins \& Daneman, 1999), ou seja, quais são as variáveis que apresentam maior ou menor potencial para o desenvolvimento dos modelos de estimativa que são o objetivo do trabalho. O nível de significância para as equações lineares múltiplas através do stepwise é de $15 \%$, ou seja, qualquer variável que obtenha um $\mathrm{R}^{2}$ acima de 0,15 ou que adicione informação significante pode ser selecionada para compor os modelos. 
Os dados relativos aos dois métodos de coleta de informações espectrais foram utilizados para elaboração de modelos de estimativa dos atributos agroindustriais dos talhões individualmente, constituindo dois resultados (item 6.3.1 e 6.3.2). Isso foi feito com o intuito de se comparar qual método de coleta proporciona os melhores resultados.

\subsection{Resultados e discussão}

\subsubsection{Estimativa de produtividade agroindustrial dos talhões pelo método das médias ponderadas}

Na tabela 2 encontram-se as equações de regressão múltipla obtidas através dos dados orbitais ETM+/LANDSAT 7 para estimar as características agroindustriais da cana-de-açúcar a saber: produtividade média $(\mathrm{Mg} / \mathrm{ha})$ estimada e realizada, produção total de cana (Mg), Brix ${ }^{\circ}$, Pol\%, Pol \% cana, Fibra \%, Pureza \%, Umidade \%, Kg ATR/Mg cana e Impurezas \%. Os dados que compuseram as equações representam a média ponderada dos pixels das sete classes espectrais contidas nos talhões de estudo, obtidas através do classificador não supervisionado "K-means" do ENVI 3.6. Wiegand et al. (1996) realizaram o mesmo procedimento de classificação não supervisionada buscando correlacionar os resultados espectrais (satélite SPOT e videografia multiespectral) com padrões da cultura de cana-de-açúcar sob stress em solos salinos.

As variáveis que mais tiveram relevância na composição das equações pelo método das médias ponderadas das classes foram as bandas B2 e B5 com quatro e cinco ocorrências, e os IV's GNDVI e RVI com três e quatro ocorrências, respectivamente (Tabela 2). A banda B3 e o SAVI foram as únicas variáveis espectrais que não foram utilizados para compor as equações. Provavelmente o SAVI não entrou na composição dos modelos uma vez que a influência do solo pode ser desconsiderada quando se realizam estudos espectrais orbitais da cultura de cana-de-açúcar (Joaquim, 1998).

Almeida et al. (2002) ressaltam que imagens muito precoces não são adequadas para estimar a produtividade, uma vez que a cultura não atingiu um desenvolvimento mínimo que assegure seu status para ocasião da colheita. Entretanto, em imagens tardias a cana pode tombar, o que dificulta a interpretação dos dados da imagem. Isso pode ser 
uma explicação de por que a banda B4 não participou na composição dos modelos de TCH_Real. A imagem deste trabalho é tardia (meio de safra) e a variedade já estava em época de colheita (Apêndice 3) e possui alto tombamento (Arizono et al., 2000).

Para a produtividade agrícola real (TCH_Real), o modelo contemplou o RVI, além da banda B5 e o GNDVI. O resultado desta estimativa obteve $\mathrm{R}^{2}$ de 0,5222 (Tabela 2). O GNDVI (Gitelson et al., 1996) incorpora no cálculo do NDVI a banda B2 (verde 520-600 nm), ao invés da B3 (vermelho 630-690 nm). O uso de bandas espectrais da região do visível azul $(500 \mathrm{~nm})$ e verde (550 nm), que não o vermelho (650 nm) é desejável no estudo de vegetação como ressaltam Chapelle et al., (1992); Gitelson \& Merzliak (1997) e Gitelson et al. (2002). Tais bandas trazem informações referentes a absorção de radiação pelos pigmentos fotossintetizanntes como as clorofilas $a$ e $b$ e os carotenóides, ao quais se relacionam bem com a eficiência fotossintética (Yocum et al., 1964) e acúmulo de biomassa (Machado et al., 1985).

Machado et al. (1985) ressaltam que a reflexão da radiação solar pela vegetação é modificada por muitos fatores físicos e biológicos tais como elevação solar, estrutura e geometria das plantas, tamanho, anatomia e idade das folhas e arranjo espacial das plantas no campo. A variedade estudada neste trabalho possui perfilhamento médio e touceiras ralas (Arizono et al. 2000) porém, apresenta colmos pesados que se acamam com facilidade em condições de cana-planta. A imagem utilizada no trabalho foi a da época de colheita da referida variedade que se encontrava em estágio adiantado de maturação. Portanto, é de se esperar que em imagens tardias, algumas informações referentes à produtividade agrícola sejam mascaradas por palha, colmos e até mesmo solo, assim como ressaltam Almeida et al. (2002) e Machado (2003).

As equações de estimativa dos parâmetros tecnológicos de uma forma geral apresentaram melhores resultados $\mathrm{R}^{2}$ do que os de produtividade agrícola (Tabela 2). A estimativa do brix (BRX) obteve $\mathrm{R}^{2}=0,5690$, considerado satisfatório. As bandas que participaram nesta equação foram B2 e B7, não havendo a participação de IV's. Estas bandas são relacionadas à reflexão verde da vegetação sadia e teor de umidade no dossel das culturas, respectivamente (Ponzoni, 2001). 
A equação da pol \% caldo (POL) pelo método de coleta das médias ponderadas contemplou em seus cálculos as bandas B2, B5 e o RVI (Tabela 2). Estas bandas estão relacionadas a reflexão verde da vegetação e a umidade das folhas. O resultado obtido $\left(\mathrm{R}^{2}=0,5865\right)$ foi considerado satisfatório, uma vez que é esta uma medida do teor de sacarose do caldo dos colmos, e sua interação (refração da luz polarizada) no sacarímetro (Stupiello, 1987). A sacarose e os açúcares redutores (glicose e frutose) sintetizados na folhas durante o dia translocam-se por todas as partes da planta através dos vasos do floema, sendo a sacarose o principal fotoassimilado translocado (80 a 90 \%) com velocidade de até $2,5 \mathrm{~cm} \mathrm{~min}{ }^{-1}$, dependendo das condições climáticas (Casagrande, 1991). Parte da sacarose produzida durante o dia é armazenada temporariamente na bainha e no limbo foliar para translocação noturna em que a planta não está realizando fotossíntese (Lucchesi, 1995). Vários autores (Curran, 1989; Kokaly Clark, 1999 e Masoni et al., 1994) elucidam que podem ser detectadas diferenças sutis nas respostas espectrais de tecidos vegetais quando em maturação, devido ao acúmulo de substâncias (no caso da cana de açúcar a sacarose) e diminuição dos teores de amido nas folhas. Gitelson et al. (2002) ressaltam que outra fonte de variação de reflectância da vegetação está no fato de ocorrer aumento da absorção pelos pigmentos fotossintéticos mesmo quando a área foliar se estabiliza. No presente trabalho, os canaviais já estavam com sua área foliar formada e em senescência devido ao adiantado estádio de maturação. Casagrande (1991) ressalta que mesmo após o início da maturação a cana-de-açúcar continua trocando substâncias com o ambiente e em atividade metabólica intensa, porém no sentido de acumular sacarose.

A pureza \% (PZA) é a razão entre brix e sacarose, ou seja, a porcentagem dos açúcares presentes no caldo que é realmente a sacarose, e não glicose, frutose e dextrana (Casagrande, 1991; Stupiello, 1987). O resultado de $\mathrm{R}^{2}=0,2193$ não foi considerado satisfatório e as variáveis que participaram da composição da equação foram as bandas B1, B2, B4 e B5 e nenhum IV (Tabela 2).

A equação da pol \% cana (PCC) foi obtida através das bandas B4, B5 e do NDVI. O resultado de estimativa para este parâmetro foi razoável, $\mathrm{R}^{2}=0,5048$ (Tabela 
2). Este atributo por sua vez é calculado em função da pol \% caldo e da fibra \%, segundo Stupiello (1987) e Cesar \& Silva (1993).

A umidade \% (UMD) foi o parâmetro que obteve melhor resultado $\mathrm{R}^{2}=0,6239$ na estimativa. Sua equação contemplou as bandas B4 e B7 além dos IV's GNDVI, RVI, SAVI e GNDVI. A banda B4 está relacionada ao vigor da vegetação (Machado, 2003) mas seu comprimento de onda também é utilizado para determinar diretamente a qualidade da matéria-prima (Fernandes \& Souza., 1997). Algumas usinas já possuem equipamentos baseados em NIRS em seus laboratórios de pagamento de cana pelo teor de sacarose (PCTS). A banda B7 por sua vez se relaciona bem com a umidade dos tecidos vegetais e obteve grande peso na equação de estimativa para este parâmetro (Tabela 2).

Na equação do parâmetro fibra \% (FBR), as variáveis relevantes para o modelo foram as bandas B1 e B2 (Tabela 2). A primeira se relaciona com a absorção da clorofila e carotenóides enquanto que a segunda é função da coloração verde da vegetação (Gitelson et al., 2002). O resultado da estimativa foi insatisfatório $\left(\mathrm{R}^{2}=0\right.$,2963), porém Gitelson et al. (2002) ressaltam que embora o modelo para fibra \% não tenha sido bom, é importante utilizar outras bandas do visível, que não a B3 e B4, para determinar a fração e cobertura do solo pela vegetação.

Para a quantidade de açúcar teórico recuperável (ATR) as variáveis que entraram no modelo foram as bandas B2 e B5 e os IV's GNDVI e NDVI. O resultado foi considerado satisfatório $\left(\mathrm{R}^{2}=0,5012\right)$, uma vez que a estimativa é realizada através de dados orbitais e relacionada a um parâmetro calculado em função da PCC e do teor de açúcares redutores da cana (Consecana, 1999). Beauclair \& Scarpari (2002) utilizaram como universo (banco de dados) as canas de ano (CA - 12 meses) de uma usina do estado de São Paulo e obtiveram bons resultados na estimativa de ATR, $\mathrm{R}^{2}=0,69$, utilizando dados de precipitação e temperatura inseridos na regressão múltipla de stepwise. No presente trabalho foram utilizadas variáveis espectrais coletadas de uma imagem de data de passagem próxima as colheitas da RB835486 e, pode-se perceber que existe tendência das características tecnológicas serem estimadas com resultados próximos aos de produtividade agrícola TCH_Real (Tabela 2). 
A impureza \% (IMP) não obteve boa estimativa $\left(\mathrm{R}^{2}=0,0971\right)$ e somente a variável RVI entrou na composição da equação (Tabela 2). Deve ser ressaltado que todas as características tecnológicas são medidas de qualidade da matéria-prima, ou seja, dos colmos entregues à indústria. Outro fato é que os dados utilizados são de póscolheita e a medição dos dados radiométricos foi realizada pelo sensor enquanto a cultura ainda estava no campo. A cana da área de estudo é colhida manualmente após a queima da palha. Segundo Stupiello (1987), a qualidade tecnológica da matéria-prima depende de fatores bióticos (variedade, florescimento, teor de nutrientes no caldo, decomposição microbiana, respiração e transpiração dos tecidos após a colheita) e abióticos (tipo de colheita, solo e tempo médio de permanência da cana cortada no campo e condições climáticas no transporte, carregamento e armazenamento). Quanto maior o intervalo de tempo entre o corte e a moagem, maiores serão as perdas de qualidade industrial devido a inversão da sacarose em glicose e frutose (Cesar \& Silva, 1993).

\subsubsection{Estimativa de produtividade agroindustrial dos talhões pelo método das médias aritméticas}

De maneira geral as características agroindustriais da cana-de-açúcar foram estimadas com um coeficiente de determinação $\left(R^{2}\right)$ de 0,6935 para a produtividade agrícola (Mg/ha) e em média 0,5807 para os atributos tecnológicos (Tabela 3). Ressaltase que tais dados representam a média aritmética dos pixels contidos nos 70 talhões de estudo.

Almeida (2000) elucida que a avaliação comparativa de vigor de canaviais através de dados espectrais deve ser aplicada somente a talhões de mesma variedade e idade, que foi o caso deste trabalho com a variedade RB835486 no estádio de primeiro corte. Este fato concorda com Rudorff et al. (1995) que comentam que o emprego de variáveis qualitativas sobre os modelos, como a variedade e o estádio de corte melhoram a relação entre a produtividade observada e os índices de vegetação obtidos das imagens de satélite. Usando somente o RVI, os autores obtiveram uma melhora no $\mathrm{R}^{2}$ de 0,13 
para 0,41 com o emprego de tais variáveis qualitativas nos modelos de estimativa de produtividade.

Segundo Almeida et al. (2002), o fato de trabalhar em condições homogêneas em termos de espécies, idade das plantas, solo e mesma iluminação (topografia suave) permitem a identificação de respostas relativamente sutis, porém de ocorrência repetitiva no dossel da cana-de-açúcar. Em sensores de bandas largas, apenas feições amplas e dominantes podem ser identificadas, com as feições mais discretas influenciando em maior ou menor grau a resposta espectral obtida. A área de estudo possui todas estas características anteriormente mencionadas sendo possível estabelecer relações entre os dados espectrais orbitais e de produtividade agroindustrial.

As bandas que foram integrantes principais dos modelos em termos de ocorrência nas onze equações de estimativa agroindustrial foram: B1 e B7 com seis, B4 com quatro, B2 e B3 com três ocorrências, respectivamente. Embora se saiba que a quantidade de biomassa da vegetação é bem relacionada com a banda B4 (Formaggio \& Epiphanio, 1988; Ponzoni, 2001; Machado 2003), esta não foi a principal componente das equações (Tabelas 2 e 3), estando ausente até mesmo no modelo de estimativa de produtividade agrícola (TCH_Real). Segundo Machado (2003), a resposta espectral da cana-de-açúcar na banda B4 próxima de seu estágio de maturação apresenta baixa correlação com a produtividade. Isso é devido a senescência das folhas, menor atividade fotossintética e menor acúmulo de água no mesófilo das folhas resultando em variações nas respostas espectrais não referentes a quantidade de biomassa. A imagem utilizada para este trabalho foi de a de junho de 2000, no mês que se inicia a colheita da variedade estudada, a RB835486 (item 6.2.2). Gitelson et al. (2002) afirmam que existem respostas espectrais dos vegetais importantes nos comprimentos de onda 550 e $700 \mathrm{~nm}$ (verde e red edge) e ressaltam a importância de estudos com outros comprimentos de onda, além da banda B4 e B3.

Outro aspecto que pode ser levado em consideração é que a variedade estudada apresenta hábito decumbente grande acamamento, principalmente em primeiro corte e/ou condições de alta fertilidade do solo (Arizono et al., 2000). A maior parte das áreas utilizadas no trabalho localizam-se perto da indústria, ou seja, são fertilizadas com 
resíduos agroindustriais (torta de filtro e vinhaça). Isso explica o fato que, embora o ano agrícola de 2000/01 tenha apresentado déficit hídrico acentuado durante o desenvolvimento da cultura (Apêndices 1 e 2), esta apresentou produtividades compatíveis aos ambientes de produção da área de estudo (Apêndice 3). A produtividade agroindustrial da cana-de-açúcar é função de muitos fatores de produção, sendo os principais a radiação interceptada, temperatura e precipitação no período de desenvolvimento, aptidão varietal e ambiente edáfico de produção (Casagrande, 1991; Lucchesi, 1995).

Para este trabalho, os IV's que mais se destacaram nos modelos de estimativa agroindustrial foram o GVI (Crist \& Cicone, 1984; Thenkabail et al., 2002) com cinco ocorrências e o GNDVI (Gitelson et al., 1996) que ocorreu em três das onze equações para as médias aritméticas (Tabela 3).

O RATIO e o SAVI foram os IV’s que não entraram na composição de nenhuma das onze equações lineares múltiplas no método das médias aritméticas. Pellegrino (2000) na usina São Martinho, Pradópolis,SP também utilizou a RB835486 e dados espectrais de campo e do NOAA/AVHRR para realizar estimativas de produtividade e IAF numa área de 694,41 ha. Ressalta que apesar de correções peculiares (particularidades), os diferentes índices de vegetação de uma forma geral estão intimamente relacionados uma vez que o NDVI pode ser obtido através do RVI e este ser a base para vários outros IV’s.

Para o modelo de produtividade agrícola (TCH_Real) as variáveis que compuseram o modelo foram as bandas B1, B7, B2 e o índice de vegetação GVI. Este último também apresentou bons resultados em Machado (2003) onde o coeficiente de determinação foi de 0,8275 na análise de regressão polinomial de $2^{\circ}$ grau com a produtividade da cana-de-açúcar, utilizando dados ETM+/LANDSAT 7 de abril, ou seja, de início de safra. Para o caso do presente modelo o GVI não obteve grande peso na equação (Tabela 3), mas entrou em sua composição com significância acima de 15\%. Gitelson et al. (2002) definem que a produtividade de uma cultura como o produto da energia solar captada ao longo da estação de desenvolvimento e a eficiência com que essa energia é convertida em biomassa, concordando com Muchow et al. (1994). As 
bandas B1 e o índice de vegetação GVI contemplam a absorção pela clorofila e carotenóides e as variáveis espectrais principais referentes a vegetação, respectivamente.

Segundo Magalhães (1987), o principal fator intrínseco à planta responsável pela elevada produção vegetal é o índice de área foliar (IAF), que varia entre as cultivares. A arquitetura foliar da cana-de-açúcar apresenta uma disposição vertical das folhas em relação ao colmo, refletindo em maior capacidade fotossintética, pois proporciona maior incidência da luz no dossel da cultura que geralmente possui uma alta densidade populacional (Goel \& Strebel, 1984). Esta afirmação concorda com Pellegrino (2000) que ressalta modelos cúbicos como os que melhor se adaptam a dados espectrais e equações de estimativa de parâmetros da cultura que envolvem folhas, como massa seca e IAF.

O Brix (BRX) foi estimado com um $\mathrm{R}^{2}$ de 0,5630 e o modelo foi composto pela banda B3 e os índices GNDVI e NDVI. O brix é o teor de sólidos solúveis totais presentes no caldo da cana e é o atributo primordial quando se pretende acompanhar o estágio de maturação da matéria-prima (Stupiello, 1987). O estádio de maturação é verificado, principalmente pelos teores de sacarose, de açúcares redutores e umidade que os colmos apresentam no decorrer do período da safra (Casagrande, 1991; Stupiello, 1987).

O modelo de estimativa da Pol \% caldo (POL) obteve $\mathrm{R}^{2}$ de 0,7416 e apresentouse como o melhor resultado de estimativa (Tabela 3). Pelegrino (2000) enumera que o ponto ótimo de se estimar a safra de cana deve se situar próximo à metade do ciclo e/ou em algum ponto no qual fatores edafoclimáticos adversos não teriam influência na produtividade final. Porém, obteve-se um $\mathrm{R}^{2}$ para a Pol \% caldo superior ao de estimativa de produtividade agrícola (TCH_Real em $\mathrm{Mg} / \mathrm{ha}$ ) que foi de 0,6935. Isso indica que dados espectrais de épocas tardias podem indicar a maturação da cana-deaçúcar como ressaltam Almeida et al. (2002), Curran (1989); Curran et al. (2001) e Fourty \& Baret (1998).

Os demais atributos como pureza \% (PZA), Pol \% cana (PCC), umidade \% (UMD), embora sejam função do Brix e da Pol \% caldo e serem obtidos através de equações (item 3.1.3) também obtiveram coeficientes de determinação acima de 0,50, 
enquanto que o $R^{2}$ para fibra \% (FBR) e ATR foram de 0,4180 e 0,4524, respectivamente. A composição química da cana-de-açúcar é muito variável, em função das condições climáticas, das propriedades físicas, químicas e microbiológicas do solo, do tipo de cultivo, da variedade, do estádio de maturação, da idade, bem como de muitos outros fatores (Stupiello, 1987). Para este trabalho, tanto a TCH_Real quanto as características tecnológicas da matéria-prima estão dentro dos limites normais (Apêndice $3)$.

Ressalta-se que todas estas características são inerentes à qualidade da matériaprima (colmos) que vai para a indústria e qualquer avaliação orbital é uma medição indireta da qualidade da produção. A qualidade tecnológica da matéria-prima a ser industrializada depende de fatores bióticos (variedade, florescimento, moléstias, respiração e transpiração dos colmos após o corte, tempo médio de permanência e decomposição microbiana) como abióticos (tipo de colheita, solo, condições agroclimáticas no momento da colheita, carregamento e transporte da matéria-prima) (Cesar \& Silva, 1993). Quanto maior o intervalo de tempo entre o corte e a moagem (TMP = tempo médio de permanência), maiores serão as perdas de sacarose. Para este trabalho, os valores de TMP da matéria prima dos setores variaram de 29,3 a 62,9 (Apêndice 3), sendo de 47,2 horas o TMP médio da variedade RB835486 na safra em estudo (2000/01). Tempos menores que 50 h são desejáveis na unidade e isto é possível para tal variedade devido seu plantio ser concentrado perto da unidade industrial. A RB835486 é indicada para plantios perto da indústria, devido sua baixa densidade de carga e intenso tombamento, o que inviabiliza o transporte a longas distâncias (Arizono et al., 2000).

$\mathrm{O}$ resultado de $\mathrm{R}^{2}$ para o modelo de estimativa de impurezas \% (IMP) não foi satisfatório. Isso ocorre por esta ser uma característica da matéria-prima a ser industrializada e é função do tipo e condições que se procede a colheita (Cesar \& Silva, 1993), ou seja, não pode ser determinada com a matéria prima ainda no campo, somente após o carregamento e o transporte.

Esta variedade apesar de muito rústica e ter sido a mais plantada na safra em questão (2000/01), apresenta como inconveniente uma susceptibilidade intermediária a 
ferrugem (Puccinia melanocephala), porém sem acarretar danos a sua produtividade, desde que plantada e manejada nas épocas corretas e em áreas menos favoráveis ao aparecimento da doença (Giglioti et al., 1999). Na maioria das áreas de produção contempladas neste trabalho, o plantio da RB835486 ocorre em meados de abril e maio e esta é colhida em junho e julho, com cerca de 14 meses em cana-planta, evidenciando seu caráter precoce. Isso pode representar influência no comportamento espectral da variedade, embora mudanças fisiológicas e sintomas foliares não sejam indicativos de diferenças de produtividade (Al-Abbas et al., 1974).

Considerando-se todos os seus aspectos botânicos e tecnológicos, a RB835486 é a variedade precoce de maior retorno econômico de diversas empresas desde que colhida de junho a agosto, embora nessa época possa brotar devagar e irregularmente (Arizono et al., 2000). Foi a principal variedade colhida na safra do trabalho (Tabela 1). Os canaviais deste trabalho, apesar de serem de primeiro corte (cana-planta), sofreram alto déficit hídrico na ocasião de seu estabelecimento, embora este fato também não tenha sido o preponderante nas diferenças espectrais entre os talhões estudados.

\subsubsection{Comparação entre os métodos de coleta de dados espectrais dos talhões}

Neste trabalho notou-se que o método de coleta dos dados espectrais tem influência na estimativa de características agroindustriais de talhões de cana-de-açúcar. De maneira geral os atributos dos 70 talhões analisados foram melhor estimados quando se realizou a coleta dos dados espectrais pelo método da média aritmética dos pixels. Os trabalhos recentes indicam que os índices de vegetação (IV's) são dados que estão relacionados a produtividade agrícola das culturas (Almeida et al., 2002; Machado, 2003; Thenkabail et al., 2002) mas também pode-se notar a participação destes na confecção dos modelos de estimativa para os atributos tecnológicos (Tabelas 2 e 3).

Almeida et al. (2002) ressaltam que dados de sensoriamento remoto, de histórico e avaliações de campo possibilitam a criação de classes (padrões) para interpretação das imagens e tomada de decisão. Por isso pretendeu-se estabelecer através de classificação não supervisionada e banco de dados, padrões espectrais dos talhões e os atributos de 
produtividade agroindustrial da matéria-prima neles contida, na ocasião da passagem do sensor.

Muchow et al. (1994) ressaltam que a biomassa (g.m ${ }^{-2}$ ) de uma cultura de canade-açúcar é função da quantidade de radiação interceptada e a eficiência do uso desta radiação, ou seja, a performance fotossintética. A produtividade de cana é expressa pelo peso $(\mathrm{Mg} / \mathrm{ha})$ de colmos frescos industrializáveis. Embora não tenha sido contemplado no trabalho destes autores, outro fator de determinação de produtividade econômica de cana-de-açúcar é a partição da biomassa em sacarose que constitui uma das pretensões deste trabalho. Neste trabalho obteve-se $R^{2}=0,5222$ e 0,6935 para a estimativa de produtividade agrícola (TCH_Real), nos métodos de médias ponderadas e aritméticas, respectivamente. As produtividades dos talhões oscilaram entre as estimativas iniciais da usina (TCH_Est) embora tenham ficado um pouco abaixo, devido ao intenso déficit hídrico ocorrido na referida safra (Tabela 1 e Apêndice 3).

O único parâmetro que apresentou melhor resultado na estimativa pelo método de médias ponderadas foi o ATR com $\mathrm{R}^{2}$ de 0,5012 contra 0,4524 pelas médias aritméticas. Este é o parâmetro mais importante atualmente na remuneração da cana-deaçúcar sendo este função da Pol \% cana e do teor de açúcares redutores da matéria-prima (Consecana, 1999). O resultado de estimativa deste parâmetro, independente do método de coleta dos dados espectrais, foi inferior ao de Beauclair \& Scarpari (2002). Estes utilizaram análise de regressão stepwise para gerar um modelo de maturação de cana-deaçúcar em uma usina do estado de São Paulo, utilizando dados de produção (Mg/ha e kg ATR/Mg cana) de três safras, valores de horas-frio e de precipitação, parâmetros altamente relacionados a maturação da cana-de-açúcar. Obtiveram um coeficiente de determinação $\left(\mathrm{R}^{2}\right)$ de 0,69, ou seja, 69 \% das variações na quantidade de ATR da cana foram explicadas pelo modelo e elucidam que os $31 \%$ restantes foram devido a fatores que não foram contemplados no modelo como, por exemplo, diferenças varietais quanto a maturação e concluíram ser possível estimar os valores de ATR com até dois meses de antecedência da colheita das canas de ano, na usina estudada. O fato de inserir variáveis climáticas nos modelos de estimativa é desejável concordando com Rudorff \& Batista (1990) e confirma que dados espectrais e de outros tipos se aplicam a estimativas de 
características das culturas. Neste trabalho enfatizou-se somente a abordagem espectral da cultura de cana-de-açúcar.

Muchow et al. (1994) elucidam que os três fatores climáticos principais que afetam a produtividade das culturas são a radiação, temperatura e precipitação. Modelos estatísticos de crescimento de cana-de-açúcar que contemplam variáveis como eficiência fotossintética e interceptação da radiação são confiáveis somente para os dados locais não podendo ser extrapolados para outras regiões diferentes daquelas em que as relações de regressão foram desenvolvidas. Assim como no presente trabalho, os autores também avaliaram a cana-de-açúcar cultivada em abril e irrigada com diferentes lâminas de irrigação. Concluíram que o acúmulo de biomassa cessa bem antes do período de colheita, cerca de 360 dias (12 meses) após o plantio, sendo que a variedade foi colhida aos 15,5 meses. A radiação solar interceptada pela cultura porém, continua mesmo após o final do período vegetativo, o que pode acarretar em diferenças nas respostas espectrais captadas pelo sensor orbital (Gitelson et al., 2002), por isso as bandas B1 e B3 participaram da maioria das equações, para o método das médias aritméticas (Tabela 2).

A cana-de-açúcar, ao atingir seu estágio máximo de desenvolvimento apresenta, aproximadamente, um índice de área foliar 7, o que corresponde a uma área foliar 7 vezes maior que a área de solo ocupada. Isto confere à cultura uma grande capacidade fotossintética e de troca de substâncias (água, nutrientes e gases) com o ambiente (Fauconnier \& Bassereau, 1975). No caso deste trabalho, as respostas espectrais dos talhões também foram influenciadas pela presença de palha devido ao adiantado estágio de maturação na ocasião de passagem do sensor e ao intenso acamamento que a variedade possui. Isso justifica os valores de estimativa de produtividade obtidos (Tabela 2 e 3) serem menores ou iguais que outros trabalhos como Rudorff \& Batista (1990) que obtiveram baixos valores de $\mathrm{R}^{2}(0,14$ a 0,59$)$ quando utilizaram somente o RVI para compor as estimativas de produtividade em três anos de safra. $O \mathrm{R}^{2}$ melhorou para 0,50 a 0,69 quando utilizaram dados meteorológicos em conjunto com o modelo espectral. Wiegand et al. (1996) obtiveram $\mathrm{R}^{2}$ de 0,77 para o a produtividade total em relação ao NDVI de imagens SPOT que apresentam melhor resolução espacial. Ressalte que os autores realizaram coletas de tecidos e solos no campo para obter padrões e calibrar os 
dados de sensor orbital, concordando com Schmidt et al. (2001). Para este trabalho não houve avaliações no campo e utilizou-se dados históricos de uma unidade produtora. Neste caso, os dados embora confiáveis podem estar sujeitos a falhas, concordando com Almeida et al. (2002).

Machado et al. (2002) desenvolveram uma metodologia para direcionar a amostragem para estimativa de produtividade de cana-de-açúcar na usina São João em Araras, SP. Utilizando imagens orbitais ETM+/LANDSAT 7 e um ambiente SIG, os autores obtiveram uma redução no erro das estimativas de 4 \% no método convencional para $2 \%$, com o auxílio de ferramentas de geoprocessamento. Almeida et al. (2002) elucidam que estimativas de produtividade de cana-de-açúcar por sensores orbitais ASTER e ETM+ foram mais precisas que as realizadas pela usina no método convencional, chegando a erros de estimativa da ordem de 3,09 e 5,65 \% respectivamente para os dois sensores, contra 9,96 \% da usina. Ressalta-se que apesar das avaliações deste trabalho ter sido baseadas somente em dados espectrais, teve-se a preocupação com a estimativa da qualidade tecnológica da cana-de-açúcar, ausente nos trabalhos anteriormente citados.

O brix ${ }^{0}(\mathrm{BRX})$ e a umidade \% (UMD) foram os parâmetros que apresentaram resultados de estimativa semelhantes em ambos os métodos. Para o Brix obteve-se $\mathrm{R}^{2}$ de 0,5630 e 0,5690 e para umidade 0,6397 e 0,6239 para os métodos de médias ponderadas e aritméticas, respectivamente. O brix é o teor de sólidos solúveis (açúcares, sais e cinzas) presentes no caldo e a umidade é o teor de água da matéria-prima entregue a indústria. A estimativa da pol \% caldo apresentou melhor resultado no método das médias aritméticas com $\mathrm{R}^{2}$ 0,7416 contra 0,5865 quando se utilizou os dados médios ponderados dos talhões.

A pureza \% é a relação entre o teor de sacarose do caldo e o brix (Cesar \& Silva, 1993) e apresentou resultados satisfatórios somente no método das médias aritméticas, com $\mathrm{R}^{2}$ 0,6306 contra 0,2193 para o outro método.

O pol \% cana (PCC) apresentou melhor estimativa no método das médias aritméticas com $\mathrm{R}^{2} 0,6200$, enquanto que no outro método este resultado caiu para 0,5048. A fibra \% também apresentou melhor resultado no método das médias 
aritméticas em relação ao das médias ponderadas embora em tenha sido considerado baixo ambos os casos baixos, com $\mathrm{R}^{2}$ de 0,4180 para o primeiro contra 0,2963 para o segundo método.

A impureza \% foi o parâmetro com menor coeficiente de determinação $\left(R^{2}\right)$ em ambos os casos, apresentando tendência de baixa confiabilidade na estimativa com $\mathrm{R}^{2}$ de 0,09 nas duas situações de coleta de dados. Este resultado era esperado uma vez que este parâmetro tecnológico é função do tipo de colheita (crua ou queimada) e condições climáticas que se procede a colheita/carregamento da matéria-prima (Cesar \& Silva, 1993).

Em relação a outros modelos de estimativa de produtividade citados na literatura, pode-se dizer que o deste trabalho apresentou resultado satisfatório, dadas as dificuldades de isolar fatores que influenciam na produtividade e utilizando somente dados espectrais orbitais. Outros trabalhos não contemplam os aspectos tecnológicos da cultura que são atualmente responsáveis pela sua remuneração.

Yocum et al. (1964) ressaltam que a densidade de fluxo dentro da cobertura vegetal (dosel) decresce exponencialmente em função do índice de área foliar acumulado de cima para baixo. As interações da radiação solar com as plantas condicionam o microclima interno da cobertura vegetal e a quantidade e qualidade de radiação disponível dentro do dossel afetam os processos fisiológicos das plantas (Machado et al., 1985). Esta variedade apesar de muito rústica e ter sido a mais plantada na safra em questão (2000/01), apresenta como inconveniente uma susceptibilidade intermediária a ferrugem (Puccinia melanocephala) porém sem acarretar danos a sua produtividade, desde que plantada e manejada nas épocas corretas e em áreas menos favoráveis ao aparecimento da doença (Giglioti et al., 1999). Na maioria das áreas de produção contempladas neste trabalho, o plantio da RB835486 ocorre em meados de abril e maio e esta é colhida em junho e julho, com cerca de 14,5 meses em cana-planta, evidenciando seu caráter precoce. Acredita-se que este fator não tenha sido o principal nas diferenças espectrais entre os talhões, porém é sabido que efeitos de stresses, deficiências nutricionais e injúrias por pragas influenciam nas respostas espectrais dos 
dosséis (Al-Abbas et al., 1974; Mariotti et al., 1996; Masoni et al., 1993 e 1994; Wiegand et al., 1996).

\subsection{Conclusões}

É possível estimar a produtividade agroindustrial da cana-de-açúcar através de dados orbitais do ETM+/LANDSAT 7.

As características agroindustriais da cana-de-açúcar foram estimadas com um coeficiente de determinação $\left(\mathrm{R}^{2}\right)$ de 0,6935 para a produtividade agrícola TCH_Real (Mg/ha) e, para os atributos tecnológicos, as melhores estimativas foram para POL e UMD com $\mathrm{R}^{2}$ de 0,7416 e 0,6397 respectivamente. O melhor método de coleta de informações espectrais foi o das médias aritméticas, em relação aos dados coletados através de uma classificação não-supervisionada.

Imagens tardias são adequadas para estudos de características tecnológicas da cultura da cana-de-açúcar embora tais parâmetros sejam inerentes à matéria-prima e, portanto, obtidas indiretamente por sensores orbitais. 
Tabela 1. Características dos setores utilizados no trabalho (Fonte: Cocal Açúcar e Álcool).

\begin{tabular}{ccccc}
\hline Setor & Área (ha) & $\mathrm{N}^{0}$ de Talhões & \multicolumn{2}{c}{ Produtividade Média $(\mathrm{Mg} / \mathrm{ha})^{1}$} \\
\cline { 3 - 5 } & & & Estimada & Real \\
\hline 003 & 206,71 & 20 & 86 & 83,71 \\
004 & 271,00 & 24 & 90 & 85,05 \\
011 & 181,23 & 18 & 100 & 101,66 \\
361 & 39,47 & 3 & 91 & 92,46 \\
366 & 44,70 & 4 & 96 & 100,45 \\
371 & 20,46 & 1 & 93 & 90,89 \\
\hline Total & 763,57 & 70 & 92,6 & 92,37 \\
\hline
\end{tabular}

${ }^{1}$ Médias por setores 
Tabela 2. Equações dos atributos agroindustriais de cana-de-açúcar, através dos dados espectrais e índices de vegetação coletados através de médias ponderadas das classes

\begin{tabular}{|c|c|c|}
\hline Atributo $^{1}$ & Equações Múltiplas ${ }^{2}$ & $\mathrm{R}^{2}$ \\
\hline TCH_Real & $-245,35533+370,66313 *$ GNDVI + 627,43077*B5 - 142,30912*RVI & 0,5222 \\
\hline BRX & $19,52677-54,54382 * \mathrm{~B} 7+83,29049 * \mathrm{~B} 2$ & 0,5690 \\
\hline POL & $22,05346-85,86643 * \mathrm{~B} 5+160,50223 * \mathrm{~B} 2+10,81231 * \mathrm{RVI}$ & 0,5865 \\
\hline PZA & $94,17545-81,15965 * \mathrm{~B} 5-44,63047 * \mathrm{~B} 4-664,53352 * \mathrm{~B} 1+422,97239 * \mathrm{~B} 2$ & 0,2193 \\
\hline PCC & $31,20568+39,90926 * \mathrm{~B} 4-68,90294 * \mathrm{~B} 5-24,03979 * \mathrm{NDVI}$ & 0,5048 \\
\hline UMD & $96,33026-33,81490 * \mathrm{~B} 4+74,28796 * \mathrm{GNDVI}+195,02849 * \mathrm{~B} 7-134,46210 * \mathrm{RVI}-60,08821 * \mathrm{SAVI}+0,03705 * \mathrm{GVI}$ & 0,6239 \\
\hline FBR & $2,40823-392,24611 * \mathrm{~B} 1+197,39906 * \mathrm{~B} 2$ & 0,2963 \\
\hline ATR & 56,74136 + 346,46560*GNDVI - 642,79366*B5 + 1709,13171*B2 - 198,64400*NDVI & 0,5012 \\
\hline IMP & $-0,37110+6,90434 * \mathrm{RVI}$ & 0,0971 \\
\hline \multicolumn{3}{|c|}{$\begin{array}{l}{ }^{1} \text { TCH_Real = Mg de cana/ha real; BRX = Brix } ; \text { POL = Pol \% caldo; PZA = Pureza \%; PCC = Pol \% cana; UMD = Umidade \%; FBR = Fibra \%; ATR = Kg de ATR/Mg } \\
\text { cana; IMP = Impureza } \% .\end{array}$} \\
\hline \multicolumn{3}{|c|}{$\begin{array}{l}\text { ² Bandas do Sensor ETM+: B1 (450-520 nm); B2(520-600 nm); B3 (630-690 nm); B4 (770-900 nm); B5 (1550-1750 nm) B7(2090-2350 nm) e Índices de Vegetaçãa } \\
\text { (Bannari et al., 1995): NDVI = (NIR - Red) / (NIR + Red); RATIO = Red/NIR; GVI = - 0,24717*TM1 - 0,16263*TM2 - 0,40639*TM3 + 0,85468*TM4 + }\end{array}$} \\
\hline
\end{tabular}




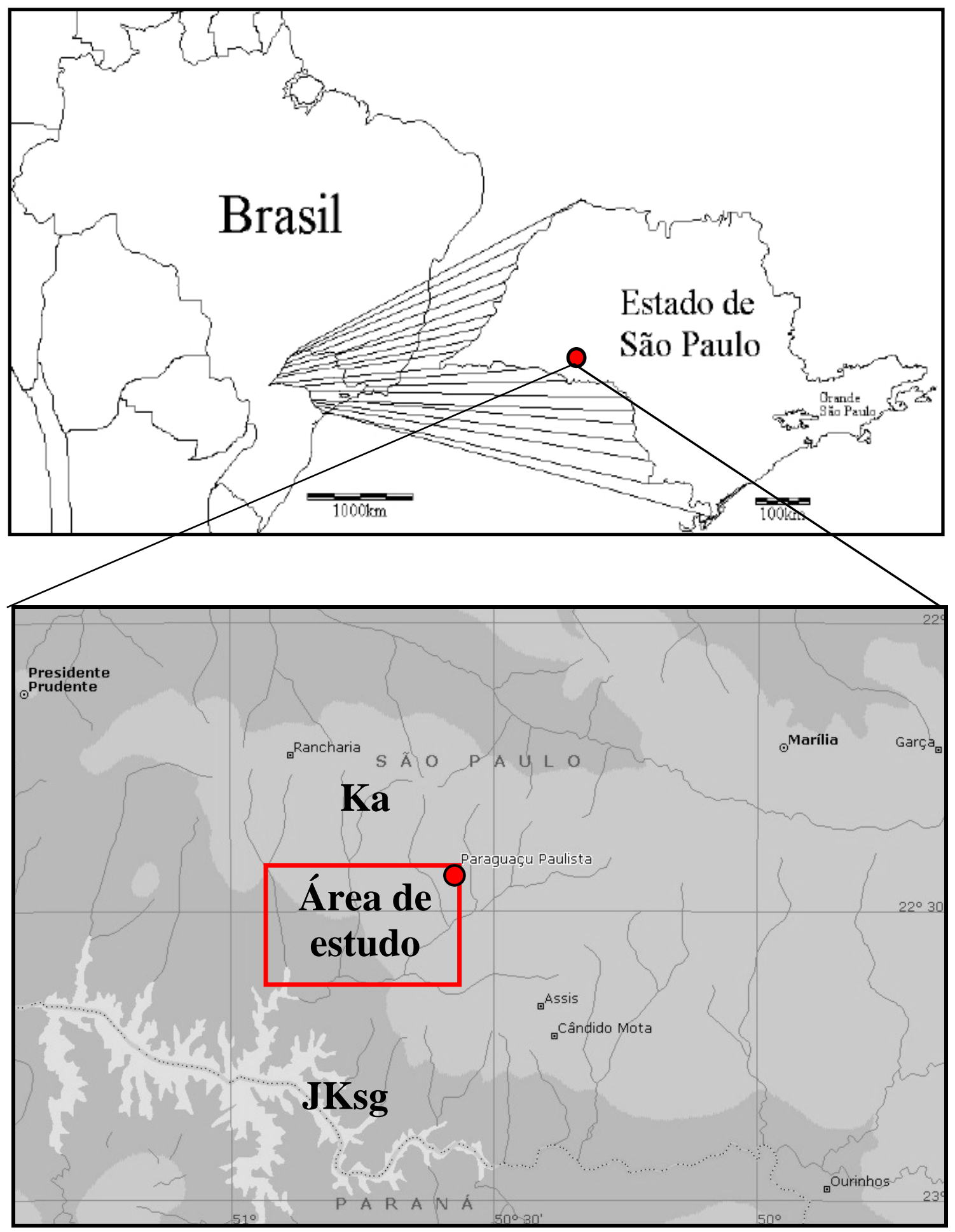

Figura 1 - Localização da área de estudo, município de Paraguaçu Paulista, SP e suas formações Geológicas Adamantina (Ka) e Serra Geral (JKsg) 


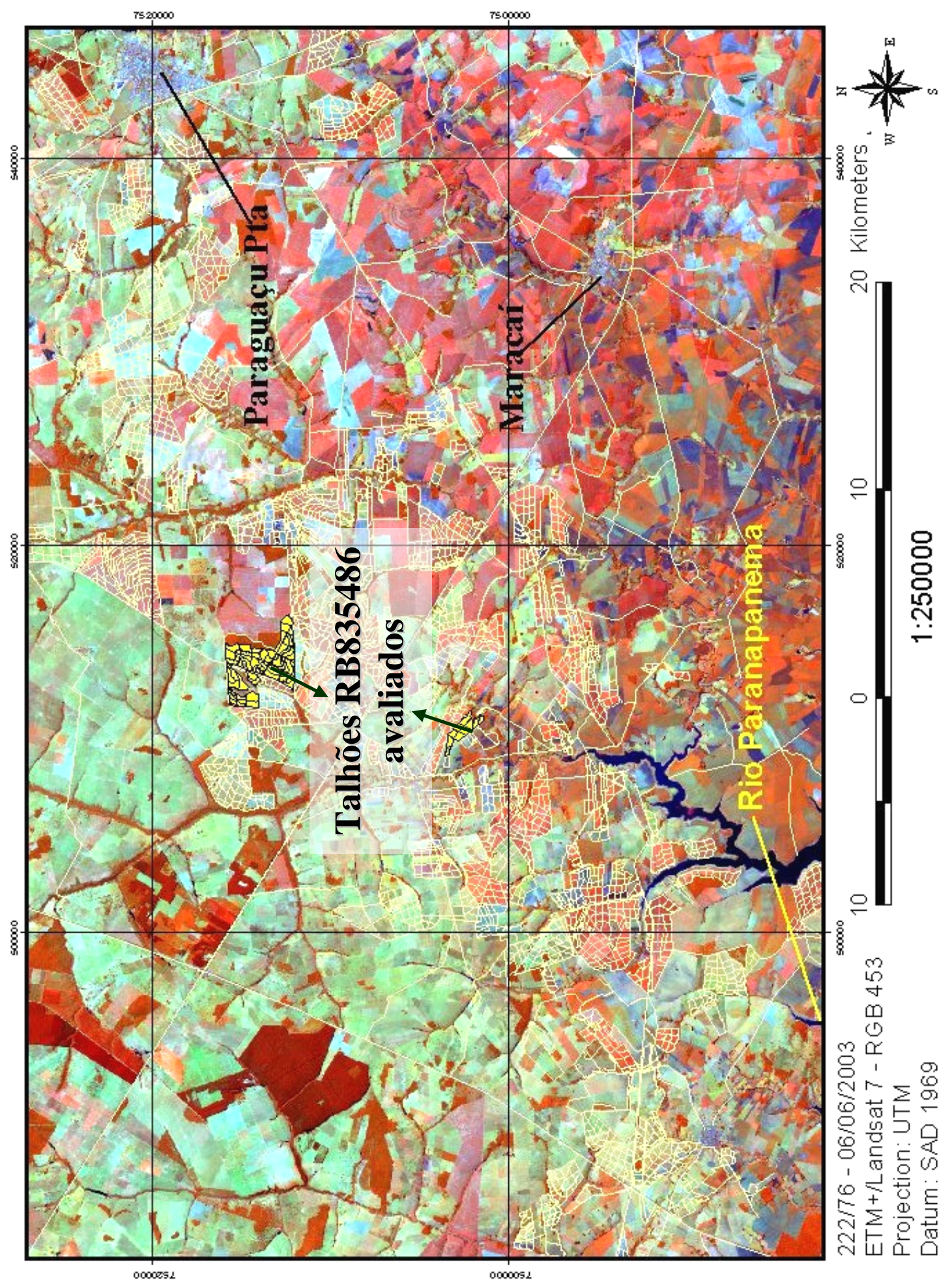

Figura 2 - Imagem falsa-cor (RGB-453) do ETM+ da área de estudo, de 06/06/2000 


\section{REFERÊNCIAS BIBLIOGRÁFICAS}

AL-ABBAS, A.H.; BARR, R.; HALL, J.D.; CRANE, F.L., BAUMGARDNER, M.F. Spectra of normal and nutrient deficient maize leaves Agronomy Journal, v.66,p.16-20., 1974.

ALFONSI, R.R.; PEDRO, M.J.; BRUNINI, O.; BARBIERI, V. Condições climáticas para a cana-de-açúcar In: PARANHOS, S.B. Cana-de-açúcar: cultivo e utilização. São Paulo: Fundação Cargill, 1987. v.1,p.42-87.

ALMEIDA, C.F.G.; SANTAELLA, M. BARATA, M.Q.F.; DODI JUNIOR, C. Sistema computacional para gerenciamento agrícola da lavoura de cana-de-açúcar (Sistema GA Versão 2.0) In: SEMINÁRIO COPERSUCAR DE TECNOLOGIA AGRONÔMICA, 6, Piracicaba/SP, Anais. Piracicaba: Centro de Tecnologia Copersucar, p.39-352, 1994.

ALMEIDA, T.I.R. Nova técnica de sensoriamento remoto para diagnóstico do vigor de cana em áreas extensivas Saccharum, Sociedade dos Técnicos Açucareiros e Alcooleiros do Brasil, Piracicaba: STAB, 2000. v.2, p.16-17. 
ALMEIDA, T.I.R.; ROSSETO, R.; SOUZA FILHO, C.R. Imagens ASTER e LANDSAT ETM aplicadas à previsão de safra de cana-de-açúcar no estado de São Paulo: discussão metodológica e primeiros resultados. In: CONGRESSO NACIONAL DA STAB, 8, Recife, Anais.. Recife: STAB, 2002. p.488-492.

ARIZONO, H.; GHELLER, A.C.A.; MASUDA, Y.; HOFFMANN, H.P.; BASSINELO, A.I.; GIGLIOTI, E.E.; MENEZES, L.L.; MATSUOKA, S. Guia das principais variedades de cana-de-açúcar RB 2000. Araras: UFSCar/CCA/DBV, 2000. 12p.

ARONOFF, S. Geographic Information Systems: A management perspective. WSL Publications, 1989. Otawa: Canada, 1989. 267p.

BANNARI, A.; MORIN, D.; BONN, F.; HUETE, A.R. A review of vegetation indices Remote Sensing Reviews, v.13, p.95-120, 1995.

BARET, F. GUYOT, G. Potentials and limits of vegetation indices for LAI and APAR assessments. Remote Sensing of Environment, v.35, p.161-173, 1991.

BARET, F.; JACQUEMOUND, S.; HANOCQ, J. F. The soil line concept in remote sensing Remote Sensing of Environment, v.7, n.1, p.1-18, 1993.

BATISTA, G.T.; MENDONÇA, F. J.; LEE, D.C.L.; TARDIN, A.T; CHEN, S.C.; NOVAES, R.A. Uso de sensores remotos a bordo de satélite e aeronave na identificação e avaliação de áreas de culturas para fins de previsão de safras. São José dos Campos/SP: INPE, 1978. p.41

BATISTA, G.T.; NOVAES, R.A.; TARDIN, A.T; MENDONÇA, F. J.; LEE, D.C.L.; SANTOS, J.R.; CHEN, S.C.; TOSCANO, L.P. Atividades do projeto estatísticas agrícolas durante o ano de 1975. São José dos Campos/SP: INPE, 1976. p.32. 
BEAUCLAIR, E.G.F.; SCARPARI, M.S. Modelo de previsão de acúmulo de sacarose para cana-de-açúcar (Saccharum spp.) através de parâmetros climáticos. In: CONGRESSO NACIONAL DA STAB, 8, Recife, Anais.. Recife: STAB, 2002. p.561-565.

BEN-GERA, I.; NORRIS, K. Determination of moisture content in soybeans by direct spectrophotometry. Israeli Journal of Agricultural Research, v.18, p.124-132, 1968.

BRONER, I.; BAUSCH, W.; WESTFALL, D.; KHOSLA, R. Decision support for crop management using remote sensing In: WORLD CONGRESS OF COMPUTERS IN AGRICULTURE AND NATURAL RESOURCES, 3, Iguaçu Falls, Brazil, Proceedings. Paraná: ASAE, 2002.

CASAGRANDE, A. A. Tópicos de morfologia e fisiologia da cana-de-açúcar. Jaboticabal: Funep, Unesp, 1991. 157p.

CESAR, M. A. A.; SILVA, F. C. A cana-de-açúcar como matéria-prima para a indústria sucroalcooleira. Piracicaba, ESALQ, 1993. 108p.

CHANG, C.W.; LAIRD, D.A.; MAUSBACH, M.J.; HURBURGH JUNIOR, C.R. Nearinfrared reflectance spectroscopy - Principal components regression analyses of soil properties. Soil Science Society of America Journal, v.65, p. 480-490, 2001.

CHAPELLE, E.M.; KIM, M.S.; McMURTREY J.E. Ratio analysis of reflectance spectra (RARS): an algorithm for the remote estimation of the concentrations of chlorophil A, chlorophil B and carotenoids in soybean leaves. Remote Sensing of Environment, v.39, n.3, p. 239-247, 1992. 
CLEVERS, J.G.P.W. The use of imaging spectrometry for agricultural applications ISPRS Journal of Remote Sensing v.54, p.299-304, 1999.

CONSELHO DOS PRODUTORES DE CANA-DE-AÇÚCAR, AÇÚCAR E ÁLCOOL DO ESTADO DE SÃO PAULO - Manual de Instruções. Piracicaba: CONSECANA, 1999. 92p.

COOPERATIVA DOS PRODUTORES DE CANA, AÇÚCAR E ÁLCOOL DO ESTADO DE SÃO PAULO Quinta geração de variedade de cana-de-açúcar. Boletim Técnico Copersucar, Piracicaba/SP: Copersucar, 1995. 24 p.

COOPERATIVA DOS PRODUTORES DE CANA, AÇÚCAR E ÁLCOOL DO ESTADO DE SÃO PAULO. Recomendação de adubação para a cultura da cana-de-açúcar. Piracicaba/SP: Centro de Tecnologia Copersucar, 1988. 7 p.

CORÁ, J. E.; MARQUES JUNIOR., J. The Potential for Precision Agriculture for Soil and Sugarcane Yield Variability in Brazil In: INTERNATIONAL CONFERENCE ON PRECISION AGRICULTURE AND OTHER PRECISION RESOURCES MANAGEMENT, 5, Bloomington, Minnesota: Veridian, 2000. p.183-197.

CREPANI, E. Princípios básicos de sensoriamento remoto. São José dos Campos: CNPQ/INPE, 1993. 45p.

CRIST, E.P.; CICONE, R.C. Application of the Tasseled cap concept to simulated Thematic Mapper data Photogrammetric Engineering \& Remote Sensing, v 50, p. 343-352, 1984.

CROSTA, A. P. Processamento digital de imagens de sensoriamento remoto. Campinas: UNICAMP, 1992. 170 p. 
CURRAN, P.J. Remote sensing of foliar chemistry Remote Sensing of Environment v30, p271-278, 1989.

CURRAN, P. J.; DUNGAN, J. L.; PETERSON, D. L. Estimating the foliar biochemical concentration of leaves with reflectance spectrometry: Testing the Kokaly and Clark methodologies Remote Sensing of Environment, v.76, p.349-359, 2001.

CURRAN, P. J.; DUNGAN, J. L.; MACLER, B.A.; PLUMMER, S.E. The effect of a red leaf pigment on the the relationship between "red edge" and chlorophyll concentration Remote Sensing of Environment, v.35, p.69-76., 1991.

DATT, B. Visible/near infrared reflectance and chlorophyll content in Eucaliptus leaves International Journal of Remote Sensing, v.20, n.20 p 2741-2759, 1999.

DEMATTÊ, J.A.M.; NANNI, M.R. Weathering sequence of soil developed from basalt as evaluated by laboratory (IRIS), airborne (AVIRIS) and orbital (TM) sensors International Journal of Remote Sensing, v.4, n.23, p.4715-4738, 2003.

DEMATTÊ, J.A.M.; HUETE A.R.; FERREIRA JUNIOR. L.G.; ALVES M.C.; NANNI M.R.; CERRI, C.E. Evaluation of tropical soils through ground and orbital sensors In: INTERNATIONAL CONFERENCE ON GEOSPATIAL INFORMATION IN AGRICULTURE. AND FORESTRY, 2, Lake Buena Vista, Florida, 2000. Proceedings, Florida: Erim, 2000. v.2, p. 34-41.

DEMATTÊ, J.A.M.; DEMATTÊ, J.L.I.; CAMARGO, W.P.; FIORIO, P.R. Remote sensing in the recognition and mapping of tropical soils developed on topographic sequences Mapping Sciences and Remote Sensing, 38, n.2, p79-102, 2001. 
EMPRESA BRASILEIRA DE PESQUISA AGROPECUÁRIA Centro Nacional de Pesquisa de Solos. Sistema Brasileiro de Classificação de Solos. Brasília: Serviço de Produção. 1999. 412 p.

ENVI 3.6, 2003 Environment of Visualizing Images Manual de Instruções em Português disponível em www.sulsoft.com.br, (20 de jun. 2003).

EPIPHANIO, J. C. N.; FORMAGGIO, A. R. Abordagens de uso de número digital e de reflectância em sensoriamento remoto com dados de satélites. In: SIMPÓSIO BRASILEIRO DE SENSORIAMENTO REMOTO, 5., Natal, 1988. Anais. São José do Campos : INPE, 1988,. p. 400-405.

ENVIRONMENT SYSTEM RESEARCH INSTITUTE, 1996 ArcView GIS 3.2 - The geographic information system for everyone ESRI: Thomas G. Lane, 1996. 254p.

FAUCONNIER, R.; BASSEREAU, D. La caña de azucar: tecnicas agricolas y producciones tropicales. Barcelona: Blume, 1975. 433p.

FERNANDES, A.; SOUZA, P.F. Análise direta da cana-de-açúcar em ensaios de competição de variedades através do NIR In: SEMINÁRIO COPERSUCAR DE TECNOLOGIA AGRONÔMICA, 7, Piracicaba/SP, Anais. Piracicaba: Centro de Tecnologia Copersucar, 1997. p.37-44.

FNP CONSULTORIA \& COMÉRCIO Agrianual, 2003: Anuário da Agricultura Brasileira. São Paulo, 2003.

FORMAGGIO, A.R.; EPIPHANIO, J.C.N. Estudos radiométricos das culturas de trigo e de feijão em três tipos de latossolos. In: SIMPÓSIO BRASILEIRO DE SENSORIAMENTO REMOTO, 5., Natal, 1988. Anais. São José dos Campos: INPE, p. 405-410, 1988. 
FOURTY, T.; BARET, F.G. On spectral estimates of fresh leaf biochemistry, International Journal of Remote Sensing v.19, n.7, p. 1283-1297, 1998.

FRANÇA, G.V.; DEMATTÊ, J.A.M. Levantamento de solos e interpretação fotográfica dos padrões desenvolvidos em solos originados do arenito Bauru. Scientia Agricola, v50, n.1, p.77-86, 1993.

FRITZ, L.W. The era of commercial earth observation satellites Photogrammetric Engineering \& Remote Sensing, v 62, n. 1, p.39-45, 1996.

GALVÃO, L.S.; VITORELLO, I. Variability of laboratory measured soil lines from southeastern Brazil. Remote Sensing of Environment, v.6, n.2, p.166-181., 1998.

GHELLER, A.C.A.; MATSUOKA, S.; GARCIA, A.A.F.; NASCIMENTO, R. Metodologia para estimativa da produtividade industrial da cana-de-açúcar. In: CONGRESSO NACIONAL DA STAB, 8, Recife, 2002, Anais. Recife: STAB, 2002. p.483-486.

GIGLIOTI, E.A.; ZAVAGLIA, L.P.; MENEZES, L.L.; MOURA, G.L.; MATSUOKA, S. Resistência e tolerância da cana-de-açúcar: o caso da RB835486 Araras, UFSCar/CCA/DBV, 1999. 10p.

GITELSON, A.A.; KAUFMAN, Y.J.; MERZLYAK, M.N. Use of a chanel in remote sensing of global vegetation from EOS-MODIS. Remote Sensing of Environment, v.58, p.289-298, 1996.

GITELSON, A.A.; MERZLYAK, M.N. Remote estimation of chlorophyll content in higher plant leaves International Journal of Remote Sensing, v.18, n.12 p 26912697, 1997. 
GITELSON, A.A.; STARK, R.; GRITS, U. RUNDQUIST, D. KAUFMAN, Y. DERRY, D. Vegetation and soil lines in visible spectral space: a concept and technique for remote estimation of vegetation fraction. International Journal of Remote Sensing v.23, n.13 p 2537-2562, 2002.

GOEL, N.S.; STREBEL, D.E. Simple beta distribution representation of leaf orientation in vegetation canopies Agronomy Journal, v.76,p.800-803, 1984.

HORLER, D.N.H; DOCKRAY, M.; BARBER, J. The "red edge” of plant leaf reflectance International Journal of Remote Sensing, v.2, p.273-288, 1983.

HUETE, A.R. A soil-adjusted vegetation index (SAVI), Remote Sensing of Environment, v.25, p.295-309, 1988.

HUETE, A.R. Soil influences in remotely sensed vegetation-canopy spectra. In: ASRAR, G. (Ed.). Theory and application of optical remote sensing, New York: Wiley Interscience, 1989. p.107-141.

HUETE, A.R. Extension of soil spectra to the satellite: Atmosphere, geometric and sensor considerations Photo Interpretation, v.34, n.2, p.101-114, 1996.

HUETE, A.R.; JACKSON, R.D.; POST, D.F. Spectral response of plant canopy under different soil background Remote Sensing of Environment, v.17, p. 37-53, 1985.

INSTITUTO DE PESQUISAS TECNOLÓGICAS DO ESTADO DE SÃO PAULO. Mapa geológico do Estado de São Paulo São Paulo: IPT, DMGA, 1981. v.1. 126p. Escala 1:500.000.

IPPOLITI-RAMILO, G. A.; EPIPHANIO, J. C. N.; SHIMABUKURO, Y. E.; FORMAGGIO, A. R. Sensoriamento Remoto orbital como meio auxiliar na previsão de safras. Agricultura em São Paulo, v.46, n.1, p.89-101, 1999. 
JACKSON, R. D.; HUETE, A. R. Interpreting vegetation indices. Preventive Veterinary Medicine n.11, p.185-200, 1991.

JOAQUIM, A.C.; DONZELLI, J.L. Desenvolvimento do geoprocessamento na cultura da cana-de-açúcar: Identificação varietal usando imagens de satélite - safra 98/99. . Piracicaba/SP: Centro de Tecnologia Copersucar, 1999. (Relatório de Projeto $\mathrm{n}^{\mathrm{o}}$ 9800875). 22p.

JOAQUIM, A. C. Identificação de variedades de cana-de-açúcar em três classes texturais de solos, na região de Araraquara - SP, através de análise de nível de cinza em imagens LANDSAT/TM. Campinas, 1998. 118p. Faculdade de Engenharia Agrícola FEAGRI, Universidade Estadual de Campinas.

JOAQUIM, A. C.; DONZELLI, J.L.; PINTO NETO, T.D.; PADULA, S.M.M. Utilização do Sistema de Tratamento de Imagens (SITIM) e do Sistema Geográfico de Informações (SGI) na cultura da cana-de-açúcar In: SEMINÁRIO COPERSUCAR DE TECNOLOGIA AGRONÔMICA, 6, Piracicaba/SP, 1994a, Anais. Piracicaba: Centro de Tecnologia Copersucar, 1994a, p.353-356.

JOAQUIM, A.C.; BELLINASO, I.F.; DONZELLI, J.L.; QUADROS, A.D.; BARATA, M.Q.S. . Potencial e manejo de solos cultivados com cana-de-açúcar In: SEMINÁRIO COPERSUCAR DE TECNOLOGIA AGRONÔMICA， 6, Piracicaba/SP, 1994, Anais. Piracicaba: Centro de Tecnologia Copersucar, 1994b, p.1-10.

KOFFLER, N.F. Técnicas de sensoriamento remoto orbital aplicadas ao mapeamento da vegetação e uso da terra. Geografia, v.17, n.2, p14-17, outubro, 1992. 
KOKALY, R.F.; CLARK, R.N. Spectroscopic determination of leaf biochemistry using band-depth analysis of absorption features and stepwise multiple linear regression, Remote Sensing Environment, v. 67, p. 267-287, 1999.

LEPSCH, I.F. Influência dos fatores edáficos na produção. In: CASTRO,P.R.C; FERREIRA, S.O.; YAMADA, T. (Coord.) Ecofisiologia da produção. Piracicaba: Associação Brasileira para pesquisa da Potassa e do Fosfato, 1987. p.83-98.

LILLESAND, T. M.; KIEFER, R.W. Remote sensing and Image interpretation. New York: John Wiley,. 2000. 724 p.

LUCCHESI, A.A. Processos fisiológicos da cultura da cana-de-açúcar (Saccharum spp). Boletim Técnico ESALQ/CENA, n.7, p.1-50, 1995.

LUIZ, A.J.B.; GÜRTLER, S.; GLERIANI, J.M.; EPIPHANIO, J.C.N.; CAMPOS, R.C. Reflectância a partir do número digital de imagens ETM+. In: SIMPÓSIO BRASILEIRO DE SENSORIAMENTO REMOTO, 11, Belo Horizonte, 2002, Anais. São José dos Campos: Instituto Nacional de Pesquisas Espaciais, 2003. p. 1 $-9$.

MACHADO E.C.; PEREIRA,A.R.; CAMARGO, M.B.P.; FAHL, J.I. Relações radiométricas de uma cultura de cana-de-açúcar Bragantia, n.44, v.1, p.229-238, 1985.

MACHADO, H. M. Determinação da biomassa de cana-de-açúcar considerando a variação espacial de dados espectrais do satélite LANDSAT 7/ETM+. Campinas, 2003. 59p. Dissertação (Mestrado)- Faculdade de Engenharia Agrícola FEAGRI, Universidade Estadual de Campinas. 
MACHADO, H. M.; LAMPARELLI, R.A.C.; ROCHA, J.V.; ZULLO JUNIOR, J.; PEREIRA, V.H. Utilização de dados orbitais (LANDSAT 7) e sistema de informações geográficas (SIG) na estimativa do potencial de produção da cana-deaçúcar In: IMPÓSIO INTERNACIONAL DE AGRICULTURA DE PRECISÃO, 2, Anais, Viçosa/MG, 2002. (Compact disc).

MAGALHÃES, A.C.N. Ecofisiologia da cana-de-açúcar: aspectos do metabolismo do carbono na planta. In: CASTRO,P.R.C; FERREIRA, S.O.; YAMADA, T. (Coord.) Ecofisiologia da produção. Piracicaba: Associação Brasileira para pesquisa da Potassa e do Fosfato, 1987. p.113-118.

MARIOTTI, M.; ERCOLI, L.; MASONI, A. Spectral properties of iron-deficient corn and sunflower leaves Remote sensing of Environment, v.58, p.282-288, 1996.

MASONI, A.; ERCOLI, L.;. MARIOTTI, M.; BARBIERI, P. Changes in spectral properties of ageing and senescing maize and sunflower leaves Physiologia Plantarum v.91, p.334-338, 1994.

MASONI, A.; MASSANTINI, F.; VOLTERRANI, M.;. MARIOTTI, M. Effect of water stress on spectral properties of corn (Zea mays L.) and sunflower (Helianthus annuus L.) leaves Agricoltura Mediterranea, v.123, p.72-85, 1993.

MENDONÇA, F. J. Uso de dados do LANDSAT para avaliação de áreas ocupadas com cana-de-açúcar no Estado de São Paulo. São José dos Campos, 1980. 82p.Dissertação (Mestrado), São José dos Campos/SP: INPE, 1980. 82 p.

MENDONÇA, F. J.; BATISTA, G.T.; TARDIN, A.T. Projeto CANASATE: Sensoriamento Remoto aplicado ao levantamento da cultura canavieira. São José dos Campos/SP: INPE, 1989. 17 p. 
MENDONÇA, F. J.; LEE, D.C.L.; TARDIN, A.T Estudo comparativo de interpretação automática e visual em imagem LANDSAT visando a identificação da cultura da cana-de-açúcar. São José dos Campos/SP: INPE, 1978. 18 p.

MENDONÇA, F. J.; LEE, D.C.L.; TARDIN, A.T; SHIMABUKURO, Y. E.; CHEN, S.C.; LUCHT, L.A.M.; MOREIRA, M.A.; LIMA, A.M.; MAIA, F.C.S Levantamento da área canavieira do Estado de São Paulo utilizando dados do LANDSAT ano safra 79/80. São José dos Campos/SP: INPE, 1981. v.1. 17p.

MORAN, M.S.; INOUE, Y.; BARNES, E.M. Opportunities and limitations for imagebased remote sensing in precision crop management. Remote Sensing Environment, v.61, p. 319-346, 1997.

MUCHOW, R.C.; SPILLMAN, M.F.; WOOD, A.W.; THOMAS, M.R. Radiation interception and biomass accumulation in a sugarcane crop grown under irrigated tropical conditions Australian Journal of Agricultural Research v.45, p.37-49, 1994.

NATIONAL AERONAUTICS AND SPACE ADMINISTRATION, 2002. LANDSAT 7: Basic Information, http://Landsat.gsfc.nasa.gov/main/PDF/L7_basics.pdf, (05, AUG., 2002).

NATIONAL AERONAUTICS AND SPACE ADMINISTRATION, 2003 http://ltpwww.gsfc.nasa.gov/IAS/handbook/handbook_toc.html (18 AUG., 2003).

NUNES JUNIOR, D.; PINTO, R.S.A.; KIL, R.A. Indicadores de desempenho da agroindústria canavieira Ribeirão Preto: Instituto de Desenvolvimento Agroindustrial, 1998. 119p. 
NUTTER, F.W. JUNIOR.; GUAN,.J.; PERCIFIELD, R. Assessing crop health in time and space by measuring spectral reflectance of solar radiation from plant canopies In: INTERNATIONAL CONFERENCE ON GEOSPATIAL INFORMATION IN AGRICULTURE. AND FORESTRY, 2, Lake Buena Vista, Florida, 2000. Proceedings, Florida: Erim, 2000. v.2, p. 165-175.

ORGANIZAÇÃO DE PLANTADORES DE CANA DO ESTADO DE SÃO PAULO, 2001 http://www.orplana.com.br/principal.htm (12 set. 2002).

PELLEGRINO, G.Q. Utilização de dados espectrais do satélite NOAA14/AVHRR como fonte de dados para modelos matemáticos de estimativa de fitomassa de canade-açúcar. Campinas, 2000. 109p. Tese (Doutorado). Faculdade de Engenharia Agrícola FEAGRI. Universidade Estadual de Campinas.

PLANALSUCAR/IAA Cultura da cana-de-açúcar - Manual de Orientação Coordenadoria Regional Sul, Planalsucar/Iaa. Piracicaba, 1986. p.37.

PONZONI, F.J Comportamento espectral da vegetação In: MENESES, P. R.; MADEIRA NETTO, J. S Sensoriamento Remoto: Reflectância dos alvos naturais. Brasília, DF: UnB; Planaltina: Embrapa Cerrados, 2001. 262p.

PONZONI, F.J.; GONÇALVES, J.L.M. Spectral features associated with nitrogen, phosphorus, and potassium deficiencies in Eucaliptus saligna seedling leaves International Journal of Remote Sensing, v.20, n.11, p.2249-2264, 1999.

ROBBINS, J.L.; DANEMAN, J.C. Parametric Estimating \& the Stepwise Statistical Technique National Estimator, v.4, august, 1999.

ROCHA, J.V. Uma nova tecnologia para o gerenciamento agrícola de usinas e destilarias. Álcool \& Açúcar, v.15, n.79, p.30- 35, 1995. 
ROCHA, J.V; LAMPARELLI, R.A.C. Geoprocessamento. In: CONGRESSO BRASILEIRO DE ENGENHARIA AGRÍCOLA, 27, Poços de Caldas, 1998.Anais Ed. FEAGRI, 1998. p.1-30.

RONDEAUX, G.; STEVEN, M.; BARET, F. Optimization of soil adjusted vegetation indices. Remote Sensing of Environment, v.55, p.95-107, 1996.

RUDORFF, B.F.T. Dados LANDSAT na estimativa da produtividade agrícola da canade-açúcar. São José dos Campos, 1985. 114p. Dissertação (Mestrado). Instituto Nacional de Pesquisas Espaciais.

RUDORFF, B.F.T.; BATISTA, G.T. Yield estimation of sugarcane based on agrometeorological-spectral models Remote Sensing of Environment, v.33, p.183-193, 1990.

RUDORFF, B.F.T.; BATISTA, G.T. Wheat yield estimation at farm level using TM Landsat and agrometeorological data International Journal of Remote Sensing, v.12, n.1, p.125-147, 1994.

RUDORFF, B.F.T.; SHIMABUKURO, Y.E.; BATISTA, G.T.; LEE, D.C.L. The contribution of qualitative variables to a sugarcane yield model based on spectral vegetation index. In: SIMPOSIO LATINO AMERICANO DE PERCEPCIÓN REMOTA, 7, México, 1995 Anais. Guadalajara: Lemon, 1995. p.705-708.

SABINS JUNIOR, F.F. Remote Sensing: principles and interpretations. San Francisco: W. H. Freeman, 1987. 449p. 
SCHMIDT, E.J.; GERS, C.; NARCISO, G.; FROST, P. Remote sensing in the south African Sugar Industry. In: INTERNATIONAL SOCIETY OF SUGARCANE TECHNOLOGISTS CONGRESS, 24, Brisbane, 2001. Proceedings Australia, PK Editorial Services, v.24, p.241-246.

SINGH, R.; GOYAL, R.C. SAHA, S.K.; CHHIHARA, R.S. Use of satellite spectral data in crop yield estimation surveys. International Journal of Remote Sensing,v.13, n.14, p.2583-2592, 1992.

SONG, C.; WOODCOCK, C.E.; SETO, K.C.; PAX-LENNEY, M.; MACOMBER, S.A. Classification and change detection using Landsat TM data: when and how to correct atmospheric effects? Remote Sensig of Environment v.75, p.230-244, 2001.

SRI, 2003 - Tecnologia de Informação Manual de instruções do PIMS/CS, http://www.sri.com.br/, (07 dez. 2003).

STAFFORD, J.V. Implementing Precision Agriculture in the 21th century Journal of Agricultural Engineering, v.76, p.267-275, 2000.

STATISTICAL ANALYSIS SYSTEM INSTITUTE. SAS, Software: User's guide version 8.2. Cary, 1999. 291 p.

STUPIELLO, J.P. A cana-de-açúcar como matéria prima. In: PARANHOS, S.B. Canade-açúcar: cultivo e utilização. São Paulo: Fundação Cargill, 1987. v.2, p.761-804. THENKABAIL, P.S.; SMITH, R.B.; PAUW, E. Evaluation of narrowband and broadband vegetation indices for determining optimal hyperspectral wavebands for agricultural crop characterization. Photogrammetric Engineering \& Remote Sensing, v.68, n.6, p. 607-621, 2002. 
TODD, S. W.; HOFFER, R. M. Responses of spectral indices to variations in vegetation cover and soil background. Photogrammetric Engineering \& Remote Sensing, v.64, n.9, p.915-922, 1998.

UNIVERSIDADE FEDERAL DE SÃO CARLOS - CENTRO DE CIÊNCIAS AGRÁRIAS Programa de Melhoramento Genético da cana-de-açúcar Catálogo de variedades RB, 2001 http://pmgca.dbv.cca.ufscar.br/InfoPublica/Catalogo/ (18 out. 2002).

UNIÃO DA AGROINDÚSTRIA CANAVIEIRA DE SÃO PAULO, 2003 A alta competitividade canavieira do estado de São Paulo, http://www.unica.com.br/pages/agroindustria_alta.asp, (24 mar. 2003).

WIEGAND, C.; ANDERSON, G.; LINGLE, S.; ESCOBAR, D. Soil Salinity Effects on crop growth and yield - Illustration of an analysis and mapping methodology for sugarcane. Journal of Plant Physiology, v.148, p.418-424, 1996.

YOCUM, C.S.; ALLEN, L.H.; LEMON, E.R. Photosynthesis under field conditions VI. Solar radiation balance and photosynthesis efficiency. Agronomy Journal, v.56, p.249-253, 1964.

ZULLO JUNIOR, J. Correção atmosférica de imagens de satélites e aplicações. Campinas, 1994. 189p. Tese (Doutorado) - Faculdade de Engenharia Elétrica, Universidade Estadual de Campinas, Campinas. 


\section{CONSIDERAÇÕES FINAIS}

Como se pode verificar, o uso do sensoriamento remoto orbital se justifica na avaliação de culturas de grandes áreas como é o caso da cana-de-açúcar. Ficam as seguintes considerações para pesquisas futuras:

- As geotecnologias tem grande potencial para o planejamento e tomadas de decisão na agroindústria canavieira e, na sua aplicação, devem ser considerados aspectos de interesse da unidade produtora, disponibilidade de recursos humanos e computacionais, volume de dados gerados, níveis de consulta de usuários entre outros;

- Os modelos de reconhecimento de espécies vegetais e de estimativa de produtividade através de dados espectrais devem ser calibrados com campanhas de campo nas diversas fases de desenvolvimento e anos agrícolas para serem obtidos padrões de respostas espectrais para diferentes variedades em diferentes épocas, visando obter consistência e histórico dos dados;

- A tecnologia NIRS também se aplica a avaliações de campo e laboratório para determinação da qualidade tecnológica como método auxiliar, não destrutivo e não poluente devendo ser considerado nas calibrações e integrações de métodos visando reduzir o tempo de obtenção dos dados.

- Outras variáveis relacionadas a produção agroindustrial devem ser contempladas em modelos de estimativa sejam elas biofísicas, (IAF, massa verde e seca, volume do sistema radicular, curvas de crescimento e maturação, ciclo fenológico das variedades), bioquímicas (teores de pigmentos fotossintetizantes e de nutrientes nas folhas) ou agroclimáticas (evapotranspiração, capacidade de armazenamento hídrico do solo, temperatura no desenvolvimento e maturação da cultura); 
- Sugere-se que a correção atmosférica deva ser efetuada com dados de espessura ótica da atmosfera e ozônio o mais fiéis possível em relação à época de obtenção das imagens para que conseqüentemente sejam diminuídos os erros nas estimativas, utilizando-se dados espectrais orbitais. 
APÊNDICES 
APÊNDICE 1 - Médias mensais de precipitação pluviométrica dos últimos 11 anos na área de estudo (Fonte: Cocal Açúcar e Álcool)

\begin{tabular}{|c|c|c|c|c|c|c|c|c|c|c|c|c|c|}
\hline Meses & 1992 & 1993 & 1994 & 1995 & 1996 & 1997 & 1998 & $1999^{1}$ & $2000^{1}$ & 2001 & 2002 & 2003 & Média \\
\hline JANEIRO & 40,0 & 224,0 & 202,0 & 216,0 & 404,0 & 381,0 & 87,0 & 462,3 & 104,5 & 210,0 & 240,4 & 502,5 & 256,1 \\
\hline FEVEREIRO & 77,0 & 487,0 & 106,0 & 225,0 & 185,0 & 228,0 & 183,0 & 116,7 & 332,0 & 397,0 & 150,5 & 190,6 & 223,2 \\
\hline MARÇO & 197,0 & 111,0 & 100,0 & 155,0 & 261,0 & 36,0 & 327,0 & 161,0 & 93,5 & 157,5 & 96,4 & 127,2 & 151,9 \\
\hline ABRIL & 192,0 & 49,0 & 130,0 & 112,0 & 41,0 & 84,0 & 153,0 & 101,0 & 30,5 & 58,5 & 3,0 & 134,0 & 90,7 \\
\hline MAIO & 174,0 & 94,0 & 69,0 & 72,0 & 71,0 & 77,0 & 148,0 & 108,0 & 13,0 & 195,4 & 233,0 & 41,0 & 108,0 \\
\hline JUNHO & 28,0 & 48,0 & 55,0 & 53,0 & 11,0 & 231,0 & 17,0 & 103,1 & 45,0 & 41,4 & 8,4 & 58,4 & 58,3 \\
\hline JULHO & 13,0 & 19,0 & 14,0 & 53,0 & 7,0 & 16,0 & 29,0 & 12,6 & 68,0 & 37,8 & 81,2 & 58,0 & 34,1 \\
\hline AGOSTO & 46,0 & 37,0 & 0,0 & 0,0 & 13,0 & 20,0 & 140,0 & 0,0 & 71,0 & 30,0 & 54,8 & 58,0 & 39,2 \\
\hline SETEMBRO & 241,0 & 94,0 & 39,0 & 70,0 & 100,0 & 72,0 & 134,0 & 20,4 & 159,0 & 81,0 & 116,0 & 72,0 & 99,9 \\
\hline OUTUBRO & 117,0 & 53,0 & 93,0 & 171,0 & 127,0 & 170,0 & 157,0 & 34,2 & 70,0 & 65,6 & 40,5 & 0,0 & 91,5 \\
\hline NOVEMBRO & 126,0 & 71,0 & 100,0 & 61,0 & 154,0 & 147,0 & 67,0 & 53,0 & 148,5 & 160,4 & 327,0 & 0,0 & 117,9 \\
\hline DEZEMBRO & 16,0 & 254,0 & 134,0 & 165,0 & 294,0 & 99,0 & 207,5 & 116,0 & 74,0 & 192,3 & 180,0 & 0,0 & 144,3 \\
\hline TOTAL & 1.267 & 1.541 & $1.042,0$ & $1.353,0$ & $1.668,0$ & $1.561,0$ & $1.649,5$ & $1.288,3$ & $1.209,0$ & $1.626,9$ & $1.531,2$ & $1.241,7$ & \\
\hline $\begin{array}{c}\text { ACUMULADO } \\
\text { SAFRA (Abr-Dez) }\end{array}$ & 953 & 719 & 634,0 & 757,0 & 818,0 & 916,0 & $1.052,5$ & 548,3 & 679,0 & 862,4 & $1.043,9$ & 421,4 & \\
\hline
\end{tabular}

${ }^{1}$ Dados de precipitação da safra (2001/02) do trabalho. 
APÊNDICE 2 - Precipitação pluviométrica média anual dos últimos 10 anos na área de estudo (Fonte: Cocal Açúcar e Álcool)

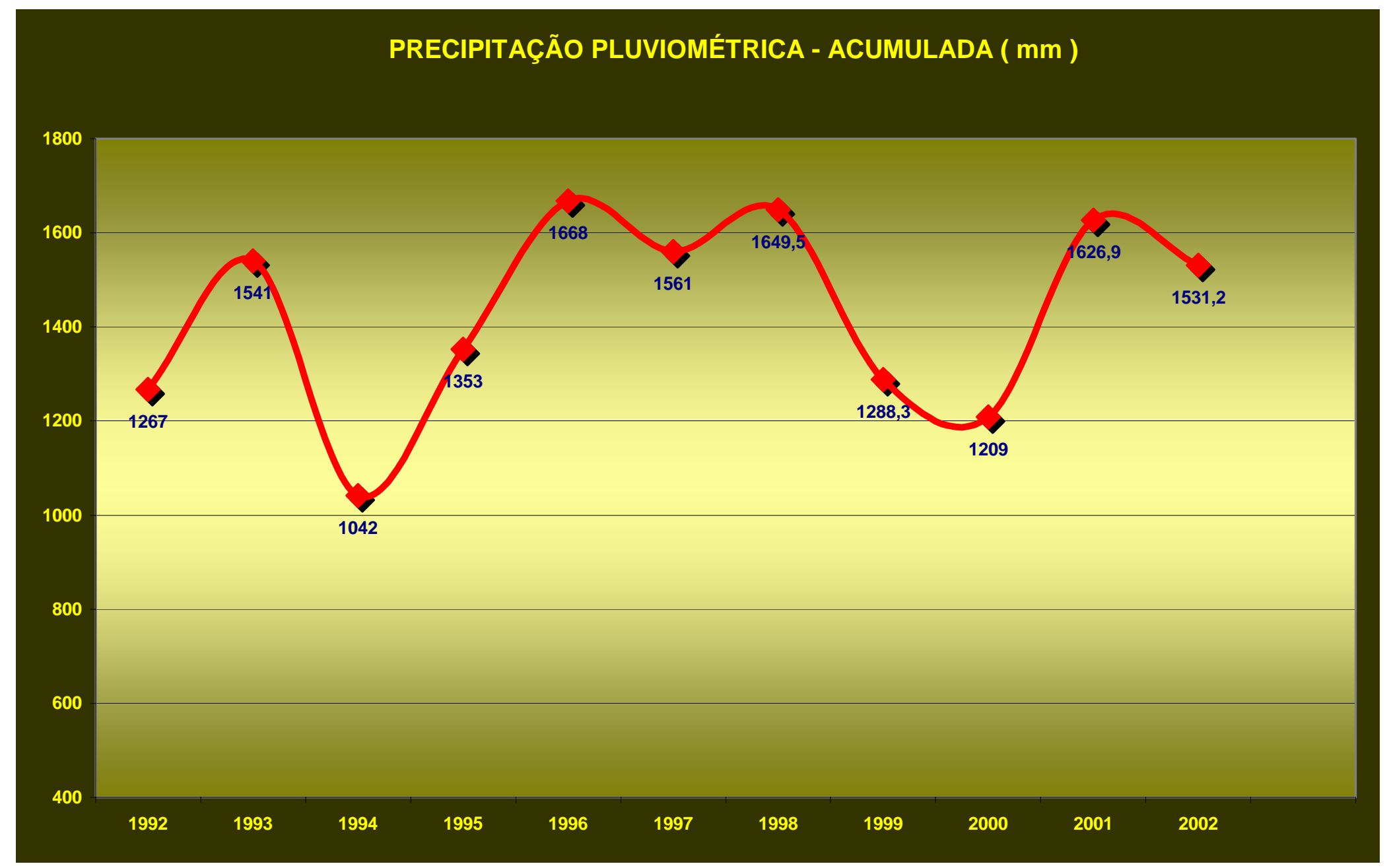


APÊNDICE 3 - Atributos agroindustriais da cana-de-açúcar dos talhões utilizados no trabalho (Fonte: Cocal Açúcar e Álcool).

\begin{tabular}{|c|c|c|c|c|c|c|c|c|c|c|c|c|c|c|c|c|c|c|}
\hline $\begin{array}{l}\text { Setor/ } \\
\text { Talhao }\end{array}$ & Variedade & Colheita & $\begin{array}{c}\text { Idade } \\
\text { (meses) }\end{array}$ & Solo & $\begin{array}{c}\text { Área } \\
\text { (ha) }\end{array}$ & $\begin{array}{c}\mathrm{TCH} \\
\text { Est }\end{array}$ & $\begin{array}{l}\mathrm{TCH} \\
\text { Real }\end{array}$ & $\begin{array}{c}\text { Var\% } \\
\text { EstXReal }\end{array}$ & $\begin{array}{c}\text { TC } \\
\text { Real }\end{array}$ & BXR & POL & PZA & PCC & UMD & FBR & ATR & TMP & IMP \\
\hline 003-1 & RB835486 & $22 / 6 / 2000$ & 13,80 & LVE3-2 & 6,67 & 86,00 & 77,99 & $-9,31$ & 520,20 & 19,56 & 17,04 & 87,12 & 14,0420 & 66,88 & 13,56 & 134,80 & 51,40 & 0,00 \\
\hline 003-2 & RB835486 & $25 / 6 / 2000$ & 13,80 & LVE3-2 & 9,11 & 5,00 & 81,54 & $-5,18$ & 742,87 & 20,38 & 17,84 & 7,54 & 14,5335 & 65,41 & 14,21 & 139,20 & 17,50 & 0,00 \\
\hline 003-3 & RB835486 & $23 / 6 / 2000$ & 13,80 & LVE3-2 & 8,27 & 86,00 & 83,16 & $-3,30$ & 687,73 & 20,58 & 18,04 & 87,66 & 14,8163 & 65,67 & 13,75 & 141,83 & 39,20 & 1,01 \\
\hline 003-4 & RB835486 & $22 / 6 / 2000$ & 13,80 & LVE3-2 & 5,06 & 86,00 & 65,83 & $-23,46$ & 333,08 & 20,13 & 17,42 & 86,54 & 14,3147 & 66,15 & 13,72 & 137,46 & 57,60 & 0,98 \\
\hline 003-5 & RB835486 & $27 / 6 / 2000$ & 13,90 & LVE3-2 & 14,14 & 86,00 & 79,47 & $-7,60$ & 1123,66 & 21,30 & 18,97 & 89,06 & 15,2113 & 63,60 & 15,10 & 145,04 & 41,30 & 1,12 \\
\hline 003-6 & RB835486 & $26 / 6 / 2000$ & 13,90 & LVE3-2 & 8,35 & 86,00 & 79,20 & $-7,90$ & 661,35 & 20,33 & 18,10 & 89,03 & 14,7035 & 65,30 & 14,37 & 140,40 & 35,80 & 1,85 \\
\hline $003-7$ & RB835486 & $26 / 6 / 2000$ & 13,90 & LVE3-2 & 10,39 & 86,00 & 94,07 & 9,38 & 977,39 & 20,53 & 18,01 & 87,73 & 14,5578 & 64,82 & 14,65 & 139,34 & 51,20 & 1,75 \\
\hline 003-10 & RB835486 & $30 / 6 / 2000$ & 13,90 & LVE3-2 & 4,13 & 86,00 & 97,30 & 13,14 & 401,86 & 20,29 & 18,29 & 90,14 & 14,8578 & 65,34 & 14,37 & 141,55 & 43,50 & 1,07 \\
\hline 003-11 & RB835486 & $30 / 6 / 2000$ & 14,00 & LVE3-2 & 15,45 & 86,00 & 91,83 & 6,78 & 1418,83 & 20,91 & 18,59 & 88,90 & 15,2546 & 65,29 & 13,80 & 145,57 & 57,30 & 1,32 \\
\hline $003-12$ & RB835486 & $28 / 6 / 2000$ & 14,00 & LVE3-2 & 11,42 & 86,00 & 87,60 & 1,86 & 1000,43 & 20,29 & 18,26 & 90,00 & 15,0738 & 66,25 & 13,46 & 143,65 & 72,70 & 1,01 \\
\hline $003-13$ & RB835486 & $27 / 6 / 2000$ & 14,00 & LVE3-2 & 10,23 & 86,00 & 88,49 & 2,90 & 905,30 & 20,00 & 17,83 & 89,15 & 14,5974 & 66,07 & 13,93 & 139,42 & 78,70 & 1,65 \\
\hline $003-14$ & RB835486 & $27 / 6 / 2000$ & 14,00 & LVE3-2 & 15,13 & 86,00 & 81,18 & $-5,61$ & 1228,22 & 20,12 & 17,61 & 87,52 & 14,4963 & 66,26 & 13,62 & 138,91 & 52,90 & 0,52 \\
\hline 003-15 & RB835486 & $26 / 6 / 2000$ & 13,80 & LVE3-2 & 9,39 & 86,00 & 93,49 & 8,71 & 877,91 & 19,58 & 17,05 & 87,08 & 14,0156 & 66,72 & 13,70 & 134,56 & 32,00 & 1,94 \\
\hline $003-16$ & RB835486 & $3 / 7 / 2000$ & 14,10 & LVE3-2 & 8,29 & 86,00 & 91,66 & 6,58 & 759,82 & 20,00 & 18,11 & 90,55 & 14,9947 & 66,71 & 13,29 & 142,79 & 59,70 & 0,00 \\
\hline $003-18$ & RB835486 & $3 / 7 / 2000$ & 14,10 & LVE3-2 & 10,62 & 86,00 & 90,62 & 5,37 & 962,36 & 19,60 & 17,43 & 88,93 & 14,6146 & 67,83 & 12,57 & 139,73 & 50,40 & 1,02 \\
\hline $003-19$ & RB835486 & $3 / 7 / 2000$ & 14,00 & LVE3-2 & 15,65 & 86,00 & 96,88 & 12,65 & 1516,20 & 19,27 & 16,99 & 88,17 & 14,3427 & 68,55 & 12,18 & 137,44 & 36,70 & 1,02 \\
\hline $003-20$ & RB835486 & $30 / 6 / 2000$ & 14,00 & LVE3-2 & 7,69 & 86,00 & 63,87 & $-25,74$ & 491,13 & 19,40 & 16,90 & 87,11 & 13,8189 & 66,60 & 14,00 & 132,70 & 68,10 & 2,74 \\
\hline $003-21$ & RB835486 & $1 / 7 / 2000$ & 14,00 & LVE3-2 & 9,51 & 86,00 & 84,44 & $-1,82$ & 802,99 & 19,73 & 17,64 & 89,41 & 14,6363 & 67,10 & 13,17 & 139,77 & 49,30 & 2,69 \\
\hline $003-22$ & RB835486 & $1 / 7 / 2000$ & 14,00 & LVE3-2 & 9,91 & 86,00 & 67,58 & $-21,42$ & 669,72 & 20,55 & 18,35 & 89,29 & 15,1348 & 65,94 & 13,51 & 144,39 & 60,20 & 1,31 \\
\hline $003-23$ & RB835486 & $1 / 7 / 2000$ & 14,00 & LVE3-2 & 17,30 & 86,00 & 77,98 & $-9,33$ & 1348,97 & 19,92 & 17,84 & 89,56 & 14,7608 & 66,75 & 13,33 & 140,87 & 65,20 & 0,86 \\
\hline 004-1 & RB835486 & $16 / 7 / 2000$ & 13,50 & LVE3-2 & 16,01 & 90,00 & 83,96 & $-6,71$ & 1344,15 & 18,82 & 16,91 & 89,85 & 13,7563 & 66,89 & 14,29 & 131,43 & 38,60 & 3,91 \\
\hline $004-2$ & RB835486 & $15 / 7 / 2000$ & 13,50 & LVE3-2 & 19,29 & 90,00 & 90,60 & 0,67 & 1747,74 & 17,13 & 15,37 & 89,73 & 12,5768 & 68,91 & 13,96 & 120,55 & 14,80 & 4,32 \\
\hline $004-3$ & RB835486 & $9 / 7 / 2000$ & 13,30 & LVE3-2 & 20,10 & 90,00 & 78,72 & $-12,53$ & 1582,26 & 20,04 & 17,80 & 88,82 & 14,7251 & 66,62 & 13,34 & 140,72 & 40,80 & 0,45 \\
\hline 004-4 & RB835486 & $8 / 7 / 2000$ & 13,30 & LVE3-2 & 13,13 & 90,00 & 83,21 & $-7,55$ & 1092,53 & 18,68 & 16,53 & 88,49 & 13,6577 & 67,91 & 13,41 & 130,91 & 36,30 & 0,83 \\
\hline $004-5$ & RB835486 & $8 / 7 / 2000$ & 13,30 & LVE3-2 & 8,66 & 90,00 & 82,86 & $-7,94$ & 717,53 & 19,95 & 17,84 & 89,42 & 14,9375 & 67,40 & 12,65 & 142,59 & 29,40 & 0,68 \\
\hline $004-6$ & RB835486 & $8 / 7 / 2000$ & 13,30 & LVE3-2 & 5,51 & 90,00 & 87,79 & $-2,46$ & 483,71 & 19,55 & 17,58 & 89,92 & 14,5125 & 66,99 & 13,46 & 138,47 & 33,70 & 0,78 \\
\hline 004-7 & RB835486 & $7 / 7 / 2000$ & 13,30 & LVE3-2 & 6,20 & 90,00 & 84,77 & $-5,82$ & 525,55 & 19,19 & 16,75 & 87,29 & 14,1401 & 68,63 & 12,18 & 135,78 & 45,40 & 0,84 \\
\hline 004-8 & RB835486 & $5 / 7 / 2000$ & 13,20 & LVE3-2 & 6,23 & 90,00 & 101,88 & 13,20 & 634,73 & 20,28 & 18,09 & 89,20 & 14,7632 & 65,61 & 14,11 & 140,93 & 40,20 & 1,12 \\
\hline $004-10$ & RB835486 & $5 / 7 / 2000$ & 13,30 & AQ-1 & 3,36 & 90,00 & 80,68 & $-10,36$ & 271,08 & 20,08 & 18,25 & 90,89 & 15,4037 & 67,73 & 12,19 & 146,57 & 54,30 & 2,22 \\
\hline
\end{tabular}




\begin{tabular}{|c|c|c|c|c|c|c|c|c|c|c|c|c|c|c|c|c|c|c|}
\hline $\begin{array}{l}\text { Setor/ } \\
\text { Talhao }\end{array}$ & Variedade & & $\begin{array}{c}\text { Idade } \\
\text { (meses) }\end{array}$ & Solo & $\begin{array}{l}\text { Área } \\
\text { (ha) }\end{array}$ & $\begin{array}{c}\mathrm{TCH} \\
\text { Est }\end{array}$ & $\begin{array}{l}\mathrm{TCH} \\
\text { Real }\end{array}$ & $\begin{array}{c}\text { Var\% } \\
\text { EstXReal }\end{array}$ & $\begin{array}{c}\text { TC } \\
\text { Real }\end{array}$ & Drivo & Pol\% & $\begin{array}{c}\text { Pureza } \\
\%\end{array}$ & PCC & U \% & Fibra & ATR & TMP & IMP\% \\
\hline 004-11 & RB835486 & $7 / 7 / 2000$ & 13,30 & LVE3-2 & 17,23 & 90,00 & 87,14 & $-3,17$ & 1501,50 & 19,90 & 17,48 & 87,84 & 14,5774 & 67,22 & 12,88 & 13964 & 35.40 & 1,14 \\
\hline & 383 & & & & & & & & & ,89 & 10 & & & & & & & 78 \\
\hline $4-13$ & 86 & & & & ,23 & & & & & & & & & & & & & 52 \\
\hline $004-14$ & 486 & & & & 66 & & & & & & ,45 & & & & & & 80 & 41 \\
\hline 004-15 & & $/ 7 / 200$ & 13 & & 9,00 & & & & & & & & & & & & .00 & 37 \\
\hline 004-16 & 5486 & //7/2000 & 13,30 & & 18,70 & 90 & & & & 18,94 & 17,02 & & & & 12,63 & & 47,30 & 0,71 \\
\hline 004-17 & 3835486 & . /7/2000 & 13,30 & & 9,60 & 90,00 & 84,42 & & & 18,91 & 16,92 & & & 68,79 & 12,30 & 136,27 & 58,40 & 1,38 \\
\hline 004-18 & B835486 & $16 / 7 / 2000$ & 13,60 & AQ-1 & 10,60 & 90,00 & 87,47 & & & 18,48 & 16,38 & & & 66,57 & 14,95 & 126,24 & 30,30 & 2,88 \\
\hline 004-19 & B835486 & i/7/2000 & 13,60 & AQ-1 & 13,25 & 90,00 & 89,35 & & & 19,36 & 17,43 & & & 66,66 & 13,98 & & 49,40 & 1,40 \\
\hline 004-20 & B835486 & i/7/2000 & 13 & LVE3-2 & 6,65 & 90,00 & 88,78 & & & 19,42 & & & & 66,27 & & & 62,10 & 2,02 \\
\hline $004-21$ & B835486 & 0 & & & 9,41 & 90, & & & & & & & & & & & & 1,22 \\
\hline $004-22$ & RB83 & 00 & & & 7,79 & 90 & 82,6 & & & & & & & & & & & 1,26 \\
\hline $004-23$ & 36 & 0 & & & 19,42 & & & & & & & & & & & & & 66 \\
\hline 004-24 & RB8 & 0 & & & & & & & & & & & & & & & & 90 \\
\hline 004-25 & RB8 & & & $3-2$ & 19,8 & 9 & & & & 19 & & & & & 13,75 & & 46,10 & 92 \\
\hline & 86 & 00 & & & 2,75 & 9 & & & & 21,21 & 81 & & &, 58 & 13,21 & 148,84 & 47,60 & 22 \\
\hline 011-2 & RB8 & 0 & & & 7,6 & & & & & 20,5 & 17,69 & & & & 14,75 & 137 & 58,30 &, 00 \\
\hline 011-3 & RB8 & & & & 6,7 & 103 & & & & 20,50 & 17,57 & & & 67,22 & 12,28 & & 48,40 & 0,50 \\
\hline $011-4$ & & & & & 5,60 & & & & & 20,60 & & & & 64,30 & 15,10 & & 10 & ,46 \\
\hline $011-5$ & & & & & 8,41 & & & & & 20 , & & & & & 13 & & 30 & ,09 \\
\hline 011-6 & & & & &, 60 & & & & & 20 & & & & & 13 & & 90 & 0,58 \\
\hline 011-7 & & & & & 21,82 & & & & & 19,2 & & & & 68 & 11 , & & 54,60 & 0,70 \\
\hline 011-8 & & & & & 8,52 & 103 & & & & 19,43 & & & & 67,97 & 12,60 & 49 & 45,30 & 1,00 \\
\hline 011-9 & & & & & 6,25 & 102,00 & & & & 18,93 & & & & 70,78 & 10,29 & 134,88 & 79,60 & 0,38 \\
\hline 011-10 & RB835486 & /6/2000 & 12,50 & AQ-1 & 2,15 & 102,00 & 5,59 & & 227,02 & 20,40 & 17,35 & 5,05 & 4,9276 & 68,52 & 11,08 & 143,75 & 60,70 & 0,20 \\
\hline 011-11 & RB835486 & $20 / 6 / 2000$ & 12,60 & AQ-1 & 14,58 & 101,00 & 04,77 & & 1527,61 & 18,90 & 16,23 & 85,87 & 13,8346 & 69,48 & 11,62 & 133,37 & 67,20 & 1,50 \\
\hline 011-12 & RB835486 & $17 / 6 / 2000$ & 12,60 & AQ-1 & 15,36 & 100,00 & 16,93 & 16,93 & 1796,05 & 19,20 & 16,58 & 86,35 & 14,2896 & 69,82 & 10,98 & 137,51 & 89,60 & 0,67 \\
\hline 011-13 & B835486 & 9/6/2000 & 12,60 & AQ-1 & 16,96 & 101,00 & 08,64 & & 1842,47 & 19,04 & 16,39 & 86,08 & 13,9976 & 69,45 & 11,51 & 134,83 & 68,00 & 1,95 \\
\hline 011-14 & B835486 & /6/2000 & 12,70 & AQ-1 & 21,59 & 101,00 & 102,64 & & 215,90 & 20,13 & 17,44 & 86,64 & 14,5720 & 67,10 & 12,77 & 139,90 & 88,60 & 0,58 \\
\hline 011-16 & B835486 & 6/6/2000 & & & 12,84 & & $92, \subseteq$ & -0 & 1193,09 & 20,89 & 18, & & & 65,37 & 13,74 & 142,37 & 57,90 & 0,40 \\
\hline 011-17 & RB835486 & $17 / 6 / 2000$ & 12,50 & AQ1-1 & 5,49 & 97,00 & 89,74 & $-7,48$ & 492,68 & 20,58 & 17,36 & 84,35 & 13,8135 & 63,89 & 15,53 & 133,19 & 56,60 & 0,28 \\
\hline
\end{tabular}




\begin{tabular}{|c|c|c|c|c|c|c|c|c|c|c|c|c|c|c|c|c|c|c|}
\hline $\begin{array}{l}\text { Setor/ } \\
\text { Talhao }\end{array}$ & Variedade & Colheita & $\begin{array}{l}\text { Idade } \\
\text { (meses) }\end{array}$ & Solo & $\begin{array}{l}\text { Área } \\
\text { (ha) }\end{array}$ & $\begin{array}{c}\text { TCH } \\
\text { Est }\end{array}$ & $\begin{array}{l}\mathrm{TCH} \\
\text { Real }\end{array}$ & $\begin{array}{c}\text { Var\% } \\
\text { EstXReal }\end{array}$ & $\begin{array}{c}\text { TC } \\
\text { Real }\end{array}$ & Brix $^{0}$ & Pol\% & $\begin{array}{c}\text { Pureza } \\
\%\end{array}$ & PCC & U \% & Fibra & ATR & TMP & IMP\% \\
\hline 011-18 & RB835486 & $16 / 6 / 2000$ & 12,50 & AQ1-1 & 7,90 & 91,00 & 91,15 & 0,17 & 720,10 & 20,05 & 17,40 & 86,78 & 13,9998 & 65,04 & 14,91 & 134,38 & 46,80 & 0,00 \\
\hline $361-1$ & 86 & 0 & 00 & & ,15 & & & & & & 36 & & &, 44 & ,61 & ,41 & 1,00 & 0,97 \\
\hline $361-2$ & RB83 & & & $3-2$ & 10,91 &, 00 & & & & 2,44 &, 48 & & & 62,47 & 15,09 & 75 & 25,50 & 0,53 \\
\hline $361-3$ & RB835486 & $8 / 7 / 2000$ & 14,10 & E5-4 & 18,41 & 91,00 & 97,25 & & 790,45 & 20,77 & 19,02 & ,57 & 15,3797 & 64,60 & 14,63 & 146,02 & 40,30 & 0,83 \\
\hline $366-2$ & RB83 & $7 / 7 / 20$ & 14,00 & E3-2 & 15,09 & 101,00 & & & & 21,86 & 20,13 & & & 62,09 & 16,05 & & 22,60 & 1,25 \\
\hline $366-3$ & RB83 & $7 / 7 / 20$ & & & 12,84 & & & & & 21,70 & 19,80 & & & 63,92 & 38 & & 34,60 & 0,64 \\
\hline $366-4$ & RB835486 & $7 / 7 / 2000$ & 14,00 & TRE-1 & 9,59 & 99,00 & 97,25 & $-1,77$ & 932,65 & 21,39 & 19,65 & 91,87 & 15,9570 & 64,22 & 14,39 & 151,31 & 35,10 & 0,98 \\
\hline $366-5$ & RB835486 & $7 / 7 / 2000$ & 14,00 & TRE-1 & 7,18 & 101,00 & 109,87 & 8,78 & 788,86 & 21,48 & 19,93 & 92,78 & 16,2102 & 64,22 & 14,30 & 153,44 & 42,10 & 0,72 \\
\hline $371-1$ & RB835486 & $5 / 7 / 2000$ & 14,00 & LVE3-2 & 13,67 & 95,00 & 104,40 & 9,90 & 1427,20 & 21,82 & 20,12 & 92,21 & 16,2315 & 63,42 & 14,76 & 153,75 & 42,80 & 1,08 \\
\hline $371-2$ & RB835486 & $5 / 7 / 2000$ & 14,00 & PE1-4 & 6,79 & 93,00 & 90,89 & $-2,26$ & 617,17 & 21,04 & 19,45 & 92,44 & 15,7722 & 64,49 & 14,47 & 149,45 & 36,20 & 1,30 \\
\hline
\end{tabular}

